\title{
INFRARED CARBONATE ROCK CHEMISTRY
}

CHARACTERIZATION

Nasrullah Zaini 


\section{Graduation committee}

Chair

Prof.dr.ir. A. Veldkamp University of Twente, ITC Supervisor

Prof.dr. F.D. van der Meer University of Twente, ITC

Co-supervisors

Dr. M.A. van der Werff University of Twente, ITC

Dr. F.J.A. van Ruitenbeek University of Twente, ITC

Members

Prof.dr. Z. Su

Prof.dr. V.G. Jetten

University of Twente, ITC

University of Twente,ITC

Prof.dr. E. Garcia-Meléndez

University of Leon, Spain

Prof.dr. S. Marsh

Prof.dr. S.M. de Jong

University of Nottingham, UK

Utrecht University

ITC dissertation number 330

ITC, P.O. Box 217, 7500 AA Enschede, The Netherlands

ISBN 978-90-365-4627-0

DOI 10.3990/1.9789036546270

Printed by ITC Printing Department

(C) Nasrullah Zaini, Enschede, The Netherlands

14 FACULTY OF GEO-INFORMATION SCIENCE AND EARTH OBSERVATION 


\title{
INFRARED CARBONATE ROCK CHEMISTRY CHARACTERIZATION
}

\author{
DISSERTATION
}

to obtain

the degree of doctor at the University of Twente, on the authority of the rector magnificus, prof.dr. T.T.M. Palstra,

on account of the decision of the graduation committee, to be publicly defended

on Thursday October 4, 2018 at 14.45 hrs

by

Nasrullah Zaini

born on January 02, 1975

in Sawang II, South Aceh, Indonesia 
This dissertation is approved by:

Prof. dr. F.D. van der Meer, supervisor

Dr. H.M.A. van der Werff, co-supervisor

Dr. F.J.A. van Ruitenbeek, co-supervisor 


\section{Summary}

This thesis presents an analytical approach for characterizing carbonate rock chemistry, especially for analyzing the chemical compositions of carbonate rocks for cement raw materials. The shortwave infrared (SWIR) spectroscopy and laboratorybased hyperspectral imagery or hyperspectral imaging techniques are combined with geochemical data analysis to estimate mineral chemistries and their compositions in carbonate rock samples.

Carbonate rocks are one of the important natural resources for construction materials and the cement industry. The uses of carbonate rocks or limestones as the main component in the raw mix for making cement clinker depend highly on the rocks' chemical compositions. The carbonate rocks are formed by a mosaic of minerals mostly containing calcium carbonate $\left(\mathrm{CaCO}_{3}\right)$ or calcite and calcium magnesium carbonate $\left(\mathrm{CaMg}\left(\mathrm{CO}_{3}\right)_{2}\right)$ or dolomite. These sedimentary rocks in nature are also composed of complex geologic mixtures that exist in the form of intimate mixtures, grain size variations, weathered constituents, and alteration products. Those mixtures can create a major obstacle in analyzing mineralogical and chemical compositions of the rocks.

Conventional analytical methods are well established for characterizing mineral chemistry of carbonate rocks, as well as to analyze and control the chemical compositions of the cement raw materials and products. However, the majority of these traditional methods involve a labor-intensive and time consuming process for sample preparation and analysis. Therefore, there is a need for a robust and reproducible approach for characterization and chemical quality control of carbonate rocks that satisfies the industry standard. Spectroscopy provides a non-destructive technique and can be used outdoors for determining mineralogy and chemical information of carbonate rocks based on their spectral feature characteristics.

In the context of this study, the infrared spectroscopy and laboratory-based hyperspectral imaging (imaging spectroscopy) methods were used to analyze mineral chemistries of carbonate rocks that are suitable for cement raw materials. This was done by combining spectroscopic parameters with geochemical characteristics to estimate mineralogical and chemical compositions of carbonate rocks.

The first study presented in this thesis analyzed the effects of grain size and carbonate mineral mixtures on spectral absorption feature characteristics of calcite and dolomite in the shortwave infrared (SWIR) (features at 2.3 and $2.5 \mu \mathrm{m}$ ) and thermal infrared (TIR) (features at 11.5 and $14 \mu \mathrm{m}$ ) wavelength regions. Spectral analysis showed that varying grain sizes and carbonate mineral contents in the synthetic samples influenced spectral reflectance values and absorption feature characteristics. Absorption band positions of pure and mixed calcite and dolomite in the SWIR and TIR regions for both features were displaced slightly as observed in previous studies. The band positions of calcite and dolomite varied relative to grain size only in the TIR region. These positions shifted to longer wavelengths for the feature at $11.5 \mu \mathrm{m}$ and to shorter wavelengths for the feature at $14 \mu \mathrm{m}$ from fine to coarse grain size. The wavelength 
positions of calcite-dolomite mixtures in the SWIR and TIR regions were determined by the quantity of calcite and dolomite in the sample.

Characterization of carbonate rock chemistry using laboratory-based SisuCHEMA hyperspectral imagery was demonstrated. Several spectral recognition approaches, such as wavelength position, spectral angle mapper (SAM) and linear spectral unmixing (LSU) were used to derive the chemical composition and the relative abundance of carbonate minerals from the spectral data of hyperspectral images by applying spectral endmembers of the carbonate synthetic samples established in the first study. Results showed that chemical composition (Ca-Mg ratio) of carbonate minerals at a pixel (e.g., sub-grain) level can be extracted from the image pixel spectra using these spectral analysis methods. For the image shortwave infrared (SWIR) spectra, the wavelength position approach was found to be sensitive to all compositional variations of carbonate mineral mixtures when compared to the SAM and LSU approaches. The correlation between geochemical characteristics and spectroscopic parameters also revealed the presence of these carbonate mixtures with various chemical compositions in the rock samples.

The application of SWIR spectroscopy as a quality control technique for the mineral chemistry analysis of Portland cement-grade limestone was investigated. The spectroscopic properties of SWIR reflectance spectra, such as wavelength position and depth of absorption feature and geochemical characteristics of limestone samples were used to identify and estimate the abundance and composition of carbonate and clay minerals on the rock surfaces by following the approaches and results of the first two studies. The depth of the carbonate $\left(\mathrm{CO}_{3}\right)$ and $\mathrm{Al}-\mathrm{OH}$ absorption features are linearly correlated with the contents of $\mathrm{CaO}$ and $\mathrm{Al}_{2} \mathrm{O}_{3}$ in the samples, respectively. Variations in the wavelength position of $\mathrm{CO}_{3}$ and $\mathrm{Al}-\mathrm{OH}$ absorption features are related to changes in the chemical compositions of the samples. The results showed that the dark gray and light gray limestone samples are better suited for manufacturing Portland cement clinker than the dolomitic limestone samples. The results indicate that SWIR spectroscopy is an alternative approach for the chemical quality control of cement raw materials.

The research provides an alternative approach for estimating mineral chemistries and compositions of carbonate rocks using SWIR spectroscopy and laboratory-based hyperspectral imaging methods. The findings of this research can be used to complement the conventional analytical approaches for chemical quality control of carbonate rocks in the cement industries. 


\section{Samenvatting}

In deze thesis wordt een analytische benadering gepresenteerd, voor het karakteriseren van carbonaatgesteenten. In het bijzonder voor het analyseren van de chemische samenstellingen van carbonaatgesteenten, voor cementproducten. De korte golf-infrarood (SWIR) spectroscopie en hyperspectrale beeldverwerking (van laboratoria), of de hyperspectrale beeldtechnieken zijn gecombineerd met geochemische data-analyse, om minerale brandstoffen en hun samenstellingen in carbonaatgesteenten (monsters), in te schatten.

Carbonaatrotsen zijn een van de belangrijkste natuurlijke grondstoffen voor bouwmaterialen en de cementindustrie. Het gebruik van carbonaatrotsen of kalkstenen als hoofdcomponent in de ruwe mix voor het maken van cementklinkers, is erg afhankelijk van de chemische samenstellingen van de gesteenten. De carbonaatgesteenten worden gevormd door een mozaïek van mineralen, hoofdzakelijk bestaande uit calciumcarbonaat $\left(\mathrm{CaCO}_{3}\right)$, calciet, magnesiumcarbonaat $\left(\mathrm{CaMg}\left(\mathrm{CO}_{3}\right)_{2}\right)$ of dolomiet. Deze sedimentaire gesteenten in de natuur, zijn ook samengesteld door complexe geologische mengsels. Zij bestaan in de vorm van innige mengsels, korrelgroottevariaties, verweerde bestanddelen en alteratieproducten. Die mengsels kunnen een groot obstakel vormen bij het analyseren van mineralogische en- chemische samenstellingen van de gesteenten.

Conventionele analytische methoden zijn gevestigde methoden om de minerale chemie van carbonaatgesteenten aan te duiden. Bovendien zijn deze methoden geschikt voor het analyseren en controleren van de chemische samenstellingen van de cementproducten (grondstoffen) en producten. Echter neemt het overgrote deel van deze traditionele methoden veel tijd in beslag. De monstervoorbereiding en analyse is een arbeidsintensief en tijdrovend proces. Derhalve is er behoefte aan een robuuste en reproduceerbare aanpak, voor de aanduiding en chemische kwaliteitscontrole van carbonaatgesteenten, die voldoen aan de industriestandaard. De spectroscopie verschaft een niet-destructieve techniek en kan buiten gebruikt worden voor het bepalen van mineralogie en chemische informatie van carbonaatgesteenten, op basis van hun spectrale kenmerken.

In de context van deze studie werden de infraroodspectroscopie en laboratoriumgebaseerde hyperspectrale beeldvorming (imaging spectroscopy) methoden gebruikt om minerale chemie van carbonaatgesteenten te analyseren die geschikt zijn voor cementgrondstoffen. Dit werd gedaan door spectroscopische parameters te combineren met geochemische kenmerken om mineralogische en chemische samenstellingen van carbonaatgesteenten te schatten.

De eerste studie die in deze thesis gepresenteerd is, analyseerde de effecten van de korrelgrootte en de mineraalmengsels van het carbonaat. Er werd gekeken naar spectrale absorptiekenmerken van calciet en dolomiet, in de golflengtegebieden van het korte golf-infrarood (SWIR) (kenmerken bij 2.3 en $2.5 \mu \mathrm{m}$ ) en thermisch infrarood (TIR) (kenmerken bij 11.5 en $14 \mu \mathrm{m}$ ). Spectrale analyses toonden aan dat diverse 
korrelgroottes en het mineraalgehalte van het carbonaat (bij de synthetische monsters), spectrale reflectiewaarden en absorptiekenmerken hebben beïnvloed. De posities van absorptiebanden van zuiver en gemengd calciet, en dolomiet in de SWIR- en TIRregio's voor beide kenmerken, waren enigszins verplaatst, zoals waargenomen in eerdere studies. De bandposities van calciet en dolomiet varieerden alleen ten opzichte van de korrelgrootte in het TIR-gebied. Deze posities veranderden naar langere golflengten (van het kenmerk), bij $11.5 \mu \mathrm{m}$ en naar kortere golflengten bij $14 \mu \mathrm{m}$, van een fijne tot grove korrelgrootte. De posities van de golflengte van calcietdolomietmengsels in de SWIR en- TIR-gebieden, werden bepaald door de hoeveelheid calciet en dolomiet in het monster.

De aanduiding van carbonaatgesteenten, met behulp van SisuCHEMA (gebaseerd op het lab) hyperspectrale beeldvorming werd aangetoond. Verschillende spectrale herkenningskaders, zoals golflengtepositie, spectrale hoek karteringsclassificatie (SAM) en LSU werden gehanteerd, om de chemische samenstelling en de relatieve abundantie van carbonaatmineralen af te leiden uit de spectrale gegevens van hyperspectrale beelden. Dit werd gedaan door de spectrale eindelementen van de synthetische carbonaatmonsters toe te passen, zoals vastgesteld in het eerste onderzoek. De resultaten toonden aan dat de chemische samenstelling ( $\mathrm{Ca}: \mathrm{Mg}$ verhouding) van carbonaatmineralen op een pixelniveau (bijv. subkorrel), met behulp van deze spectrale analytische methoden, kan worden geëxtraheerd uit het spectrum van de beeldpixels. Voor het beeld van de korte golf-infrarood (SWIR) spectra, bleek de benadering van de golflengtepositie, gevoelig te zijn voor alle variaties in de samenstelling van (carbonaat) mineraalmengsels, in vergelijking tot de SAM en- LSU-benaderingen. De correlatie tussen geochemische kenmerken en spectroscopische parameters, onthulden ook de aanwezigheid van deze carbonaatmengsels, met verschillende chemische samenstellingen in de gesteentemonsters.

Er is onderzoek gedaan naar de toepassing van SWIR-spectroscopie, als een techniek voor de kwaliteitscontrole van de minerale chemie (analyse) van de Portland 'cement-grade' kalksteen. De spectroscopische eigenschappen van SWIRreflectantiespectra, zoals de golflengtepositie en de absorptiediepte en de geochemische eigenschappen van kalksteenmonsters, werden gebruikt om de abundantie en samenstelling van carbonaat en- kleimineralen op de rotsoppervlakten vast te stellen, door de benaderingen en resultaten van de eerste twee onderzoeken op te volgen. De diepte van carbonaat $\left(\mathrm{CO}_{3}\right)$ en $\mathrm{Al}-\mathrm{OH}$ absorptiekenmerken, zijn lineair gecorreleerd met de inhoud van de monsters van respectievelijk $\mathrm{CaO}$ en $\mathrm{Al}_{2} \mathrm{O}_{3}$. Variaties in de golflengtepositie van $\mathrm{CO}_{3}$ en- $\mathrm{Al}-\mathrm{OH}$-absorptiekenmerken houden verband met veranderingen in de chemische samenstelling van de monsters. De resultaten toonden aan dat de donkergrijze en lichtgrijze kalksteenmonsters, beter geschikt zijn voor het vervaardigen van Portland cementklinkers, dan de dolomitische kalksteenmonsters. De resultaten indiceren dat SWIR-spectroscopie een alternatieve benadering is voor de chemische kwaliteitscontrole van cementproducten (grondstoffen). 
Het onderzoek biedt een alternatieve benadering voor het schatten van minerale chemie en samenstelling van carbonaatgesteenten met behulp van SWIR-spectroscopie en laboratorium-gebaseerde hyperspectrale beeldvorming methoden. De bevindingen van dit onderzoek kunnen worden gebruikt als aanvulling op de conventionele analytische benaderingen voor chemische kwaliteitscontrole van carbonaatgesteenten in de cementindustrie. 


\section{Acknowledgements}

First and foremost, I must praise and thank Almighty Allah, the Lord of the worlds, the Most Gracious and the Most Merciful, who gave me the infinite blessing, guidance and ability to successfully complete this $\mathrm{PhD}$ study. The life stories of the Prophet Muhammad, peace and blessing of Allah be upon him, has become a major inspiration and encouragement for attaining any circumstances and each step of my $\mathrm{PhD}$ journey in the University of Twente, Enschede, the Netherlands.

I am deeply indebted to my parents, my dear father (Ayah) Almarhum Zaini Usman and my beloved mother (Nyak) Cut Nilawati Ibrahim for their love, care and prayers throughout my life. I could never have attained this stage of life without your unwavering support, hardship, suffering and encouragement. O my Lord, bestow on them Thy mercy and grace as they nurtured and cherished me when I was a child.

I would like to take this opportunity to express my acknowledgement to all people and organizations who have contributed to accomplish this work. I am heartily grateful to my promoter and supervisor, Prof. Freek van der Meer. This dissertation might not be completed without your endless support, motivation and encouragement. Freek, from the beginning of the $\mathrm{PhD}$ research I am uncertain how to accomplish this challenging work due to my insufficient scientific knowledge, especially in geology, mineralogy and hyperspectral remote sensing, but with your futuristic scientific vision, immense knowledge, trust, enthusiasm and patience, its became possible. You have also educated me a lot on scientific guidance and constructive comments how to improve the quality of my research and to revise a manuscript after a nasty review by journal's reviewers. Thank you very much for always been caring, understanding and supporting me during my $\mathrm{PhD}$ research, difficult moments and scientific writing.

I am particularly grateful to my second supervisor, Dr. Harald van der Werff. Harald, your contributions and scientific assistance and experience are the valuable basis of the results in this dissertation. Many thanks for your immense knowledge, support and constructive comments.

I would like to extend my hearty gratitude to my third supervisor, Dr. Frank van Ruitenbeek. Frank, your inspiring discussions and contributions to the thesis have been invaluable for me. Thank you for your immense support and scientific advises.

My most sincerely gratitude goes to the Government of the Province of Aceh and Human Resources Development Commission (HRDC), Banda Aceh, Indonesia for awarding me a PhD scholarship. Thanks for their financial support and trust. I am thankful to Head of Department of Physics, Dean of Faculty of Mathematics and Natural Sciences and Rector of Syiah Kuala University, Darussalam, Banda Aceh, who gave me permission and recommendations to pursue a PhD study.

My special thanks and highly appreciation to Boudewijn de Smeth, who always ready to help me during my $\mathrm{PhD}$ research in the GeoScience Laboratory. I enjoyed working with you and thank you for your continuous support and scientific guidance on geochemical analysis. I want to express my gratitude to Prof. Steven de Jong and teams 
for providing dolomitic limestone samples from the Bedarieux dolomite mine, southern France, Dr. Christoph Hecker and Henk Wilbrink for helping me with the spectral data measurements using the BRUKER and ASD spectrometers, Wim Bakker for HypPy software assistance, Abigail for her assisting in the SisuCHEMA hyperspectral data measurements and Caroline Lievens for helping me with XRD analysis. I am also grateful to the managers and staff of PT. Lafarge Cement Indonesia, Aceh Besar, especially Pak Saifuddin, Pak Fadli, Ibu Rizka, Pak Yan, and Pak Yasar who assisted me during the fieldwork and rock samples collection from the Lhoknga limestone quarry. My sincere thanks go to Pak Suhartono and Pak Rajibussalim for English editing.

I would also like to thanks all staff members of Department of Earth Systems Analysis (ESA) and Faculty of Geo-Information Science and Earth Observation (ITC) for their tremendous support and service. Many thanks go to Prof. Victor Jetten, Head of ESA Department, for giving me permission and opportunity to perform this research in the department. I warmly thank to Dr. Paul van Dijk, Loes Colenbrander, Christie Agema, Theresa van den Boogaard, Bettine Geerdink, Marie Chantal Metz, Marion Pierik, Marga Koelen, Job Duim, Benno Masselink and Carla Gerritsen for their support and administrative assistance from the beginning to the end of my PhD study at ITC.

It is my pleasure to acknowledge all my colleagues and the $\mathrm{PhD}$ community at ITC with whom I shared many interesting discussions and pleasant time: Khamarrul, Shafique, Islam, Saad, Saleem, Abebe, Aljoufie, Zahir, Yaseen, Norhakim, Rehmat, Mustafa, Jehanzeb, Haris, Ahmad, Nugroho, Tolga, Haydar, Fekerte, Sanaz, Sumbal, Matthew, Thea, Effie, Irena, Riswan, Frederick, Fangyuan and Tang. Thank you for your support and friendship.

Profound thanks to all Indonesian friends, IMEA, PPIE, ITC- and UT-Muslims and IVEO for their support, company and encouragement during my $\mathrm{PhD}$ period in Enschede, the Netherlands. My heartfelt thanks to: Pak Tito, Pak Bayu, Pak Yusuf, Pak Syarif, Pak Anas, Pak Rahman, Pak Arif, Mas Faris, Mas Andry, Habib, Mas Rusydi, Ibu Tyas, Mas Diwan, Brothers Kamal and Mikail, Mas Iwan, Mas Unggul, Pak Hero, Pak Sunu, Mas Agung, Mas Hendri, and all.

Finally, I am very grateful to my entire family, brothers and sisters for their endless help and support, encouragement and prayers that made me success in achieving this goal. Last but not the least, I am heartily gratitude to my wife, Juwairiah Djuned, and my lovely daughters and son, Iffa, Naya, and Arkan. Thank you for your love, support, patience and prayers during my study and difficult moments. My deepest apologies for being away from all of you. Insha Allah, I always be there with you to continue our wonderful time. 


\section{Table of Contents}

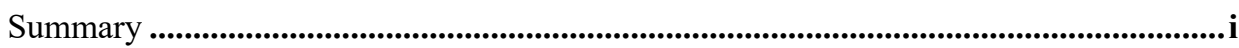

Samenvatting..........................................................................................................................iii

Acknowledgements ................................................................................................................... vii

Table of Contents ..............................................................................................................................ix

List of Figures ............................................................................................................................

List of Tables.................................................................................................................................iii

1. Introduction ................................................................................................................. 1

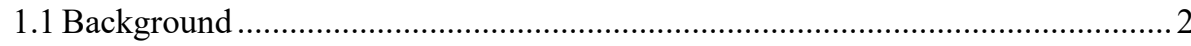

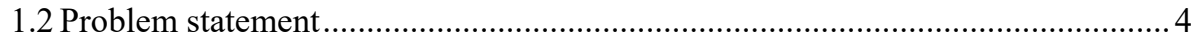

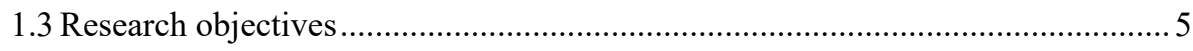

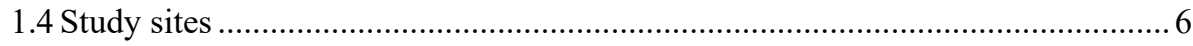

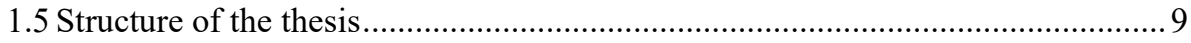

2. Carbonate rock chemistry characterization-a review ...............................................11

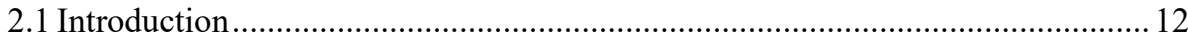

2.2 The significance of carbonate rocks .......................................................... 12

2.3 Mineralogical and geochemical compositions of carbonate rocks ..................... 15

2.4 Mineral chemistry analysis of carbonate rocks ............................................. 17

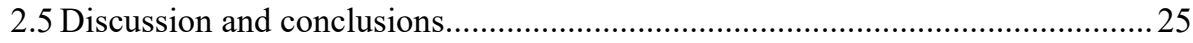

3. Effect of grain size and mineral mixing on carbonate absorption features in the SWIR and TIR wavelength regions ................................................................29

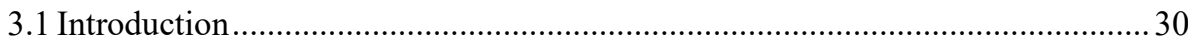

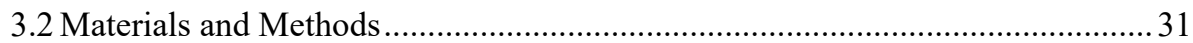

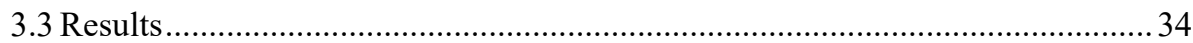

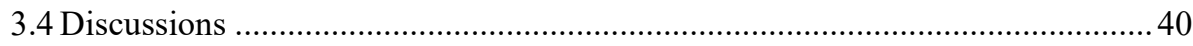

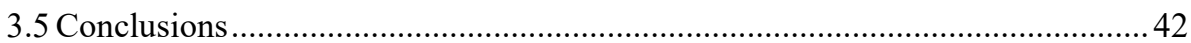

4. Determination of carbonate rock chemistry using laboratory-based hyperspectral imagery ................................................................................................45

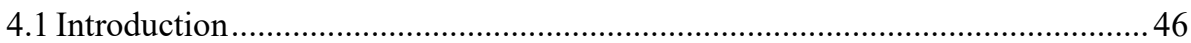

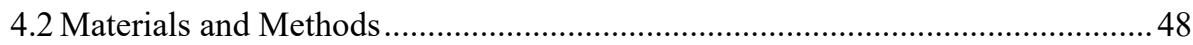

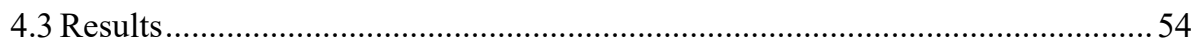

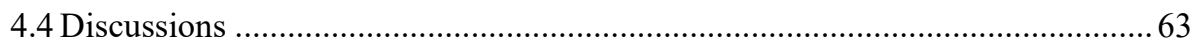

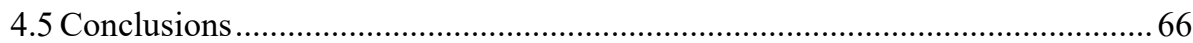

5. An alternative quality control technique for mineral chemistry analysis of Portland cement-grade limestone using shortwave infrared spectroscopy.........67

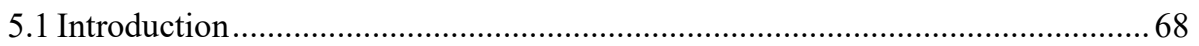




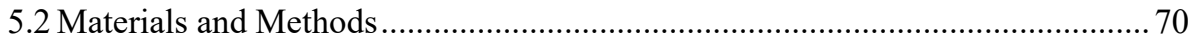

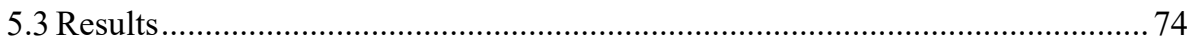

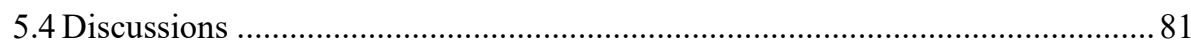

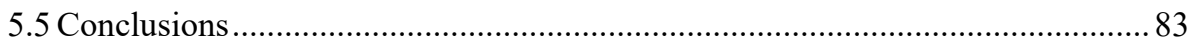

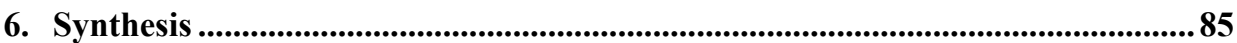

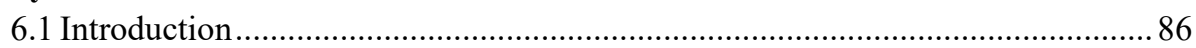

6.2 Carbonate absorption feature characteristics.................................................. 87

6.3 Hyperspectral imagery of carbonate rock chemistry .......................................... 89

6.4 Shortwave infrared spectroscopy for chemical quality control of Portland cement raw materials.............................................................................. 90

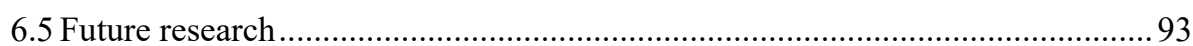

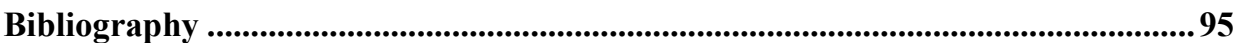

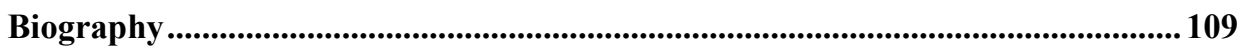

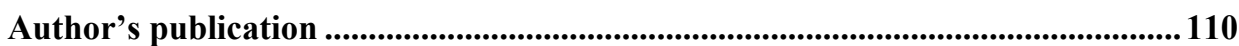

Appendix A: XRD analysis of limestone samples ................................................... 111 


\section{List of Figures}

Figure 1.1: Location map of study site at the Bédarieux dolomite mine ......................... 7

Figure 1.2: Field photograph of the Bédarieux dolomite mine and dolomitic limestone sample ................................................................................ 7

Figure 1.3: Location map of study site at PT. Lafarge Cement Indonesia. ...................... 8

Figure 1.4: Field photograph of the Lhoknga limestone quarry and limestone samples

Figure 2.1: Carbonate drill core staining of a chlorite-carbonate-sphalerite schist sample

Figure 2.2: Reflectance spectra of calcite and dolomite in the SWIR wavelength region.

Figure 2.3: Reflectance spectra of calcite and dolomite in the TIR wavelength region

Figure 2.4: Sketch of a hyperspectral imaging dataset (hyperspectral imagery)............24

Figure 2.5: Wavelength position image of the iron absorption feature at $\sim 900 \mathrm{~nm}$.......24

Figure 2.6: XRD and XRF analytical methods used in the cement production process.

Figure 3.1: Definitions of absorption feature characteristics.

Figure 3.2: Reflectance spectra of calcite and dolomite for each grain size fraction in the SWIR wavelength region.

Figure 3.3: Absorption feature parameters of calcite and dolomite in the SWIR wavelength region as a function of grain size.

Figure 3.4: Reflectance spectra of calcite and dolomite for each grain size fraction in the TIR wavelength region.

Figure 3.5: Absorption band positions of calcite and dolomite in the TIR wavelength region as a function of grain size

Figure 3.6: Spectral features of calcite-dolomite mixtures in the SWIR wavelength region.

Figure 3.7: SWIR absorption feature parameters of calcite-dolomite mixtures ............. 38

Figure 3.8: TIR spectral features of calcite-dolomite mixtures ....................................... 39

Figure 3.9: Absorption band positions of calcite-dolomite mixtures in the TIR region.

Figure 4.1: An integrated system of SisuCHEMA hyperspectral scanner.................... 49

Figure 4.2: Fresh surfaces of carbonate rock samples ................................................ 49

Figure 4.3: Selected SisuCHEMA images A, B, C, and D of carbonate rocks ..............50

Figure 4.4: Example of SisuCHEMA spectra of carbonate minerals. .............................50

Figure 4.5: Laboratory spectral endmembers of pure and mixed calcite and dolomite synthetic samples. ..............................................................5 52

Figure 4.6: Wavelength position images and estimated proportion of classified minerals derived from the images.. 
Figure 4.7: SAM classification results and estimated proportion of classified

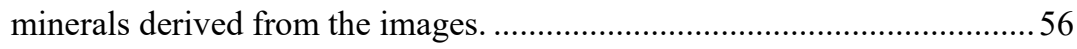

Figure 4.8: LSU classification results and estimated proportion of classified

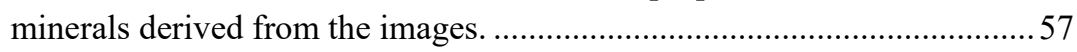

Figure 4.9: Histograms comparing proportion estimation of carbonate mineral

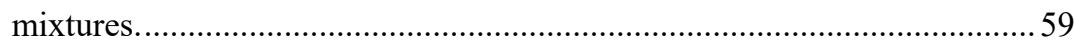

Figure 4.10: Correlation between major geochemical elements and the average of spectral parameter results.

Figure 5.1: Carbonate rock samples collected from the mines. .71

Figure 5.2: Examples of hand specimens of carbonate rock samples collected from the mines. .72

Figure 5.3: Continuum removed spectra of dark gray limestone samples...................... 76

Figure 5.4: Continuum removed spectra of light gray limestone samples....................... 77

Figure 5.5: Continuum removed spectra of dolomitic limestone samples...................... 77

Figure 5.6: Correlation between spectral and geochemical characteristics .................... 78

Figure 5.7: Geochemical charts of $\mathrm{CaO}$ vs. $\mathrm{MgO}$ and $\mathrm{SiO}_{2}$ vs. $\mathrm{Al}_{2} \mathrm{O}_{3}$ contents............. 79 


\section{List of Tables}

Table 1.1: Summary of conventional analytical methods...............................................

Table 2.1: Summary of the strengths and weaknesses of analytical methods ................. 13

Table 2.2: Some physical properties of common carbonate minerals. ............................. 16

Table 2.3: Staining colors of carbonate minerals using various chemical solutions .......17

Table 2.4: The electromagnetic spectrum classification................................................20

Table 2.5: The positions and widths of absorption bands of calcite and dolomite in

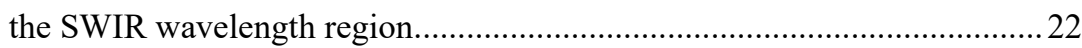

Table 4.1: Elemental concentrations of the rock samples. ………………………......... 51

Table 4.2: Confusion matrix of the classified carbonate mineral mixtures ........................6 60

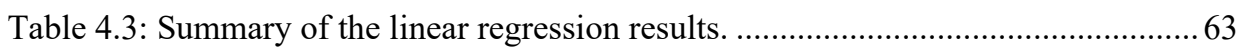

Table 5.1: Chemical composition of the selected limestone samples...............................75

Table 6.1: Summary of the linear regression results between spectroscopic characteristics and geochemical parameters...............................................92 
1. Introduction 


\subsection{Background}

Carbonate rocks are sedimentary rocks that mostly contain calcium carbonate $\left(\mathrm{CaCO}_{3}\right)$, calcite and calcium magnesium carbonate $\left(\mathrm{CaMg}\left(\mathrm{CO}_{3}\right)_{2}\right)$, dolomite (Blatt et al., 1972; Pettijohn, 1975). These rocks and minerals have played an essential role in the functioning of modern societies and accelerating economic growth of many nations (Deer et al., 1966; Harbaugh, 1976; Hatch \& Rastall, 1965; Pettijohn, 1975). Therefore, the sustainable supply and access to the rocks and minerals are vital to the success of industrial sectors and the continuous existence of community developments. Carbonate rocks in the form of limestones are recognized as a primary natural resource for construction materials and the cement industry (Blatt et al., 1972; Pettijohn, 1975; Pohl, 2011). They are the preferred source of lime or calcium oxide $(\mathrm{CaO})$ for Portland cement clinker manufacturing (Chatterjee, 1983; Ghosh, 1983; Meade, 1926; Taylor, 1997). The rocks are also economically important in terms of petroleum and gas reserves, because their porosity is a potential storage reservoir for oil and gas (Blatt et al., 1972; Friedman \& Sanders, 1967; Harbaugh, 1976; Pettijohn, 1975). Many hydrocarbon reservoirs worldwide, such as the Permian of Texas, the Cretaceous of Mexico and Iraq, the Jurassic of Saudi Arabia and the Tertiary of the Persian Gulf and California are found in carbonate rocks (Beccari \& Romano, 2005; Harbaugh, 1976). Besides the interest in petroleum geology characterization, there is a considerable potential from an 'ore geology' perspective, as carbonates are important pathfinder and alteration minerals associated with calcic skarn deposits, low sulphidation epithermal deposits and porphyry $\mathrm{Cu}$ deposits (Kozak et al., 2004; Rockwell \& Hofstra, 2008). Moreover, the majority of carbon on the earth is deposited in carbonate sediments and the rocks contribute to carbon sequestration (Liu \& Zhao, 2000; Luquot \& Gouze, 2009), the capture of carbon dioxide $\left(\mathrm{CO}_{2}\right)$ from the atmosphere, and act as natural carbon sinks. Hence, their overriding factors have significant implications for the global carbon cycle and climate change (Baker et al., 2008).

Carbonate rocks in nature are composed by a complex mixture of minerals and rarely formed by a pure and homogeneous mineral (Blatt et al., 1972; Deer et al., 1966; Pettijohn, 1975). Further complexity is added by the fact that physical phenomena or spatial distribution of mineral mixtures and chemical compositions constituted the rocks differ between geologic sites and alter to different minerals over time due to the dynamic geological processes of the earth (Blatt et al., 1972; Deer et al., 1966; Waltham, 2009). The rocks may contain various amounts of other mineralogical associations, such as aragonite $\left(\mathrm{CaCO}_{3}\right)$, siderite $\left(\mathrm{FeCO}_{3}\right)$, magnesite $\left(\mathrm{MgCO}_{3}\right)$, ankerite $\mathrm{CaFe}\left(\mathrm{CO}_{3}\right)_{2}$, rhodochrosite $\left(\mathrm{MnCO}_{3}\right)$, strontianite $\left(\mathrm{SrCO}_{3}\right)$, cerussite $\left(\mathrm{PbCO}_{3}\right)$, witherite $\left(\mathrm{BaCO}_{3}\right)$, smithsonite $\left(\mathrm{ZnCO}_{3}\right)$, goethite $(\mathrm{FeO}(\mathrm{OH}))$, quartz $\left(\mathrm{SiO}_{2}\right)$, clays (kaolinite $\left(\mathrm{Al}_{2} \mathrm{Si}_{2} \mathrm{O}_{5}(\mathrm{OH})_{4}\right)$, montmorillonite $\left((\mathrm{Na}, \mathrm{Ca})_{0.33}(\mathrm{Al}, \mathrm{Mg})_{2}\left(\mathrm{Si}_{4} \mathrm{O}_{10}\right)\right)$, and illite $\left.\left(\left(\mathrm{K}, \mathrm{H}_{3} \mathrm{O}\right)(\mathrm{Al}, \mathrm{Mg}, \mathrm{Fe})_{2}(\mathrm{Si}, \mathrm{Al})_{4} \mathrm{O}_{10}\left[(\mathrm{OH})_{2},\left(\mathrm{H}_{2} \mathrm{O}\right)\right]\right)\right)$, halides (fluorite $\left(\mathrm{CaF}_{2}\right)$ and halite $(\mathrm{NaCl})$ ), phosphates (hydroxylapatite $\left(\mathrm{Ca}_{5}\left(\mathrm{PO}_{4}\right)_{3} \mathrm{OH}\right)$, fluorapatite $\left(\mathrm{Ca}_{5}\left(\mathrm{PO}_{4}\right)_{3} \mathrm{~F}\right)$, and chlorapatite $\left(\mathrm{Ca}_{5}\left(\mathrm{PO}_{4}\right)_{3} \mathrm{Cl}\right)$ ), sulfates (gypsum $\left(\mathrm{CaSO}_{4} \cdot 2 \mathrm{H}_{2} \mathrm{O}\right)$, barite $\left(\mathrm{BaSO}_{4}\right)$, alunite 
$\left(\mathrm{KAl}_{3}\left(\mathrm{SO}_{4}\right)_{2}(\mathrm{OH})_{6}\right)$, and celestite $\left.\left(\mathrm{SrSO}_{4}\right)\right)$, and sulfides (pyrite $\left(\mathrm{FeS}_{2}\right)$ and realgar $\left(\mathrm{As}_{4} \mathrm{~S}_{4}\right)$ ) (Blatt et al., 1972; Boggs, 2006; Deer et al., 1966; Pettijohn, 1975). Furthermore, the mineralogical and chemical composition depend on the mode of origin and depositional environment (Blatt et al., 1972; Ghosh, 1983; Pettijohn, 1975).

The uses of limestones as cement raw materials and quality of cement products depend highly on their chemical compositions (Chatterjee, 1983; Meade, 1926; Taylor, 1997). The rocks that are suitable for manufacturing the cement clinker should contain specific chemical compositions, such as $44 \%-52 \% \mathrm{CaO}, 3 \%-3.5 \% \mathrm{MgO}, 0.6 \%$ (maximum) $\mathrm{Na}_{2} \mathrm{O}$ and $\mathrm{K}_{2} \mathrm{O}, 0.6 \%-0.8 \%$ (maximum) $\mathrm{SO}_{3}, 0.25 \%-0.6 \%$ (maximum) $\mathrm{P}_{2} \mathrm{O}_{5}, 1.3 \% \mathrm{TiO}_{2}, 0.5 \% \mathrm{Mn}_{2} \mathrm{O}_{3}$, and $\mathrm{SiO}_{2}, \mathrm{Al}_{2} \mathrm{O}_{3}$, and $\mathrm{Fe}_{2} \mathrm{O}_{3}$ in proportions suitable for cement manufacturing (Chatterjee, 1983; Meade, 1926; Taylor, 1997). The presence of some minor constituents in limestones such as $\mathrm{MgO}, \mathrm{SO}_{3}, \mathrm{Na}_{2} \mathrm{O}$ and $\mathrm{K}_{2} \mathrm{O}$ that exceed the cement standard requirement is deleterious for the cement manufacture and product (Chatterjee, 1983; Horkoss et al., 2011; Ichikawa \& Kanaya, 1997; Li et al., 2014; Meade, 1926; Taylor, 1997). Therefore, to identify and characterize accurately these mineral resources, studying and estimating the relative abundances and compositions of mineral chemistries on the rock surfaces is required, especially for the chemical quality control of carbonate rocks as cement raw materials.

The developments in spectroscopy and hyperspectral imaging technologies have gave opportunities to characterize a particular mineral at a pixel level, based on their spectral reflectance characteristics (Kruse et al., 2003). Reflectance spectra in the wavelength range of visible and near infrared (VNIR), shortwave infrared (SWIR) and thermal infrared (TIR) have been used intensively in the last decades to analyze mineral components of rocks (Gupta, 2003; Longhi et al., 2001; Qaid et al., 2009; van der Meer, 1995). These spectral features analysis have also been revealed as a useful method to distinguish a particular mineral from others. The diagnostic absorption features of minerals in the VNIR wavelength range are determined by electronic processes or transitions of metal ions and iron oxide in atomic level which involves a number of processes for instance crystal field effect, charge transfer effect, and conduction band effect (Bedini et al., 2009; Clark \& Roush, 1984; Gupta, 2003; Hunt \& Salisbury, 1970; van der Meer, 1995). The SWIR and TIR spectral absorption features of minerals are caused by vibrational processes of carbonate ion, silicon oxide and interaction between hydroxide and metal ion (Bedini et al., 2009; Clark \& Roush, 1984; Gupta, 2003; Hunt \& Salisbury, 1970; van der Meer, 1995). The vibrational absorptions at molecular scale consist of three modes of vibrations such as fundamental, overtone, and combination (Gupta, 2003). Spectral absorption feature characteristics of minerals vary, depending on the chemical compositions, structural arrangements, and bonding characteristics (Clark, 1999; Povarennykh, 1978; van der Meer, 1995).

Carbonate minerals have diagnostic absorption features in the shortwave infrared (SWIR) and thermal infrared (TIR) regions due to vibrational processes of the carbonate ions $\left(\mathrm{CO}_{3}^{2-}\right)$ (Clark, 1999; Clark et al., 1990; Gupta, 2003; Hunt \& Salisbury, 1971; Salisbury et al., 1987). In general, carbonate minerals can be distinguished from other 
minerals by the presence of two prominent spectral absorption features in the wavelength ranges of 2.50-2.55 $\mu \mathrm{m}$ and 2.30-2.35 $\mu \mathrm{m}$ in the SWIR (Baissa et al., 2011; Clark et al., 1990; Gaffey, 1986; Hunt \& Salisbury, 1971; van der Meer, 1995; Zaini et al., 2012) and 13.70-14.04 $\mu \mathrm{m}$ and 11.19-11.40 $\mu \mathrm{m}$ in the TIR (Clark, 1999; Huang \& Kerr, 1960; Lane \& Christensen, 1997; Salisbury et al., 1987; Zaini et al., 2012). These features can be used to identify pure and mixed calcite and dolomite in synthetic samples or carbonate rocks, because the absorption band position of calcite is located at a slightly longer wavelength than that of dolomite (Gaffey, 1986; van der Meer, 1995). Spectral absorption features of carbonate minerals in the infrared region are influenced by physical and chemical parameters such as grain size (Crowley, 1986; Gaffey, 1986; van der Meer, 1995), texture (Crowley, 1986), packing or porosity (Gaffey, 1986), carbonate mineral content (van der Meer, 1995), and mineral impurities (Crowley, 1986; Gaffey, 1986; van der Meer, 1995).

This study investigates the applications of infrared spectroscopy and laboratorybased hyperspectral imaging methods combined with geochemical analysis for estimating mineral chemistries and their compositions in carbonate rock samples. The spectroscopic approaches offer an alternative technique for chemical quality control of carbonate rocks used in manufacturing process of Portland cement clinker.

\subsection{Problem statement}

The continuous demand for high-quality carbonate rocks and the need for accurate and rapid chemical analysis of the raw materials are increasing in cement industry and become more important. There are various conventional analytical methods (Table 1.1) that have been developed and employed to determine and estimate the mineral chemistry of carbonate rocks, as well as to characterize and control the chemical compositions of the cement raw materials and products. Infrared spectroscopy and laboratory-based hyperspectral imaging (imaging spectroscopy) techniques have been found suitable for determining mineral components of rocks or geologic materials (Baissa et al., 2011; Clark et al., 1990; Green \& Schodlok, 2016; Haest et al., 2012a; Hunt \& Salisbury, 1971; Mathieu et al., 2017; Murphy et al., 2014; Oh et al., 2017; Schodlok et al., 2016; Tappert et al., 2011; Tappert et al., 2015; Zaini et al., 2014; Zaini et al., 2016). However, these spectroscopic approaches have not been fully investigated in quantifying mineral chemistry of carbonate rocks.

The spectroscopic data within the SWIR region contain spectral signature of chemical composition of minerals in numerous spectral bands (Clark et al., 1990; Hunt \& Salisbury, 1970, 1971). This spectral information is useful for characterization of mineral chemistry and their composition that constitute rocks. Infrared spectroscopy methods combined with geochemical data have been used for identifying and estimating mineral chemistry and chemical composition of carbonate rocks or ore materials (Haest et al., 2012a; Magendran \& Sanjeevi, 2014; Oh et al., 2017; Zaini et al., 2016). Furthermore, these spectroscopic techniques have shown the ability to characterize the 
chemistry of cement products and the hydration rate (Kocak \& Nas, 2014; Mollah et al., 2000; Perraki et al., 2010; Pipilikaki et al., 2008; Ylmen et al., 2010). However, their applications in determining the mineral chemistry and chemical compositions of carbonate rocks or limestones as cement raw materials have not been completely explored. These applications and the benefit of infrared spectroscopy techniques, which are in the end simpler and faster than conventional methods, could be applied directly as a quality assurance for chemical quality control of carbonate rocks that are suitable for Portland cement clinker manufacture.

Table 1.1: Summary of conventional analytical methods used to identify mineral chemistry of carbonate rocks and chemical compositions of cement raw materials and products.

\begin{tabular}{lll}
\hline Analytical method & Application & References \\
\hline $\begin{array}{l}\text { Petrographic microscope } \\
\text { thin section analysis) }\end{array}$ & $\begin{array}{l}\text { Mineral chemistry } \\
\text { identification }\end{array}$ & $\begin{array}{l}\text { (Forbes et al., 2010; Vincent et al., } \\
\text { 2011) }\end{array}$ \\
\hline $\begin{array}{l}\text { Scanning electron } \\
\text { microscopy (SEM) }\end{array}$ & (Kaplan et al., 2013; Lein, 2004) \\
\hline X-ray diffraction (XRD) & (Bishop et al., 2011; Gaffey, 1986; \\
& $\begin{array}{l}\text { Kaplan et al., 2013; Sepulcre et al., } \\
\text { 2009) }\end{array}$ \\
\hline $\begin{array}{l}\text { Different thermal analysis } \\
\text { (DTA) }\end{array}$ & (Kaplan et al., 2013) \\
\hline Staining method & \\
& & (Dickson, 1965; Friedman, 1959; \\
\hline X-ray fluorescence (XRF) & Chemical composition & Hitzman, 1999; Kato et al., 2003) \\
\hline analysis & (Fernandez et al., 2011; Mazouzi et \\
Energy dispersive X-ray & & (De Weerdt et al., 2015; Irassar et al., \\
spectroscopy (EDS) & 2003; Pipilikaki et al., 2008; Tosun et \\
& al., 2009) \\
\hline $\begin{array}{l}\text { Inductively coupled } \\
\text { plasma optical emission }\end{array}$ & & (Frias et al., 1994; Marjanovic et al., \\
spectrometer (ICP-OES) & 2000; Potgieter \& Maljanovic, 2007; \\
& Silva et al., 2002) \\
\hline Electron microprobe & \\
analysis (EMPA) & (Bertron et al., 2009; Ifka et al., 2014; \\
& Kurokawa et al., 2013; Taylor \& \\
& Newbury, 1984) \\
\hline
\end{tabular}

\subsection{Research objectives}

The general objective of this research is to develop a methodology for determining and estimating the relative abundances and compositions of mineral chemistries from carbonate rocks using an integrated approach of spectroscopy, geochemistry and hyperspectral imagery, particularly for the chemical quality control of carbonate rocks as cement raw materials. To achieve these aims, the following specific objectives have been formulated: 
1. To analyze the effects of grain size and calcite-dolomite mixtures on carbonate spectral absorption feature characteristics.

2. To estimate the relative abundance and chemical composition of carbonate minerals on the rock surfaces using SisuCHEMA hyperspectral imagery.

3. To investigate the potential and accuracy of SWIR spectroscopy approach for chemical quality control of Portland cement-grade limestone.

\subsection{Study sites}

For the purposes of this study, the carbonate rock samples used for this research were collected from two different geological sites. The first study site was the Bédarieux dolomite mine in the Hérault department of the Languedoc-Roussillon region, southern France. The other site was the Lhoknga limestone quarry in Aceh Besar, Aceh, Indonesia. These study sites were selected based on the information and physical appearance of their variations in carbonate rock types and mineral compositions. The mines contain carbonate rocks of different types, which are dolomitic limestones and limestones, respectively.

\subsubsection{The Bédarieux dolomite mine}

This study site is located in the Bédarieux mining area, which is an open and partly active dolomite mine at $43^{\circ} 37^{\prime} \mathrm{N}$ and $3^{\circ} 12^{\prime} \mathrm{E}$, the Hérault department of LanguedocRoussillon region, southern France (Figure 1.1). The mine quarries dolomitic limestones (Figure 1.2). Being a source of magnesium, these rocks are used for fertilizer. The dolomite mine is also surrounded by abandoned mines with some bauxite pockets inside the area. The carbonate rocks are originating from the Jurrassic-Bathomien formation (Bogdanoff et al., 1984). From a geological point of view, the area is a part of consolidated rocks, which are a transition zone between the coastal plain, the alluvial sediments of the Hérault river and the metamorphous rock of 'Massif Central' (Gèze, 1979). The area has unique geological structures ranging from sandstone formation, limestone plateaus, dolomite formation, and volcanic tuffs and volcanic basalt deposits (Sluiter, 2005). 

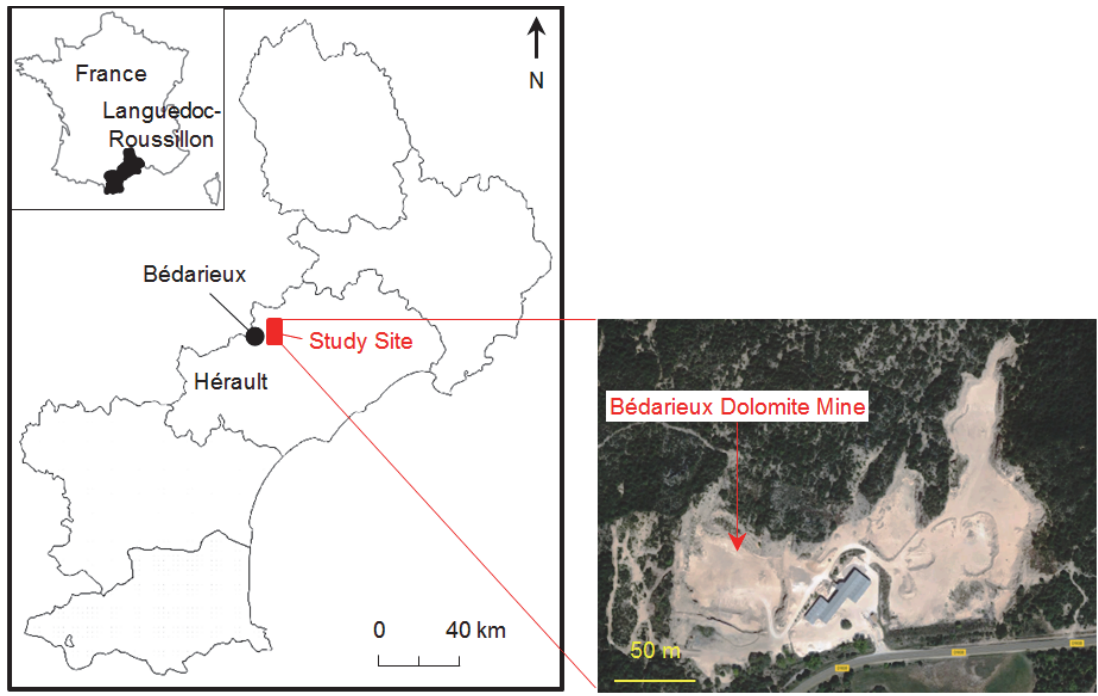

Figure 1.1: Location map of study site at the Bédarieux dolomite mine, the Hérault department of the Languedoc-Roussillon region, southern France. Google maps image shows the location of dolomite mine. (C) 2017 Google.
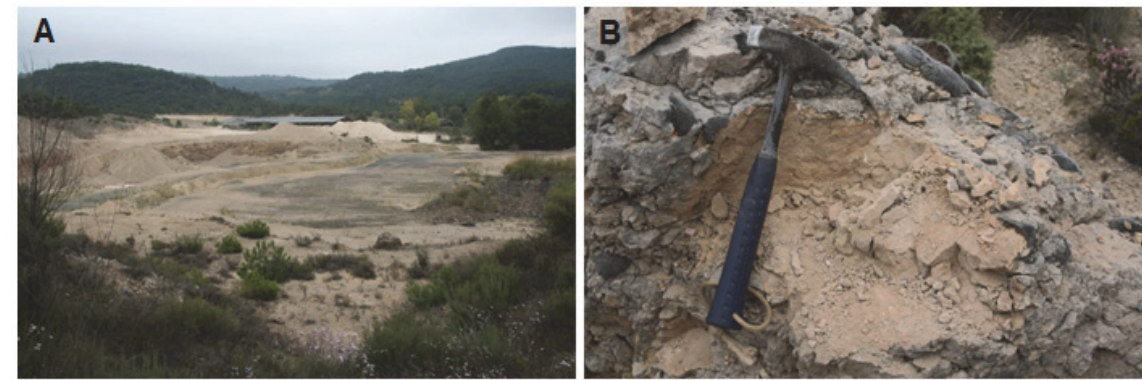

Figure 1.2: A) Field photograph of the Bédarieux dolomite mine in the Hérault department of the Languedoc-Roussillon region, southern France. B) Example of dolomitic limestone sample in the mine (photographs: de Jong, S.M., taken 18 September 2008).

\subsubsection{The Lhoknga limestone quarry}

The study site is an open active limestone mine of PT. Lafarge Cement Indonesia, located approximately $2 \mathrm{~km}$ south of Lhoknga, Aceh Besar or around $25 \mathrm{~km}$ south of Banda Aceh, the Aceh province, Indonesia (Figure 1.3). The Lhoknga limestone quarry is situated behind the cement plant at $5^{\circ} 27^{\prime} \mathrm{N}$ and $95^{\circ} 15^{\prime} \mathrm{E}$. In general, the quarry has two types of limestones, namely dark gray and light gray limestones (Figures 1.4). These quarried limestones are used as the primary raw materials for Portland cement manufactured by the Lafarge cement plant. The sedimentary rocks are from the Jurassic to Cretaceous-Raba Limestone Formation of the Woyla group, which is composed of 
massive calcarenite and calcilutite and dark gray thin-bedded argillaceous and siliceous limestones (Barber \& Crow, 2005; Bennett et al., 1981). These massive limestones crop out along the coast and in the Barisan Mountains to the south and west of Banda Aceh (Barber \& Crow, 2005; Bennett et al., 1981), and are closely associated with a lithological unit of the basaltic-andesitic arc assemblage (Barber, 2000; Barber \& Crow, 2005; Cameron, 1980) of the Bentaro Volcanic Formation (Bennett et al., 1981). They are interpreted as a volcanic arc with fringing reefs (Cameron, 1980). The volcanic formation is composed of porphyritic basalts and andesitic basalts with agglomerates and mafic dykes (Barber \& Crow, 2005; Bennett et al., 1981).

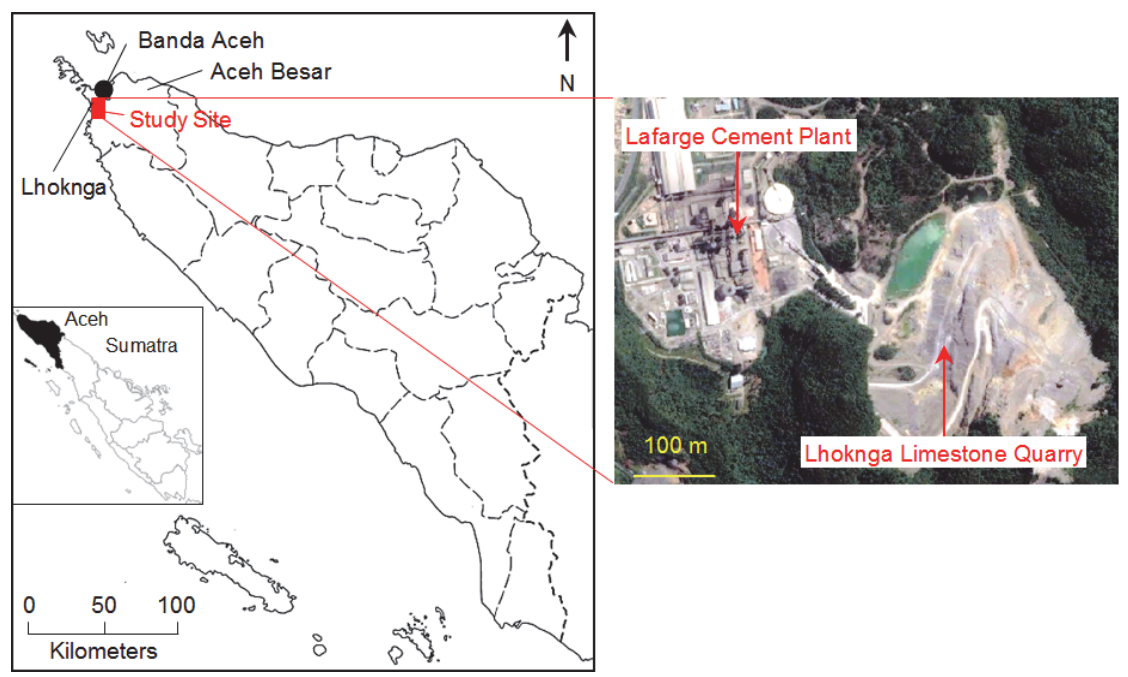

Figure 1.3: Location map of study site at PT. Lafarge Cement Indonesia, Lhoknga, Aceh Besar, Indonesia. Google maps image shows the location of Lhoknga limestone quarry behind the cement plant. (C) 2017 Google. 


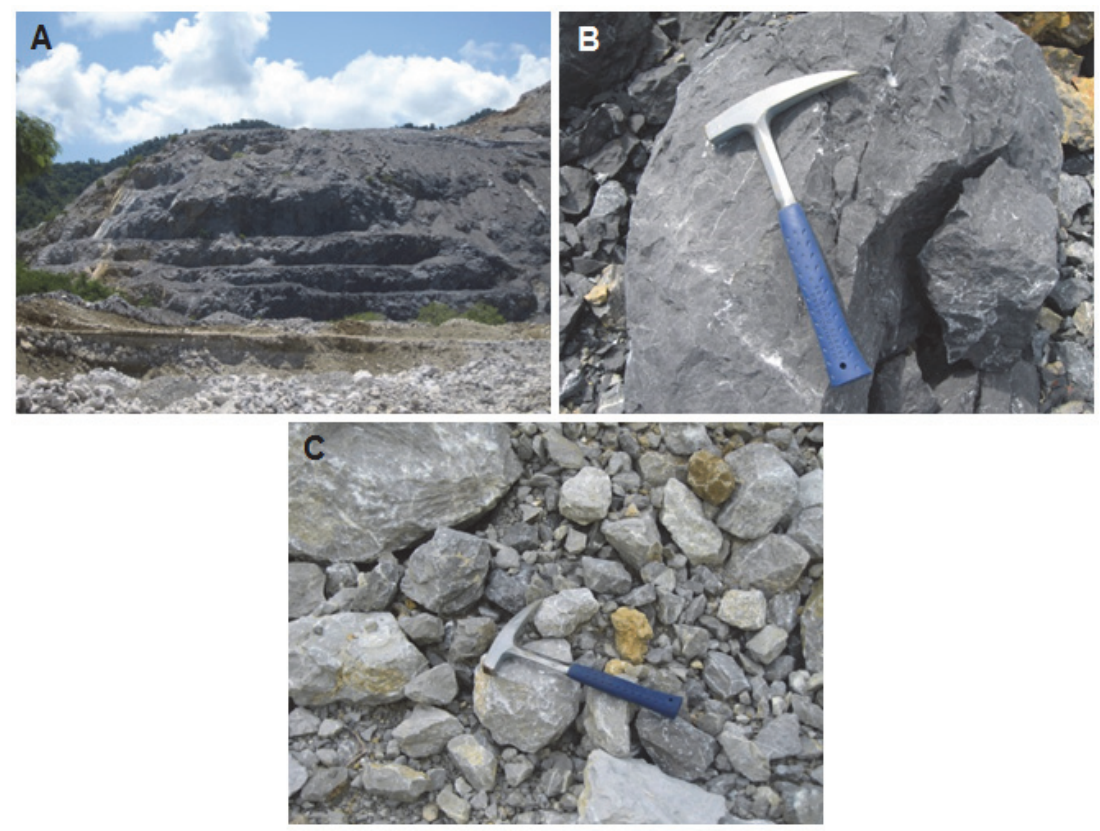

Figure 1.4: A) Field photograph of the Lhoknga limestone quarry of PT. Lafarge Cement Indonesia, Lhoknga, Aceh Besar, Indonesia. Example of B) dark gray and C) light gray limestone samples in the quarry (photographs: Zaini, N., taken 1 September 2014).

\subsection{Structure of the thesis}

This thesis has six chapters, contributed and linked together in understanding of the carbonate absorption feature characteristics and determining mineral chemistries of carbonate rocks. Apart from the introduction, literature review and synthesis, the three remaining chapters are scientific papers that have been published in peer-reviewed journals (Chapters 3 to 5).

Chapter 1 describes a general introduction of the thesis. In this chapter, research background, objectives, study sites and structure of the thesis are presented subsequently.

Chapter 2 provides a literature review of carbonate mineral chemistry characterization. It includes the significance of carbonate rocks and various technical approaches for mineral chemistry analyses of carbonate rocks, such as conventional analytical methods, infrared spectroscopy techniques and hyperspectral imagery approaches.

Chapter 3 analyzes the effect of grain size and carbonate mineral mixtures on spectral absorption feature characteristics of calcite and dolomite in the shortwave infrared (SWIR) and thermal infrared (TIR) wavelength regions. For the purpose of this chapter, synthetic samples of powdered calcite and dolomite with different grain size fractions and compositions of calcite-dolomite mixtures were prepared and measured 
successively their reflectance spectra in these infrared wavelength ranges. Spectral feature characteristics (e.g., wavelength position, depth, full width at half maximum (FWHM), and asymmetry of absorption feature) of those carbonate minerals are analyzed and established from four prominent carbonate vibrational absorption features of the continuum-removed spectra, consisted of features at 2.3 and $2.5 \mu \mathrm{m}$ (SWIR) and features at 11.5 and $14 \mu \mathrm{m}$ (TIR).

Chapter 4 presents the application of SisuCHEMA hyperspectral imagery, laboratory-based hyperspectral data, for estimating the chemical composition and the relative abundance of carbonate minerals on the rock surfaces. Various spectral recognition algorithms, such as wavelength position, spectral angle mapper (SAM) and linear spectral unmixing (LSU) approaches were used to extract compositional information of mineral mixtures from the spectral images, based on spectral endmembers of the synthetic samples established in Chapter 3. The accuracy of these classification methods and correlation between mineral chemistry and mineral spectral characteristics in determining mineral constituents of rocks are also analyzed.

Chapter 5 investigates the potential and accuracy of SWIR spectroscopy as an alternative quality control technique for chemical and mineralogical analyses of Portland cement-grade limestone or carbonate rocks that are suitable for manufacturing Portland cement clinker. The spectroscopic parameters, particularly the wavelength position and depth of absorption feature of carbonate and phyllosilicate minerals within the SWIR spectral ranges, are formulated and integrated with the geochemical characteristics, i.e. $\mathrm{CaO}, \mathrm{MgO}, \mathrm{Al}_{2} \mathrm{O}_{3}$ and $\mathrm{SiO}_{2}$ as determined by the portable X-ray fluorescence (PXRF) measurements, to determine and estimate the relative abundance of mineral chemistries and compositions in the rock samples.

Chapter 6 summarizes and synthesizes the results and findings of this research. This chapter also discusses the outcome and practical implications of the study with regard to the quality control of cement raw materials or carbonate rock chemistry characterization using an integrated approach of spectroscopy, geochemistry and hyperspectral imagery. 


\section{Carbonate rock chemistry characterization- a review ${ }^{1}$}

${ }^{1}$ This chapter will be submitted to Journal of Geochemical Exploration as: Zaini, N., van der Meer, F., van der Werff, H. and van Ruitenbeek, F. Carbonate rock chemistry characterization: A review (In preparation) 


\subsection{Introduction}

This chapter presents a review of carbonate rock chemistry characterization as reported in literature of earlier studies. The significance of carbonate rocks in a scientific and economic perspective, as well as their mineralogical contents and chemical compositions are summarized. The two essential carbonate minerals, calcite and dolomite that mostly constitute those sedimentary rocks, are highlighted in terms of their functionality and applicability in nature and industry. Furthermore, various analytical methods that have been used in numerous studies for determining and analyzing mineral chemistry and composition of carbonate sediments or rocks are discussed, including the advantages and weaknesses of these approaches (Table 2.1). Firstly, conventional analytical methods on carbonate mineral chemistry analysis are described concisely. They involve staining method, petrographic microscope (thin section analysis), scanning electron microscopy (SEM), electron microprobe analysis (EMPA), X-ray diffraction (XRD), and X-ray fluorescence (XRF). Subsequently, the uses of infrared spectroscopy and field and laboratory-based hyperspectral imagery techniques for carbonate rock chemistry analyses are also discussed.

\subsection{The significance of carbonate rocks}

Carbonate rocks can be divided into two dominant groups based on their carbonate mineral compositions, namely limestone and dolomitic limestone or dolostone (Bissell \& Chilingar, 1967; Pettijohn, 1975). Limestone is constituted predominantly of calcium carbonate $\left(\mathrm{CaCO}_{3}\right)$, normally in the form of calcite or aragonite. Dolostone is composed mostly of calcium magnesium carbonate $\left(\mathrm{CaMg}\left(\mathrm{CO}_{3}\right)_{2}\right)$, dolomite. In this thesis, dolomite refers to the carbonate mineral and dolomitic limestone or dolostone refers to a type of carbonate rock.

The majority of carbonate sedimentary rocks are deposited from seawater and made by bioclastic accumulation or precipitation of calcareous organisms (Boggs, 2006). Limestone and dolostone are the most common types of carbonate rocks in stratigraphic record. Limestones are built up from dissolved organic matters or calcareous organisms and inorganic materials, which depend on their depositional environment, and then deposited and compacted into a rock by lithification process throughout geological time (Blatt et al., 1972; Pettijohn, 1975). These carbonate sedimentary rocks can occur in various depositional environments, such as non-marine environments, shallow marine platforms and deep-sea environments (Blatt et al., 1972; Sanders \& Friedman, 1967). Dolostones are formed principally by the dolomitization process of limestone, which involves the replacement of calcite by dolomite in the rock when magnesium-rich water permeates through limestone (Friedman \& Sanders, 1967; Hatch \& Rastall, 1965; Pettijohn, 1975). 
Table 2.1: Summary of the strengths and weaknesses of various analytical methods used for chemical and mineralogical characterization of carbonate sediments or rocks.

\begin{tabular}{|c|c|c|c|}
\hline Analytical method & Strength & Weakness & References \\
\hline Staining method & $\begin{array}{l}\text { A relatively easy, rapid } \\
\text { and inexpensive technique } \\
\text { for carbonate minerals } \\
\text { analysis; effective for field } \\
\text { application }\end{array}$ & $\begin{array}{l}\text { Less accurate and } \\
\text { certainty compared to } \\
\text { other analytical } \\
\text { techniques (e.g., SEM, } \\
\text { XRD, EMPA) } \\
\end{array}$ & $\begin{array}{l}\text { (Brasier et al., 2013; } \\
\text { Dickson, 1965; Friedman, } \\
\text { 1959; Hitzman, 1999; James } \\
\text { \& Jones, 2015) }\end{array}$ \\
\hline $\begin{array}{l}\text { Petrographic } \\
\text { microscope (thin } \\
\text { section analysis) }\end{array}$ & $\begin{array}{l}\text { It can be used to } \\
\text { characterize mineralogy, } \\
\text { crystal structure, grain } \\
\text { shapes, fossil distributions } \\
\text { and diagenetic constituents } \\
\text { of carbonate rocks }\end{array}$ & $\begin{array}{l}\text { Requiring a skillful } \\
\text { operator for sample } \\
\text { preparation and } \\
\text { analysis; } \\
\text { impracticality for field } \\
\text { measurement }\end{array}$ & $\begin{array}{l}\text { (Andriani \& Walsh, 2002; } \\
\text { Brasier et al., 2013; Crne et } \\
\text { al., 2014; James \& Jones, } \\
\text { 2015; Johansson et al., 2017; } \\
\text { Vincent et al., 2011) }\end{array}$ \\
\hline $\begin{array}{l}\text { Scanning electron } \\
\text { microscopy (SEM) }\end{array}$ & $\begin{array}{l}\text { A high resolution and } \\
\text { magnification image; it can } \\
\text { be used to characterize } \\
\text { crystallography, } \\
\text { topographical, and } \\
\text { compositional information } \\
\text { of the surface; useful to } \\
\text { visualize microscopically } \\
\text { features in carbonates }\end{array}$ & $\begin{array}{l}\text { Samples must be solid } \\
\text { and fit into the } \\
\text { microscope chamber; } \\
\text { time consuming for } \\
\text { sample preparation; } \\
\text { impracticality for field } \\
\text { measurement }\end{array}$ & $\begin{array}{l}\text { (Črne et al., 2014; Goldstein } \\
\text { et al., 2003; James \& Jones, } \\
\text { 2015; Johansson et al., 2017; } \\
\text { Kaplan et al., 2013; Lein, } \\
\text { 2004; Reed, 2005; Vincent et } \\
\text { al., 2011) }\end{array}$ \\
\hline $\begin{array}{l}\text { Energy dispersive } \\
\text { X-ray } \\
\text { spectroscopy } \\
\text { (EDS) attached to } \\
\text { SEM (SEM-EDS) }\end{array}$ & $\begin{array}{l}\text { A rapid and accurate } \\
\text { technique for chemical } \\
\text { analysis of geologic } \\
\text { samples }\end{array}$ & $\begin{array}{l}\text { Spot chemical } \\
\text { analyses; the EDS } \\
\text { analyzer is insensitive } \\
\text { to very light elements } \\
\text { such as } \mathrm{H}, \mathrm{He} \text { and } \mathrm{Li} \text {; } \\
\text { less sensitivity for } \\
\text { detecting low element } \\
\text { contents in the sample; } \\
\text { impracticality for field } \\
\text { measurement }\end{array}$ & $\begin{array}{l}\text { (Goldstein et al., 2003; } \\
\text { James \& Jones, 2015; } \\
\text { Johansson et al., 2017; Reed, } \\
2005 \text { ) }\end{array}$ \\
\hline $\begin{array}{l}\text { Electron } \\
\text { microprobe analysis } \\
\text { (EMPA) }\end{array}$ & $\begin{array}{l}\text { A rapid and accurate } \\
\text { technique for chemical } \\
\text { analysis of geologic } \\
\text { samples; the elemental } \\
\text { concentration analysis of } \\
\text { microprobe is more precise } \\
\text { than the EDS }\end{array}$ & $\begin{array}{l}\text { Spot chemical } \\
\text { analyses; time } \\
\text { consuming for sample } \\
\text { preparation; the } \\
\text { EMPA's image is } \\
\text { lower resolution than } \\
\text { the SEM's image; } \\
\text { overlapping peak } \\
\text { positions for some } \\
\text { elements; } \\
\text { impracticality for field } \\
\text { measurement }\end{array}$ & $\begin{array}{l}\text { (James \& Jones, 2015; Lane } \\
\text { \& Christensen, 1997; Lane \& } \\
\text { Dalton, 1994; Reed, 2005) }\end{array}$ \\
\hline
\end{tabular}


Table 2.1: (continued)

\begin{tabular}{|c|c|c|c|}
\hline Analytical method & Strength & Weakness & References \\
\hline $\begin{array}{l}\text { X-ray powder } \\
\text { diffraction (XRD) }\end{array}$ & $\begin{array}{l}\text { A common and convenient } \\
\text { analytical technique for } \\
\text { determining mineralogy; } \\
\text { bulk mineralogical } \\
\text { analyses; it can be used to } \\
\text { analyze the proportions } \\
\text { and compositions of } \\
\text { carbonate minerals and the } \\
\text { ordering of dolomite } \\
\text { crystals in carbonate rocks }\end{array}$ & $\begin{array}{l}\text { Powdered and } \\
\text { homogenous samples; } \\
\text { overlapping peak } \\
\text { positions that affect } \\
\text { ambiguous mineral } \\
\text { identification; less } \\
\text { accurate for measuring } \\
\text { small crystalline } \\
\text { structures; requires } \\
\text { standard libraries; } \\
\text { impracticality for field } \\
\text { application }\end{array}$ & $\begin{array}{l}\text { (Bishop et al., 2011; Brasier } \\
\text { et al., 2013; Forbes et al., } \\
\text { 2010; Gaffey, 1986; Hardy \& } \\
\text { Tucker, 1988; James \& Jones, } \\
\text { 2015; Kaplan et al., 2013; } \\
\text { Sdiri et al., 2010; Sepulcre et } \\
\text { al., 2009) }\end{array}$ \\
\hline $\begin{array}{l}\text { X-ray fluorescence } \\
\text { (XRF) }\end{array}$ & $\begin{array}{l}\text { A rapid and accurate } \\
\text { technique for chemical } \\
\text { analysis of geologic } \\
\text { samples; bulk chemical } \\
\text { analyses of major and trace } \\
\text { elements; it can be applied } \\
\text { to solid or liquid materials }\end{array}$ & $\begin{array}{l}\text { Time consuming for } \\
\text { sample preparation; } \\
\text { less accurate for } \\
\text { analyzing light } \\
\text { elements with a } \\
\text { particular atomic } \\
\text { number (e.g., } Z<11 \text { ); } \\
\text { impracticality for field } \\
\text { application except for } \\
\text { a hand-held analyzer }\end{array}$ & $\begin{array}{l}\text { (Brasier et al., 2013; Črne et } \\
\text { al., 2014; Fitton, 2014; } \\
\text { Forbes et al., 2010; Lai et al., } \\
\text { 2015; Sdiri et al., 2010) }\end{array}$ \\
\hline $\begin{array}{l}\text { Infrared } \\
\text { spectroscopy }\end{array}$ & $\begin{array}{l}\text { A non-destructive } \\
\text { technique to determine } \\
\text { mineralogical composition } \\
\text { of geologic samples; } \\
\text { requiring a small quantity } \\
\text { of sample; easy sample } \\
\text { preparation and analysis; it } \\
\text { can be applied effectively } \\
\text { in field measurement, } \\
\text { especially for field } \\
\text { spectrometer }\end{array}$ & $\begin{array}{l}\text { Requires standard } \\
\text { spectral libraries and } \\
\text { skilled interpreter for } \\
\text { minerals identification; } \\
\text { spectral features are } \\
\text { influenced } \\
\text { considerably by } \\
\text { chemical composition } \\
\text { and grain size } \\
\text { variations; less } \\
\text { accurate to identify } \\
\text { low abundance of } \\
\text { mineral mixtures that } \\
\text { present in geologic } \\
\text { samples }\end{array}$ & $\begin{array}{l}\text { (Clark, 1999; Clark et al., } \\
\text { 1990; Crowley, 1986; Gaffey, } \\
\text { 1986; Hunt \& Salisbury, } \\
\text { 1971; Oh et al., 2017; Reig et } \\
\text { al., 2002; Sdiri et al., 2010; } \\
\text { van der Meer, 1995; Xie et } \\
\text { al., 2016; Zaini et al., 2016) }\end{array}$ \\
\hline $\begin{array}{l}\text { Hyperspectral } \\
\text { imagery } \\
\text { (Hyperspectral } \\
\text { imaging) }\end{array}$ & $\begin{array}{l}\text { A non-destructive } \\
\text { technique to determine } \\
\text { mineralogical composition } \\
\text { of geologic samples; easy } \\
\text { sample preparation; } \\
\text { hyperspectral image } \\
\text { allowing spectral analysis } \\
\text { of each pixel for } \\
\text { compositional mineral } \\
\text { mapping; it can be used for } \\
\text { field application. }\end{array}$ & $\begin{array}{l}\text { Less accurate to } \\
\text { identify low } \\
\text { abundance of mineral } \\
\text { mixtures that present } \\
\text { in geologic samples; } \\
\text { requires standard } \\
\text { spectral libraries and } \\
\text { skilled interpreter for } \\
\text { minerals identification } \\
\text { and pre-processing } \\
\text { hyperspectral imagery }\end{array}$ & $\begin{array}{l}\text { (Baissa et al., 2011; Buckley } \\
\text { et al., 2013; Kurz et al., 2013; } \\
\text { Kurz et al., 2012; Murphy et } \\
\text { al., 2016; Zaini et al., 2014) }\end{array}$ \\
\hline
\end{tabular}


The importance and functionality of these sedimentary rocks in nature and industry have been described in many studies. In nature, carbonate rocks that exist in all geologic systems, from the Precambrian to the Quaternary (Blatt et al., 1972; Boggs, 2006), are essential geological formations for hydrocarbon reservoirs and water aquifers (Ahr, 2008; Beccari \& Romano, 2005; Harbaugh, 1976), precious ore and mineral deposits (Deer et al., 1966; Pettijohn, 1975) and carbon sequestration sites (Liu \& Zhao, 2000; Luquot \& Gouze, 2009).

In industry, carbonate rocks are one of the essential materials used in many sectors, such as construction, cement industry, agricultural industry and household industries. These sedimentary rocks, limestones, are the main component in the raw mix for cement clinker (Chatterjee, 1983; Ghosh, 1983; Meade, 1926; Taylor, 1997). Moreover, raw and dehydrated products of carbonate rocks that content high-purity of calcite and dolomite are applied to agricultural industries as a fertilizer and acid neutralizer of the soil, and are important additive materials for various household products, such as pharmaceuticals, paper, glass, plastic and paint (Freas et al., 2006; Krukowski, 2006; Pohl, 2011). Its derivative product in the form of lime is also used in manufacturing process of steel as well as for environmental applications, including water and sewage treatment and flue gas desulfurization (Freas et al., 2006; Krukowski, 2006; Pohl, 2011). In the treatment of water and sewage, lime serves as a powerful chemical agent for such applications: elimination of turbidity and suspended matter, acid neutralization, $\mathrm{pH}$ controlling, precipitation of metals and sulfates, and disinfectant (Krukowski, 2006). Lime is required in the flue gas scrubber system for removal sulfur or sulfur dioxide $\left(\mathrm{SO}_{2}\right)$ from stack gases of coal electric power plants (flue gas desulfurization) (Krukowski, 2006). It is important to control the emission of $\mathrm{SO}_{2}$ into the atmosphere, because the gas can react with water to form $\mathrm{H}_{2} \mathrm{SO}_{4}$.

\subsection{Mineralogical and geochemical compositions of carbonate rocks}

The main mineralogical compositions of carbonate rocks are carbonate minerals consisted of calcite, calcium carbonate $\left(\mathrm{CaCO}_{3}\right)$ and dolomite, calcium magnesium carbonate $\left(\mathrm{CaMg}\left(\mathrm{CO}_{3}\right)_{2}\right)$ (Blatt et al., 1972; Pettijohn, 1975). Carbonate minerals are a group of minerals composed of carbonate ion $\left(\mathrm{CO}_{3}{ }^{2-}\right)$ as the basic molecular structure. The rocks may also be constituted by other common carbonate minerals and mineralogical associations in various amounts, which depend on their modes of origin and depositional environment (Blatt et al., 1972; Boggs, 2006; Deer et al., 1966; Pettijohn, 1975).

Carbonate minerals have relatively similar physical properties (Table 2.2) (Boggs, 2006; Deer et al., 1966; Hamilton et al., 1995; Pettijohn, 1975), and are consequently difficult to differentiate the minerals from one another. Calcite and dolomite occur in the hexagonal crystal system and have perfect rhombohedral cleavage. Aragonite, which is a metastable mineral and has identical chemical composition as calcite, exists in the 
orthorhombic crystal system and alters to calcite through time. Calcite can also be distinguished from dolomite by their specific characteristics, for instance effervescence and dissolving quickly in cold dilute hydrochloric acid. The hardness value of calcite is 3.0 on the Mohs scale, while dolomite is slightly harder ranging between 3.5 and 4.0. Therefore, calcite is easier to pulverize into a powder with different grain size fractions than dolomite. Calcite has a wide variety of colors in its appearance, which is usually colorless or white and shaded by grey and black due to the presence of organic matter, yellowish, brown or reddish due to iron oxides impurity, and greenish due to infiltrating of clayey mineral into the rock (Hamilton et al., 1995; Kirkaldy, 1976). Dolomite also has various colors in its appearance, which is generally white and sometime it may be reddish, brown, greenish, gray or black due to infiltrating of other matters into the rock (Hamilton et al., 1995; Kirkaldy, 1976).

Table 2.2: Some physical properties of common carbonate minerals (Boggs, 2006; Deer et al., 1966; Hamilton et al., 1995; Pettijohn, 1975).

\begin{tabular}{lllll}
\hline Mineral & Crystal system & Mohs hardness & Specific gravity & Luster \\
\hline Calcite $\left(\mathrm{CaCO}_{3}\right)$ & Hexagonal & 3 & 2.7 & Vitreous \\
Dolomite $\left(\mathrm{CaMg}_{\left.\left(\mathrm{CO}_{3}\right)_{2}\right)}\right.$ & Hexagonal & $3.5-4.0$ & $2.8-3.0$ & Vitreous to pearly \\
Aragonite $\left(\mathrm{CaCO}_{3}\right)$ & Orthorhombic & $3.5-4.0$ & $2.9-3.0$ & Vitreous to dull \\
Siderite $\left(\mathrm{FeCO}_{3}\right)$ & Hexagonal & 4 & 4 & Vitreous to pearly \\
Magnesite $\left(\mathrm{MgCO}_{3}\right)$ & Hexagonal & 4 & 3 & Vitreous \\
Rhodochrosite $\left(\mathrm{MnCO}_{3}\right)$ & Hexagonal & $3.5-4.0$ & 3.7 & Vitreous \\
Strontianite $\left(\mathrm{SrCO}_{3}\right)$ & Orthorhombic & 3.5 & $3.7-3.8$ & Vitreous to greasy \\
Cerussite $\left(\mathrm{PbCO}_{3}\right)$ & Orthorhombic & $3.0-3.5$ & $6.5-6.6$ & Adamantine \\
Witherite $\left(\mathrm{BaCO}_{3}\right)$ & Orthorhombic & $3.0-3.5$ & 4.3 & Vitreous to dull \\
Ankerite $\left(\mathrm{CaFe}\left(\mathrm{CO}_{3}\right)_{2}\right)$ & Hexagonal & $3.5-4.0$ & $2.9-3.0$ & Vitreous to pearly \\
\hline
\end{tabular}

Moreover, the principal chemical elements of carbonate rocks are calcium $\left(\mathrm{Ca}^{2+}\right)$, magnesium $\left(\mathrm{Mg}^{2+}\right)$ and carbonate ions $\left(\mathrm{CO}_{3}{ }^{2-}\right)$ (Barber, 1974; Boggs, 2006; Wolf et al., 1967). These major elements attribute to the dominant minerals of calcite and dolomite in carbonate rocks, respectively. The rocks may also contain other chemical elements in minor and trace concentrations (Barber, 1974; Boggs, 2006; Robinson, 1980; Thompson et al., 1970; Wolf et al., 1967). Minor elements that are commonly found in carbonate rocks are $\mathrm{Si}, \mathrm{Al}, \mathrm{Fe}, \mathrm{K}$ and $\mathrm{Na}$. These elements indicate the presence of minor constituents of silicate minerals in intimate mixture with carbonate rocks, such as quartz, feldspars and clay minerals. Various trace elements might be incorporated into carbonate rocks, namely $\mathrm{Ag}, \mathrm{B}, \mathrm{Be}, \mathrm{Ba}, \mathrm{Bi}, \mathrm{Br}, \mathrm{Cl}, \mathrm{Cd}, \mathrm{Co}, \mathrm{Cr}, \mathrm{Cu}, \mathrm{Ga}, \mathrm{Li}, \mathrm{Mn}, \mathrm{Mo}, \mathrm{Ni}$, $\mathrm{Pb}, \mathrm{Rb}, \mathrm{Sn}, \mathrm{Sr}, \mathrm{Ti}, \mathrm{V}, \mathrm{Y}, \mathrm{Zn}$ and Zr (Barber, 1974; Boggs, 2006; Robinson, 1980; Thompson et al., 1970; Wolf et al., 1967). Other geochemical components that are helpful in identifying carbonate rock are stable isotopes. They are oxygen and carbon. The amount of these isotopes in carbonate rocks is affected by chemical and physical parameters, such as organic processes and sea water compositions and temperature. In 
addition, the chemical compositions and concentrations of minor and trace elements in carbonate rocks depend on mineral chemistry, organic matters and skeletal materials forming the rocks (Barber, 1974; Boggs, 2006; Robinson, 1980; Thompson et al., 1970; Wolf et al., 1967). The detailed study of mineralogical and geochemical compositions of carbonate rocks can be found in the following literatures reviewed by several authors (Bissell \& Chilingar, 1967; Blatt et al., 1972; Boggs, 2006; Deer et al., 1966; Pettijohn, 1975; Wolf et al., 1967).

\subsection{Mineral chemistry analysis of carbonate rocks}

\subsubsection{Conventional analytical methods}

To analyze mineralogy and chemical compositions of a carbonate rock, various conventional analytical methods have been utilized, such as staining, petrographic microscope (thin section analysis), scanning electron microscopy (SEM), electron microprobe analysis (EMPA), X-ray diffraction (XRD), and X-ray fluorescence (XRF). A concise description and application of these classical methods on a carbonate rock are designated in the following paragraphs.

Table 2.3: Staining colors of carbonate minerals using various chemical solutions, adapted after (Hitzman, 1999; Parbhakar-Fox et al., 2017).

\begin{tabular}{|c|c|c|c|c|}
\hline Mineral & $\begin{array}{l}\text { Alizarin red S } \\
\text { (ARS) }\end{array}$ & $\begin{array}{l}\text { Potassium } \\
\text { ferricyanide }(\mathrm{PF})\end{array}$ & $\begin{array}{l}\text { Combination of } \\
\text { ARS and PF }\end{array}$ & Titan yellow \\
\hline Calcite & Pink to red & Unstained & Pink to red & Unstained \\
\hline Aragonite & Pink to red & Unstained & Pink to red & Unstained \\
\hline Ferroan calcite & $\begin{array}{l}\text { Pink to pale } \\
\text { pink }\end{array}$ & Pale to deep blue & $\begin{array}{l}\text { Purple to royal } \\
\text { blue }\end{array}$ & Unstained \\
\hline Dolomite & Unstained & Unstained & Unstained & Red to orange \\
\hline $\begin{array}{l}\text { Ferroan } \\
\text { dolomite }\end{array}$ & Unstained & $\begin{array}{l}\text { Pale to deep } \\
\text { turquois }\end{array}$ & $\begin{array}{l}\text { Pale to deep } \\
\text { turquois }\end{array}$ & Unstained \\
\hline Siderite & Unstained & Unstained & Unstained & Unstained \\
\hline Magnesite & Unstained & Unstained & Unstained & Red to orange \\
\hline Rhodochrosite & Unstained & Pale brown & Pale brown & Unstained \\
\hline Cerussite & Mauve & Unstained & Mauve & Unstained \\
\hline Witherite & Red & Unstained & Red & Unstained \\
\hline
\end{tabular}

Staining is a practical method used in determining mineralogy of a carbonate rock by treating it with specific chemical solutions (Friedman, 1959). This method is a relatively easy, rapid and inexpensive technique for extracting compositional information of carbonate minerals, especially calcite, aragonite and dolomite contents in a carbonate rock (Brasier et al., 2013; Dickson, 1965; Friedman, 1959; Hitzman, 1999; James \& Jones, 2015; Parbhakar-Fox et al., 2017). There are several chemical solutions that are frequently used for staining a carbonate rock, such as Alizarin red S, potassium ferricyanide, and Titan yellow (Brasier et al., 2013; Dickson, 1965; Friedman, 1959; Hitzman, 1999; James \& Jones, 2015; Parbhakar-Fox et al., 2017). These staining solutions impart a specific color to carbonate minerals (Table 2.3) that allow identifying 
the minerals in various geologic samples. Figure 2.1 show an example of carbonate minerals identification by applying staining solutions on carbonate drill core of a chlorite-carbonate-sphalerite schist sample from the Palacoproterozoic Koongie Park Formation, Western Australia (Parbhakar-Fox et al., 2017).
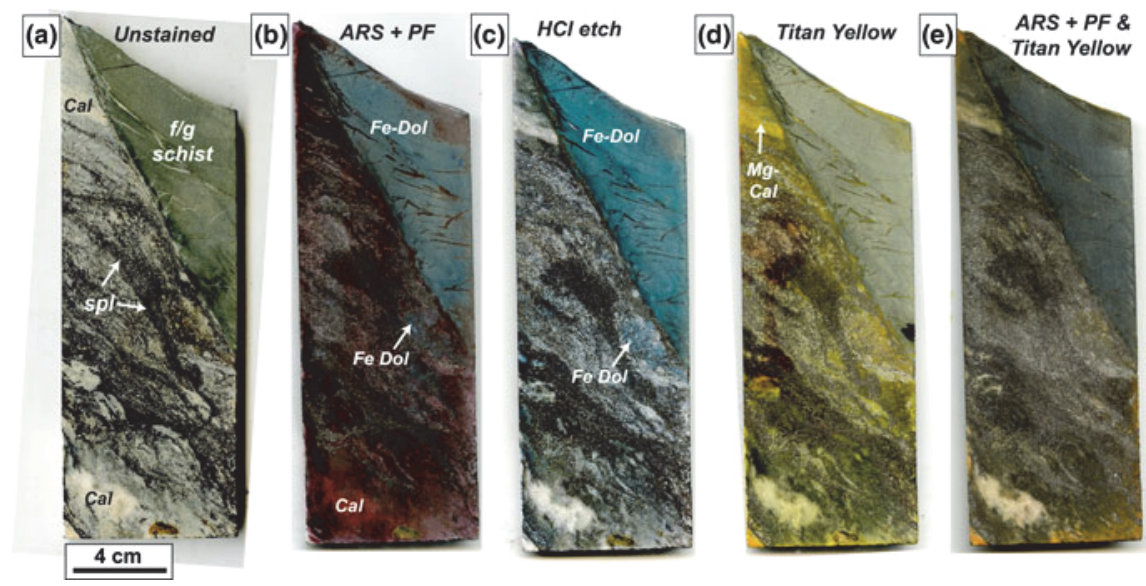

Figure 2.1: Carbonate drill core staining of a chlorite-carbonate-sphalerite schist sample: (a) unstained sample; (b) Ferroan dolomite (Fe-Dol) stained blue and calcite (Cal) stained red with a combination staining solution of alizarin red $\mathrm{S}$ (ARS) and potassium ferricyanide (PF); (c) post ARS-PF staining etch with $\mathrm{HCl}$, showing the $\mathrm{Fe}$ Dol areas with a bright blue; (d) dolomite remains unstained and $\mathrm{Mg}$-rich calcite $(\mathrm{Mg}$ Cal) stained yellow with titan yellow; (e) Ferrous dolomite stained dark blue when applying ARS-PF staining followed by the titan yellow. (f/g: fine-grained, spl: sphalerite), taken with permission of Springer Nature and without changes from (Parbhakar-Fox et al., 2017). (C) 2017 Springer.

Petrographic microscope of thin section analysis has been demonstrated to be an invaluable method for determining mineralogical compositions, crystal structure, grain shapes, fossil distributions and diagenetic constituents of carbonate rocks (Andriani \& Walsh, 2002; Brasier et al., 2013; Črne et al., 2014; James \& Jones, 2015; Johansson et al., 2017; Vincent et al., 2011). This method requires a skillful operator in terms of sample preparation and analysis. The petrographic microscope can be integrated with cathodoluminescence unit to assess carbonate rock constituents. It highlights mineralogical compositions of areas that are exhibited by different luminescent colors. However, this approach cannot accurately identify rock components based on various luminescent indicators.

Scanning electron microscopy (SEM) is an essential instrument to acquire a high resolution and magnification image by scanning a pointing area on the rock surface with a focused electron beam (Goldstein et al., 2003; Reed, 2005). The electron beam generated by an electron gun strikes the rock surface to form a black and white image that can be used to characterize crystallography, topographical and compositional information of the surface that assist in mineral identification (Goldstein et al., 2003; 
Reed, 2005). This method is time consuming for sample preparation including surface stain-coating with metal for electron conducting.

SEM method is commonly used for studying carbonate rocks (Črne et al., 2014; James \& Jones, 2015; Johansson et al., 2017; Kaplan et al., 2013; Lein, 2004; Vincent et al., 2011). SEM image is also useful to visualize microscopically features, such as microfossils, microbes, cement growth zonation and microscale fabric variations in carbonate rocks that are unidentified by an optical microscope (James \& Jones, 2015). The advanced development in SEM technology has created a possibility for chemical characterization of the analyzed sample using an additional instrument, such as energy dispersive X-ray spectroscopy (EDX or EDS). The EDS analyzer is a semi-qualitative technique used in conjunction with SEM for analyzing elemental constituents of small areas of solid materials (Goldstein et al., 2003; Reed, 2005). The EDS data of chemical compositions of the sampled volume complemented by crystal analysis can precisely determine mineralogical compositions of carbonate rocks in area being analyzed (James \& Jones, 2015; Johansson et al., 2017).

Electron microprobe analysis (EMPA) is a quantitative microanalysis technique for determining chemical compositions of microvolume spot measurements of solid materials (Reed, 2005). The instrument also uses a focused electron beam as the SEM in characterizing elemental constituents that exist in small analyzed areas of the sample. The elemental concentration analysis of electron microprobe is more precise than the EDS results attached on a SEM, although the EMPA's image is lower resolution than the SEM's image. This method is time consuming for sample preparation including polished thin sections and coated with carbon for such analysis. The microprobe technique has been applied for chemical analyses of carbonate rocks and minerals (James \& Jones, 2015; Lane \& Christensen, 1997; Lane \& Dalton, 1994). The information derived from the microprobe technique allows the examination process of elemental compositions, fabrics and zoned crystals of carbonate rocks (James \& Jones, 2015).

$X$-ray powder diffraction $(X R D)$ is a common and convenient analytical technique for determining mineralogy of crystalline structured materials (Klug \& Alexander, 1974; Waseda et al., 2011). In this technique the collimated X-rays are directed at the surface of the powdered sample. The resulting reflectance peaks generated by constructive interference of atoms in a crystal can be utilized to identify mineralogical composition. The method is also widely used for analyzing the composition of carbonate sediments or rocks (Bishop et al., 2011; Brasier et al., 2013; Forbes et al., 2010; Gaffey, 1986; Hardy \& Tucker, 1988; James \& Jones, 2015; Kaplan et al., 2013; Sdiri et al., 2010; Sepulcre et al., 2009). It is invaluable technique for characterizing fine-grained carbonate rocks. XRD patterns exhibit distinctive information about the chemical composition of carbonate minerals, the proportions and variations of carbonate minerals, and the ordering of dolomite crystals composing carbonate rocks (Hardy \& Tucker, 1988; James \& Jones, 2015). XRD has limitations, such as time overlapping peak positions that can be ambiguous for mineral identification, less accurate for 
measuring small crystalline structures, and failing to detect small structures presenting in trace amounts.

$X$-ray fluorescence $(X R F)$ is a chemical analysis technique used to determine elemental compositions (major and trace elements) of rocks, minerals, and sediments (Fitton, 2014). This spectrometer works using a high energy X-ray beam to irradiate a sample and the emission of characteristic X-rays excited by the sample depend on their chemical compositions. The output of fluorescence X-ray can be used to examine the elemental composition of a sample. The XRF method has been applied to analyze the relative amounts of major and trace elements of carbonate rocks (Brasier et al., 2013; Črne et al., 2014; Forbes et al., 2010; Lai et al., 2015; Sdiri et al., 2010). These elemental analyses reveal the historical information of sedimentary and diagenetic process of carbonate rocks. However, the method is time consuming for sample preparation and less accurate for analyzing light elements with a particular atomic number (e.g., $\mathrm{Z}<11$ ).

\subsubsection{Infrared spectroscopy}

The basic principle of spectroscopy is derived from the interactions of electromagnetic radiation with materials in the form of solid, liquid, or gas. The interactions will generate a series of physical or optical processes such as absorption, reflection, and transmission that contain certain information of the materials or minerals. Spectroscopy is the study of the interaction between electromagnetic radiation and materials, which results spectra of the materials at specific wavelengths (Clark, 1999). The electromagnetic spectrum, which is commonly used in spectroscopy or remote sensing for characterizing rocks and minerals, can be classified into several spectral domains of wavelength range (Clark, 1999; Warner et al., 2009), such as visible and near-infrared (VNIR), shortwave infrared (SWIR), midwave infrared (MIR) and thermal infrared (TIR) (Table 2.4).

Table 2.4: The electromagnetic spectrum classification with various spectral regions used frequently in spectroscopy or remote sensing (Clark, 1999; Warner et al., 2009).

\begin{tabular}{lll}
\hline Spectral domains & Abbreviations & Wavelength range $(\mu \mathrm{m})$ \\
\hline Visible and Near-infrared & VNIR & $0.4-1.0$ \\
Shortwave infrared & SWIR & $1.0-2.5$ \\
Midwave infrared & MIR & $2.5-6.0$ \\
Thermal infrared & TIR & $7.5-20$ \\
\hline
\end{tabular}

Infrared spectroscopy technique on the basis of spectral shapes and feature characteristics has been used intensively for many decades to determine mineral chemistry and composition of carbonate rocks or other carbonate samples (Clark, 1999; Clark et al., 1990; Crowley, 1986; Gaffey, 1986; Huang \& Kerr, 1960; Hunt \& Salisbury, 1971; Oh et al., 2017; Reig et al., 2002; Sdiri et al., 2010; van der Meer, 1995; Xie et al., 2016; Zaini et al., 2012; Zaini et al., 2016). The spectroscopic method is a non-destructive technique to determine mineralogy and to obtain information of 
chemical composition of geologic samples. It requires a small quantity of sample and easy sample preparation. This analytical method can be applied effectively for laboratory and field measurement using a field spectrometer or spectroradiometer. However, the method has limitations, such as requiring standard spectral libraries and skilled interpreter for minerals identification, less accurate for measuring low abundance of mineral mixtures in geologic samples, and overlapping spectral features that can be obscure to identify mineralogy.

Reflectance spectra of absorption features of minerals or rocks in the wavelength range of visible and near-infrared (VNIR), shortwave infrared (SWIR) and thermal infrared (TIR) are determined by electronic and vibrational processes (Clark, 1999; Clark et al., 1990; Gupta, 2003; Hunt, 1977; Hunt \& Salisbury, 1970, 1971; van der Meer, 1995). The diagnostic absorption features of carbonate minerals in the SWIR and TIR wavelength regions are determined by vibrational processes of the carbonate ions $\left(\mathrm{CO}_{3}^{2-}\right)$ (Clark, 1999; Clark et al., 1990; Gupta, 2003; Hunt \& Salisbury, 1971; Salisbury et al., 1987). The minerals have two distinctive spectral absorption features in the wavelength ranges. The positions of these spectral features are centered at 2.50-2.55 $\mu \mathrm{m}$ and 2.30-2.35 $\mu \mathrm{m}$ in the SWIR region (Baissa et al., 2011; Clark et al., 1990; Gaffey, 1986; Hunt \& Salisbury, 1971; van der Meer, 1995; Zaini et al., 2012) and at 13.70-14.04 $\mu \mathrm{m}$ and 11.19-11.40 $\mu \mathrm{m}$ in the TIR region (Clark, 1999; Huang \& Kerr, 1960; Lane \& Christensen, 1997; Salisbury et al., 1987; Zaini et al., 2012). Additional carbonate vibrational bands or weak absorption bands in the SWIR region occur around 2.23-2.27 $\mu \mathrm{m}, 2.12-2.16 \mu \mathrm{m}, 1.97-2.00 \mu \mathrm{m}, 1.85-1.87 \mu \mathrm{m}$ and 1.75-1.80 $\mu \mathrm{m}$ (Clark, 1999; Clark et al., 1990; Gaffey, 1986; Hunt \& Salisbury, 1971; van der Meer, 1995). The presence of clay minerals in an intimate mixture with carbonates is usually indicated by a vibrational absorption feature around $2.20 \mu \mathrm{m}$ and $2.30 \mu \mathrm{m}$ due to the combination of the $\mathrm{OH}$ stretch with the Al-OH (Aluminium hydroxide) and $\mathrm{Mg}-\mathrm{OH}$ (Magnesium hydroxide) bending modes, respectively (Clark et al., 1990; Hunt, 1977; Hunt \& Salisbury, 1970).

Reflectance spectra of calcite and dolomite in the SWIR wavelength region are depicted in Figure 2.2. Calcite and dolomite have two prominent absorption features in this spectral region. The positions of these absorption bands are centered at the wavelength ranges around $2.33-2.34 \mu \mathrm{m}$ and $2.53-2.54 \mu \mathrm{m}$ for calcite and around 2.31$2.32 \mu \mathrm{m}$ and 2.51-2.52 $\mu \mathrm{m}$ for dolomite (Clark, 1999; Clark et al., 1990; Gaffey, 1986; Hunt \& Salisbury, 1971; van der Meer, 1995; Zaini et al., 2012). The positions and widths of strong and weak absorption bands of calcite and dolomite in the SWIR are shown in Table 2.5 (Gaffey, 1986). Figure 2.3 shows reflectance spectra of calcite and dolomite in the TIR wavelength region. Calcite and dolomite also have two prominent spectral absorption features in the TIR region. The positions of these absorption bands are centered at the wavelength ranges around $11.40-11.60 \mu \mathrm{m}$ and $13.92-14.04 \mu \mathrm{m}$ for calcite and around 11.35-11.53 $\mu \mathrm{m}$ and 13.40-13.70 $\mu \mathrm{m}$ for dolomite (Clark, 1999; Huang \& Kerr, 1960; Reig et al., 2002; Zaini et al., 2012). 


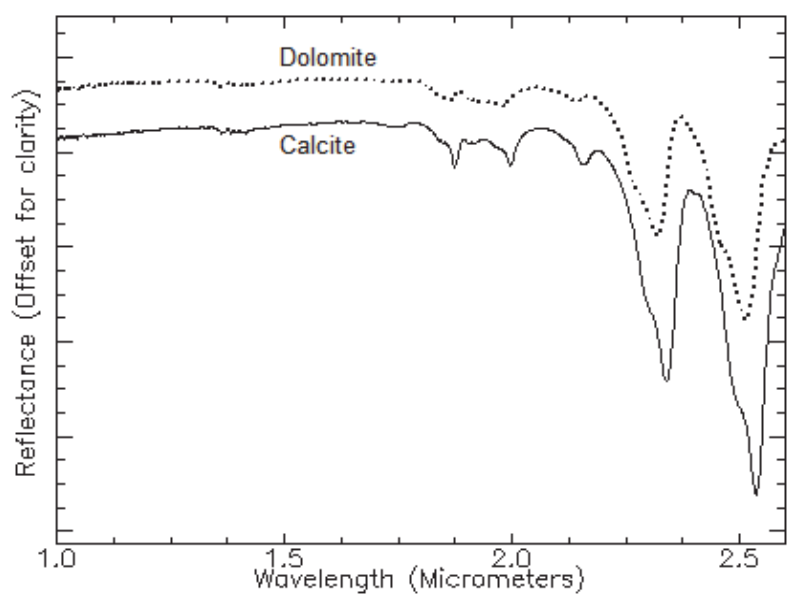

Figure 2.2: Reflectance spectra of calcite and dolomite in the SWIR wavelength region. The spectra show two prominent carbonate absorption features centered at $\sim 2.3 \mu \mathrm{m}$ and $\sim 2.5 \mu \mathrm{m}$.

Table 2.5: The positions and widths of absorption bands of calcite and dolomite in the SWIR wavelength region, adapted after (Gaffey, 1986).

\begin{tabular}{ccccc}
\hline \multirow{2}{*}{$\begin{array}{c}\text { Carbonate } \\
\text { band }\end{array}$} & \multicolumn{2}{c}{ Calcite } & \multicolumn{2}{c}{ Dolomite } \\
\cline { 2 - 5 } & Position $(\mu \mathrm{m})$ & Width $\left(\mu \mathrm{m}^{-1}\right)$ & Position $(\mu \mathrm{m})$ & Width $\left(\mu \mathrm{m}^{-1}\right)$ \\
\hline 1 & $2.530-2.541$ & $0.0223-0.0255$ & $2.508-2.518$ & $0.0208-0.0228$ \\
2 & $2.333-2.340$ & $0.0154-0.0168$ & $2.312-2.322$ & $0.0173-0.0201$ \\
3 & $2.254-2.272$ & $0.0121-0.0149$ & $2.234-2.248$ & $0.0099-0.0138$ \\
4 & $2.167-2.179$ & $0.0170-0.0288$ & $2.150-2.170$ & $0.0188-0.0310$ \\
5 & $1.974-1.995$ & $0.0183-0.0330$ & $1.971-1.979$ & $0.0206-0.0261$ \\
6 & $1.871-1.885$ & $0.0190-0.0246$ & $1.853-1.882$ & $0.0188-0.0261$ \\
7 & $1.753-1.770$ & $0.0255-0.0430$ & $1.735-1.740$ & $0.0178-0.0395$ \\
\hline
\end{tabular}

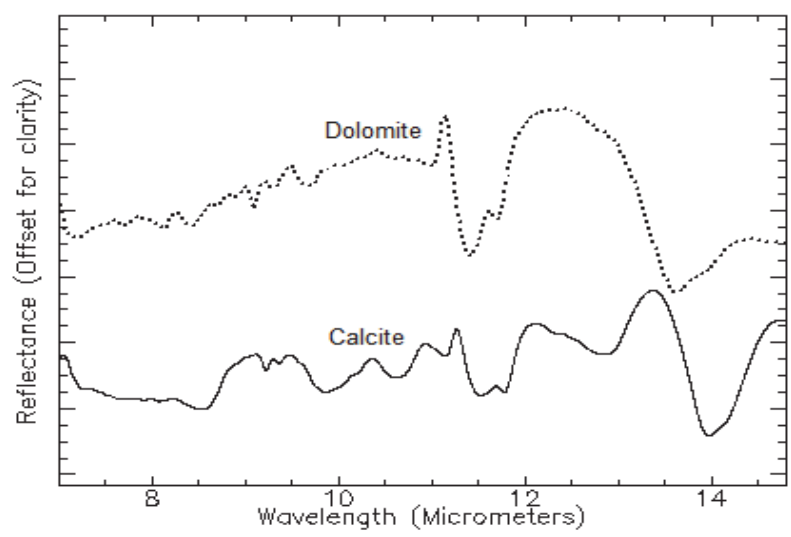

Figure 2.3: Reflectance spectra of calcite and dolomite in the TIR wavelength region, showing two prominent carbonate absorption features centered at $\sim 11.5 \mu \mathrm{m}$ and $\sim 14$ $\mu \mathrm{m}$. 


\subsubsection{Hyperspectral imagery}

Hyperspectral imagery, which consists of numerous image data in narrow and contiguous spectral bands (Figure 2.4), has allowed for rapid and accurate identification of mineralogy based on the analysis of the spectral feature characteristics of image pixels (van der Meer \& de Jong, 2001). This image data is a three-dimensional data cube, where the $\mathrm{x}$ axis represents wavelength, the $\mathrm{y}$ axis represents reflectance or brightness, and the $\mathrm{z}$ axis represents the accumulation of spectral bands (Campbell, 1996).

The developments of field and laboratory-based imaging spectrometry or spectroscopy sensors such as HyLogging ${ }^{\mathrm{TM}}$ (Haest et al., 2012a, 2012b), HyLogger-3 (Green \& Schodlok, 2016; Schodlok et al., 2016), HySpex (Baissa et al., 2011; Kurz et al., 2012; Mathieu et al., 2017), and SisuROCK and SisuCHEMA of Spectral Imaging Ltd. (SPECIM), Finland (Murphy et al., 2014; Murphy et al., 2016; Specim, 2007; Tappert et al., 2015; Zaini et al., 2014) hyperspectral imagers, which integrated the digital imaging of airborne hyperspectral sensor technologies with the high spectroscopic resolution of field and laboratory spectrometers, have generated a new type of hyperspectral imagery that can be used for identifying geologic mixtures of surface mineralogy (Baissa et al., 2011; Green \& Schodlok, 2016; Haest et al., 2012a, 2012b; Kurz et al., 2012; Mathieu et al., 2017; Murphy et al., 2014; Murphy et al., 2016; Schodlok et al., 2016; Specim, 2007; Tappert et al., 2015; Zaini et al., 2014). The spectrometers can acquire hyperspectral images of various geologic samples or sites from the ideal condition in the laboratory to the close range application in the field. These datasets present opportunities for analysis of the complex mixtures of surface mineralogy. Figure 2.5 shows the application of hyperspectral imagery to identify and map surface mineralogy of hematite and goethite in hand specimens of iron ore samples. 


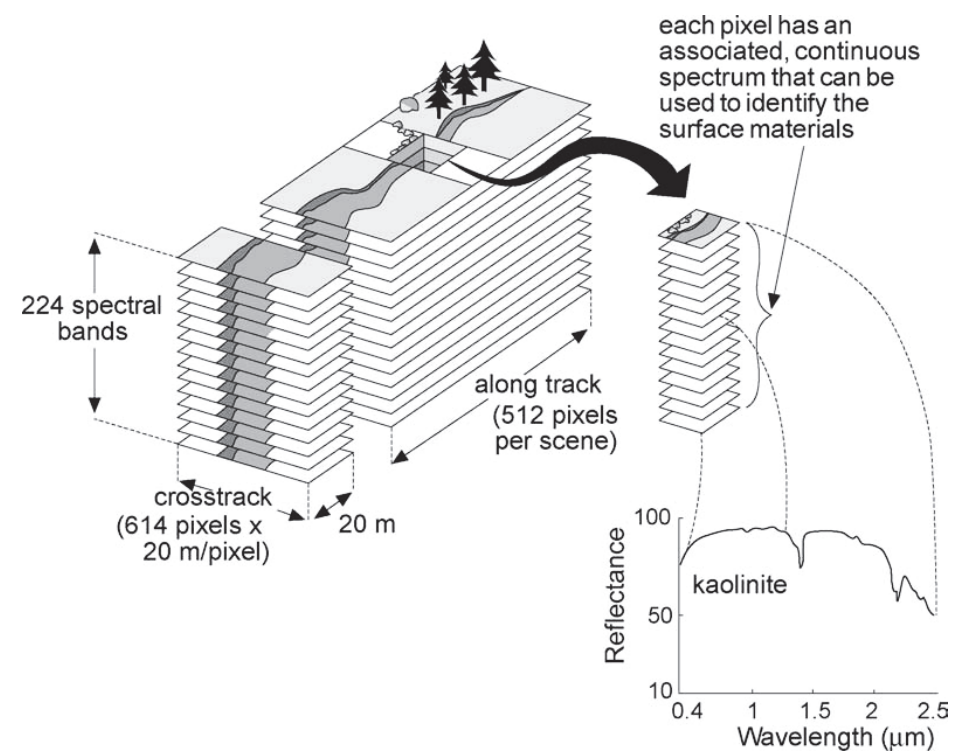

Figure 2.4: Sketch of a hyperspectral imaging dataset (hyperspectral imagery). Each image pixel exhibits a reflectance spectrum of surface materials, taken with permission of Springer Nature and without changes from (van der Meer \& de Jong, 2001). (C) 2001 Springer.

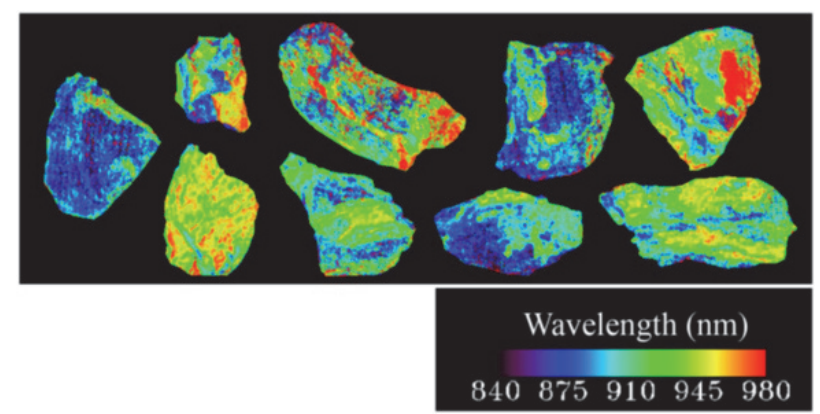

Figure 2.5: Wavelength position image of the iron absorption feature at $\sim 900 \mathrm{~nm}(\sim 0.9$ $\mu \mathrm{m})$ derived from the polynomial fit of hyperspectral imagery of iron ore samples. The classified image shows compositional variations of the rock samples composed of hematite and goethite, taken with permission of IEEE and with minor changes from (Murphy et al., 2014). (C) 2014 IEEE.

Hyperspectral imagery or hyperspectral imaging technique has been used frequently to determine carbonate mineral chemistry and composition of rocks or geologic materials in a wide variety of geologic samples including hand specimen (Baissa et al., 2011; Zaini et al., 2014), fossil (Murphy et al., 2016), drill core materials (Green \& Schodlok, 2016; Haest et al., 2012a, 2012b; Mathieu et al., 2017; Schodlok et al., 2016) and outcrop of mine face (Buckley et al., 2013; Kurz et al., 2013; Kurz et al., 2012). Hyperspectral imaging or imaging spectroscopy is a non-destructive technique in 
identification and estimation of the abundance of carbonate mineral mixtures and compositions. It requires a small quantity of sample and easy sample preparation. This imaging technique with higher image resolution allows characterizing crystallinity in carbonate rocks. However, the method has some limitations for mineral identification, such as requiring standard spectral libraries and skilled interpreter, pre-processing imagery, and less accurate to identify low abundance of mineral mixtures that present in geologic samples. The imaging method can be used for field application, but the resulted image will be difficult to process and analysis due to effects of atmospheric conditions and mixing and weathering of surface features. Therefore, the application of higher resolution laboratory-based hyperspectral imagery can determine the relative abundance of mineral chemistry and map spatial distribution of compositional variations on carbonate rock surfaces.

\subsection{Discussion and conclusions}

Carbonate rocks in the form of limestone and dolostone, which are mainly composed of calcite $\left(\mathrm{CaCO}_{3}\right)$ and dolomite $\left(\mathrm{CaMg}\left(\mathrm{CO}_{3}\right)_{2}\right)$ (Blatt et al., 1972; Pettijohn, 1975), have played an important role in continuing development of modern society and accelerating economic growth of many nations (Deer et al., 1966; Harbaugh, 1976; Hatch \& Rastall, 1965; Pettijohn, 1975). This is because these sedimentary rocks possess and hold significance natural resources, such as precious ore and mineral deposits (Deer et al., 1966; Pettijohn, 1975), hydrocarbon reservoirs and water aquifers (Ahr, 2008; Beccari \& Romano, 2005; Harbaugh, 1976), and including carbon sequestration site (Liu \& Zhao, 2000; Luquot \& Gouze, 2009). Carbonate rocks are also an essential industrial material that are principally used for construction and cement industry. The rocks, for instance limestones are the preferred source of lime or calcium oxide $(\mathrm{CaO})$ for manufacturing Portland cement clinker (Chatterjee, 1983; Ghosh, 1983; Meade, 1926; Taylor, 1997). However, the suitability of carbonate rocks to make the cement clinker depends on their chemistry and composition. In other words, the chemical composition of those rocks should fulfil the standard requirement of cement industry. Therefore, identification and determination of mineral chemistry and composition of carbonate rocks using an appropriate analytical method is essential for exploration of the rocks and minerals that are being used as the main component of cement raw materials, and for understanding ore and hydrocarbon characterizations deposited in carbonate rocks.

Chemical and mineralogical analyses of carbonate rocks using various analytical methods with strengths and weaknesses of these approaches have been revealed in many studies of existing literatures (Table 2.1). Although the conventional analytical methods are well established in characterizing carbonate rock chemistry, most of these techniques have some limitations compared with infrared spectroscopy and hyperspectral imaging (imaging spectroscopy) approaches (Table 2.1). They are labor intensive and time consuming for sample preparation and analysis. The traditional 
methods are also designed for a particular purpose in analyzing mineral chemistry of carbonate rocks, such as thin section, petrographic microscope, SEM, and XRD for identifying mineralogy; and SEM-EDS, EMPA, and XRF for chemical analyses of major and trace elements. The infrared and imaging spectroscopic techniques are recognized as advanced analytical methods for determining mineralogy and chemical information of carbonate rocks. These spectroscopic methods are fast and nondestructive for mineralogical and compositional determination of the rocks based on their spectral feature characteristics analysis (Table 2.1). Furthermore, the hyperspectral imagery allows characterizing crystallinity and mapping compositional variations on carbonate rock surfaces. However, most of the conventional methods are impracticality for field application compared with the spectroscopic methods, especially during mineral chemistry exploration and measurement process in a quarry or geological site. This is because the analytical instruments require a specific treatment for sample preparation and acquisition of the data (Table 2.1).

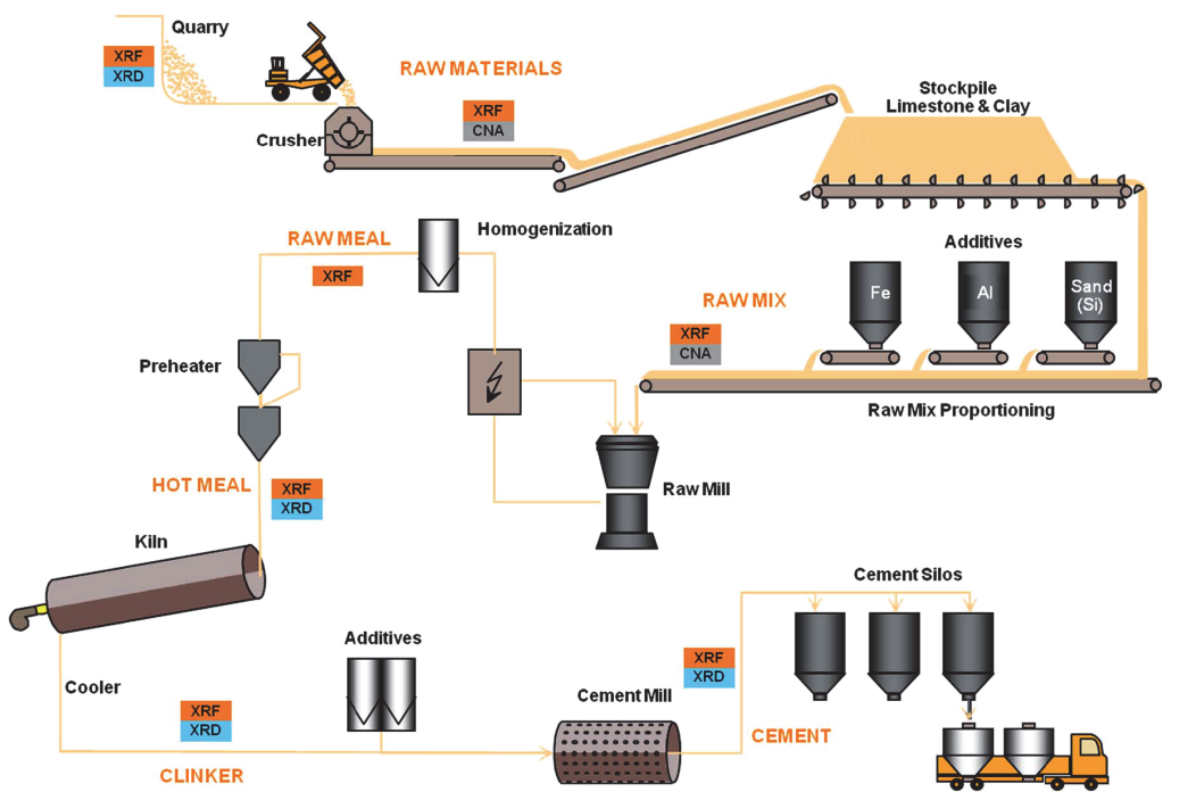

Figure 2.6: XRD and XRF analytical methods used in the cement production process, showing the importance of those conventional methods in quality control of the cementmaking process, taken with permission of IEEE and without changes from (Anderson et al., 2015). (C) 2015 IEEE.

The predominant use of carbonate rocks as cement raw materials requires a rapid and precise analytical method that can be employed directly in mining areas or field sites is critical. In the cement industry, XRD and XRF are the most commonly used analytical methods to control mineral and chemical composition in each stage of the cement production process (Figure 2.6), chain from the exploration of high quality raw 
materials in a quarry to the final cement products (Anderson et al., 2015). However, these conventional methods are impractical to apply in mining areas or field sites. The infrared spectroscopic technique of field spectrometry with faster and accurate spectral data acquisition in the wavelength range of $0.7-2.5 \mu \mathrm{m}$ (from NIR to SWIR regions) is more practical and effective to characterize and determine mineralogical composition of carbonate rocks or geologic samples in mining areas or field sites. This mineral identification technique offers an alternative analytical method to the cement industry in controlling and analyzing mineral chemistry of carbonate rocks that are well suited to make Portland cement clinker (Zaini et al., 2016). However, the spectroscopic method cannot determine exactly chemical compositions or elemental concentrations in carbonate rocks compared with other analytical methods such as XRF, SEM-EDS and EMPA. The infrared spectroscopy provides a great potential and opportunity for the chemical quality control and the quantitative analysis of carbonate rocks in the mining and cement industries by combining spectroscopic data of field spectrometry with geochemical data of X-ray analyzer (XRF) (Oh et al., 2017; Zaini et al., 2016).

Chapters 3 to 6 present and discuss the spectral absorption feature characteristics of carbonate minerals (calcite and dolomite) in the infrared wavelength regions; the application of laboratory-based hyperspectral imagery for estimating the chemical composition and the relative abundance of carbonate minerals on the rock surfaces; and the potential and accuracy of infrared spectroscopy integrated with geochemical data as an alternative quality control technique for chemical and mineralogical analyses of carbonate rocks that are suitable for manufacturing Portland cement clinker. 


\section{Effect of grain size and mineral mixing on carbonate absorption features in the SWIR and TIR wavelength regions ${ }^{2}$}

${ }^{2}$ This chapter has been published as: Zaini, N., van der Meer, F., van der Werff, H., 2012. Effect of grain size and mineral mixing on carbonate absorption features in the SWIR and TIR wavelength regions. Remote Sensing 4, 987-1003. 


\subsection{Introduction}

Carbonate rocks, which are recognized as an important natural resource for construction materials and the cement industry (Blatt et al., 1972; Pettijohn, 1975), are sedimentary rocks that mostly consist of calcite $\left(\mathrm{CaCO}_{3}\right)$ and dolomite $\left(\mathrm{CaMg}\left(\mathrm{CO}_{3}\right)_{2}\right)$ (Blatt et al., 1972; Deer et al., 1966; Pettijohn, 1975; Waltham, 2009). These carbonate minerals in the form of limestones also have an economic interest in terms of petroleum geology, because their porosity is a potential storage reservoir for oil and natural gas (Blatt et al., 1972; Friedman \& Sanders, 1967; Harbaugh, 1976; Pettijohn, 1975). The development of porosity in limestones is affected by the sequence of diagenetic processes, which include dolomitization (Friedman \& Sanders, 1967; Harbaugh, 1976; Pettijohn, 1975). The dolomitization process involves the replacement of calcite by dolomite in the rock when magnesium-rich water permeates through limestone (Friedman \& Sanders, 1967; Hatch \& Rastall, 1965; Pettijohn, 1975). The process may result in an increase in the porosity of the rock by up to $12 \%$, making it suitable as a natural reservoir for oil (Friedman \& Sanders, 1967; Harbaugh, 1976; van der Meer, 1995). The implications of dolomitization for oil exploration (van der Meer, 1996a, 1998) and the importance of dolomite in making cement make it a favorable mineral to be investigated.

Besides the interest in oil and gas reservoir characterization, there is an interest in looking into calcite-dolomite mineralogy from an 'ore geology' perspective, as carbonates are important pathfinder and alteration minerals associated with calcic skarn deposits, low sulphidation epithermal deposits and porphyry $\mathrm{Cu}$ deposits (Kozak et al., 2004; Rockwell \& Hofstra, 2008). In addition, coral reefs are under worldwide decline as a result of climate change (Baker et al., 2008). Corals are among the species that contribute to carbon sequestration, the capture of carbon dioxide $\left(\mathrm{CO}_{2}\right)$ from the atmosphere, and act as natural carbon sinks. As they are largely built of carbonate material, more information on its spectral characteristics will help in better species differentiation and in mapping using remote sensing (Hochberg \& Atkinson, 2000; van der Meer, 1996b).

Carbonate minerals have diagnostic absorption features in the shortwave infrared (SWIR) and thermal infrared (TIR) regions due to vibrational processes of the carbonate ions $\left(\mathrm{CO}_{3}^{2-}\right)$ (Clark, 1999; Clark et al., 1990; Gupta, 2003; Hunt \& Salisbury, 1971; Salisbury et al., 1987). In general, carbonate minerals can be distinguished by the presence of two prominent spectral absorption features in the wavelength ranges around 2.50-2.55 $\mu \mathrm{m}$ and 2.30-2.35 $\mu \mathrm{m}$ in the SWIR (Baissa et al., 2011; Clark et al., 1990; Gaffey, 1986; Hunt \& Salisbury, 1971; van der Meer, 1995) and around 13.70-14.04 $\mu \mathrm{m}$ and 11.19-11.40 $\mu \mathrm{m}$ in the TIR (Clark, 1999; Huang \& Kerr, 1960; Lane \& Christensen, 1997; Salisbury et al., 1987). These features can be used to identify pure and mixed calcite and dolomite in synthetic samples or carbonate rocks, because the absorption band position of calcite is located at a slightly longer wavelength than that of dolomite (Gaffey, 1986; van der Meer, 1995). Although the absorption band positions 
of these particular minerals have been observed by multiple researchers, the precise position of calcite and dolomite absorption bands in the SWIR (Baissa et al., 2011; Gaffey, 1986; Hunt \& Salisbury, 1971; van der Meer, 1995) and TIR (Huang \& Kerr, 1960; Ji et al., 2009; Lane \& Christensen, 1997; Reig et al., 2002; Salisbury et al., 1987) spectra has been recorded at different wavelengths.

There are several factors controlling the position of carbonate absorption bands at the atomic level: cation mass, cation radius, cation and anion valences, cation coordinate number, the gap between cation and anion, and site symmetry (Gaffey, 1985; Povarennykh, 1978). Spectral absorption features of carbonate minerals in the infrared region are also influenced by physical and chemical parameters such as grain size (Crowley, 1986; Gaffey, 1986; van der Meer, 1995), texture (Crowley, 1986), packing or porosity (Gaffey, 1986), carbonate mineral content (van der Meer, 1995), and chemical composition (metal ion impurity) (Gaffey, 1985; Hunt \& Salisbury, 1971; van der Meer, 1995). Previous studies of the effect of particle size on carbonate absorption features in the SWIR revealed that differences in grain size change reflectance values and absorption feature depth (Crowley, 1986; Gaffey, 1986; van der Meer, 1995), but absorption band position, width (Gaffey, 1986; van der Meer, 1995), and asymmetry of the features (van der Meer, 1995) are invariant to grain size. Position, depth, and asymmetry of carbonate absorption feature in the SWIR are displaced by changing the relative amounts of calcite and dolomite composing a sample (van der Meer, 1995). The presence of iron in the form of $\mathrm{Fe}^{2+}$ in carbonate minerals reduces the reflectance value (Gaffey, 1985; van der Meer, 1995) and depth of the carbonate absorption feature in the SWIR (van der Meer, 1995).

Although the spectral absorption features of carbonate minerals in the SWIR wavelength region have been extensively studied (Crowley, 1986; Gaffey, 1986; van der Meer, 1995), they have not been fully explored and observed in the TIR region, particularly with regard to the influences of grain size and carbonate mineral mixtures. In this chapter, we analyze the spectral absorption feature characteristics of calcite and dolomite in both the SWIR and TIR wavelength regions as a function of grain size and calcite-dolomite mixtures. To accurately identify carbonate minerals in pure and mixed forms, it is necessary to analyze the effects of those parameters that change spectral characteristics.

\subsection{Materials and Methods}

\subsubsection{Sample preparation}

Synthetic samples of calcite and dolomite were prepared by crushing, sieving, mixing and packing. Rock samples of calcite from the Serra de Ficalho, Moura, Portugal and dolomite of chemical grade from the UK were separately pulverised using a jaws-crusher and a steel percussion mortar and pestle. The pulverized samples were dried in an oven overnight at $105^{\circ} \mathrm{C}$ to evaporate water, and subsequently sieved into six grain size fractions of pure powdered minerals $(<45 \mu \mathrm{m}, 45-90 \mu \mathrm{m}, 90-125 \mu \mathrm{m}, 125-$ 
$250 \mu \mathrm{m}, 250-500 \mu \mathrm{m}$ and $>500 \mu \mathrm{m})$ using a Fritsch sieving machine with stainless steel sieves. Synthetic mixtures of calcite and dolomite were prepared by mixing weight percentages of powdered minerals ranging from pure calcite to pure dolomite with same grain size fractions. The samples used in this mixing process consisted of three different grain size fractions with a combination of some pure fractions, namely $<45,45-125$, and $125-500 \mu \mathrm{m}$. The pure powdered calcite and dolomite were weighed on the basis of weight percentage of each mineral respectively, using a top-loading precision balance (Mettler PE360) with a reading precision of $\pm 1 \mathrm{~g}$. The total amount of material needed to prepare a synthetic sample was 25 grams and the compositions of calcite-dolomite mixtures with different mineral contents for each grain size fractions were $75 \%-25 \%$, $50 \%-50 \%$, and $25 \%-75 \%$. To obtain homogenous mixtures, samples were manually stirred in a porcelain mortar using a spoon-spatula for $5 \mathrm{~min}$. For packing of the samples, the pure and mixed synthetic samples were placed separately in a cylindrical aluminum cup of $5 \mathrm{~cm}$ in diameter and $5 \mathrm{~mm}$ in depth, and pressed using a weight pressure of 1090 grams for 5 minutes.

\subsubsection{FTIR reflectance spectra measurement}

A Bruker Vertex 70 FTIR Spectrometer was used to measure reflectance spectra of the synthetic samples in the SWIR $(1.0-3.3 \mu \mathrm{m})$ and TIR $(5.0-20 \mu \mathrm{m})$ wavelength regions. The spectrometer was equipped with a near infrared (NIR) source, Calcium Fluoride $\left(\mathrm{CaF}_{2}\right)$ beam splitter, and Indium Gallium Arsenide (InGaAs) on-sphere detector for the SWIR spectra measurements. The spectrometer measured the SWIR spectra with $16 \mathrm{~cm}^{-1}$ spectral resolution at 256 scans per acquisition. The TIR spectra were recorded using an external mid infrared (MIR) source, Potassium Bromide (KBr) beam splitter, and Mercury Cadmium Telluride (MCT) on-sphere detector cooled by liquid nitrogen. The sample was scanned 4,096 times per acquisition with $8 \mathrm{~cm}^{-1}$ spectral resolution.

Directional hemispherical reflectance measurements were made using a custombuilt integrating sphere (Hecker et al., 2011) attached to the Bruker Vertex 70. The beam of SWIR or TIR radiation from the spectrometer passed through the sphere and illuminated the sample surface with an angle of approximately $10^{\circ}$. The sample was placed under a sample port at the bottom of the sphere. The sample area measured was approximately $25 \mathrm{~mm}$ in diameter. Radiation reflected by the sample and scattered by the gold-coated sphere was recorded by detectors placed on the top (MCT) and the rear (InGaAs) of the sphere. A gold-coated plate was used for referencing, before each sample measurement was conducted.

\subsubsection{Spectral absorption features analysis}

Absorption feature characteristics analysis consisted of determining absorption band position, depth, full width at half maximum (FWHM), and asymmetry (Clark \& Roush, 1984; Kruse, Lefkoff, \& Dietz, 1993; van der Meer, 1995; van der Meer, 2004), 
calculated from continuum-removed spectra (Clark \& Roush, 1984; Kokaly \& Clark, 1999; Kruse, Lefkoff, \& Dietz, 1993; van der Meer, 2004) (Figure 3.1). The position of the absorption band is defined as the wavelength at which the maximum absorption or minimum reflectance of an absorption feature occurred (van der Meer, 1995; van der Meer, 2004). The depth of the absorption feature indicates the reflectance value at the shoulders minus the reflectance value at the position of the absorption wavelength (Clark \& Roush, 1984; van der Meer, 1995; van der Meer, 2004). The FWHM is defined as the width of the spectral feature at half the maximum depth (Kruse, Lefkoff, $\&$ Dietz, 1993). The asymmetry of the absorption feature represents the logarithm of the ratio of the area right of the absorption position (Area B) to the area left of the absorption position (Area A) (Kruse, Lefkoff, \& Dietz, 1993), where the result of the calculation is zero if the absorption feature has a perfect asymmetry, a negative value for a skewed absorption feature towards shorter wavelengths, and a positive value for a skewed absorption feature towards longer wavelengths (Kruse, Lefkoff, \& Dietz, 1993).

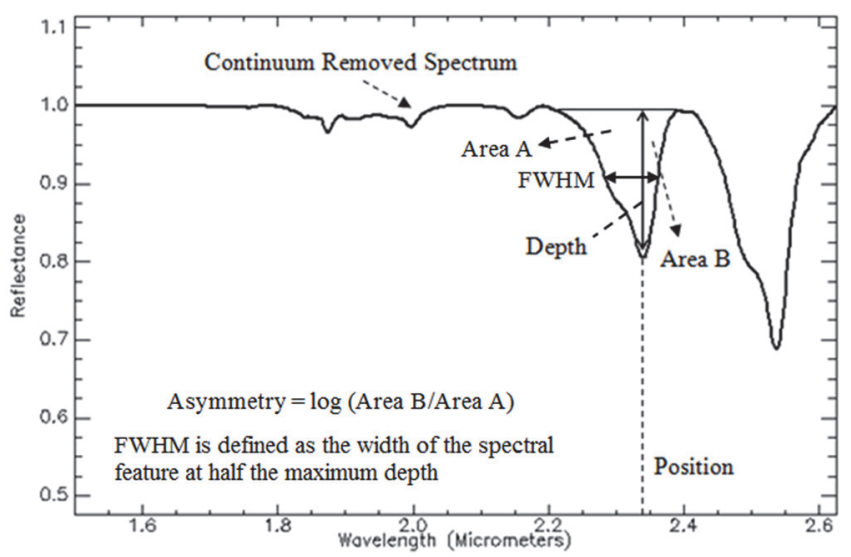

Figure 3.1: Definitions of absorption feature characteristics.

A continuum is a mathematical function that can isolate and enhance specific spectral absorption features (Clark \& Roush, 1984), which has been used for various applications to analyze the feature characteristics of field (Kokaly \& Clark, 1999; Mutanga et al., 2004; Smith et al., 2011), laboratory (Luleva et al., 2011; Yitagesu et al., 2011), and image (Hecker et al., 2008; Hubbard et al., 2003; van der Meer, 2004; Youngentob et al., 2011) reflectance spectra. We analyzed four prominent vibrational absorption features in carbonate reflectance spectra: features at 2.3 and $2.5 \mu \mathrm{m}$ in the wavelength range of 2.164-2.653 $\mu \mathrm{m}$ (SWIR) and features at 11.5 and $14 \mu \mathrm{m}$ in the wavelength range of 10.89-14.81 $\mu \mathrm{m}$ (TIR). The absorption feature characteristics were computed using custom IDL scripts (Luleva et al., 2011; van der Meer, 2004) within IDL-ENVI software package (ITT, 2010). 


\subsection{Results}

\subsubsection{SWIR spectra of pure calcite and dolomite with varying grain size}

SWIR spectral characteristics of the two vibrational absorption features in pure powdered calcite and dolomite are shown for each grain size fraction in Figure 3.2. It can be observed that varying the grain size fraction influences the reflectance value and absorption feature characteristics, especially the depth of absorption bands and the overall brightness in the SWIR wavelength region. The depth of absorption bands increases with increasing grain size fraction of calcite and dolomite between 45 and 250 $\mu \mathrm{m}$, and decreases when the grain size is greater than $250 \mu \mathrm{m}$ (Figure 3.3). Overall reflectance decreases with increasing grain size fraction of the sample (Figure 3.2).
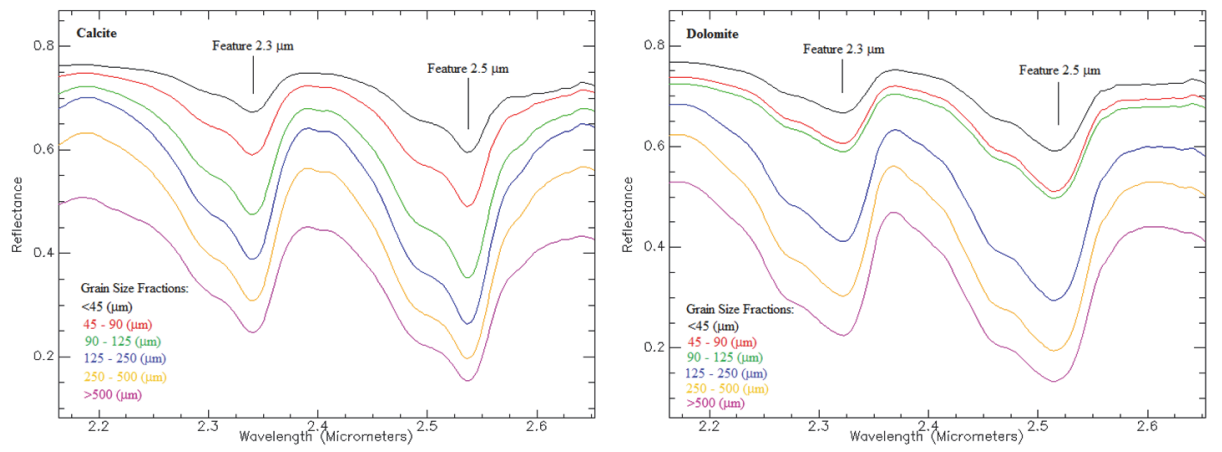

Figure 3.2: Reflectance spectra of pure powdered calcite and dolomite for each grain size fraction in the shortwave infrared (SWIR) wavelength region. The center of absorption band position is not affected by grain size.

FWHM and asymmetry of the features also vary slightly with grain size fraction, but the position of absorption bands for both features of calcite and dolomite is invariant to grain size fraction (Figure 3.2). The absorption band positions are centered at 2.340 $\mu \mathrm{m}$ and $2.537 \mu \mathrm{m}$ for calcite and at $2.323 \mu \mathrm{m}$ and $2.515 \mu \mathrm{m}$ for dolomite (Figure 3.3(a,b)). The FWHM increases with increasing grain size fractions from 45 to $500 \mu \mathrm{m}$, but slightly decreases when grain size is larger than $500 \mu \mathrm{m}$ (Figure 3.3). The feature at $2.5 \mu \mathrm{m}$ is wider and deeper than the feature at $2.3 \mu \mathrm{m}$ for both minerals. The asymmetry of calcite and dolomite features has a negative value which tends to skew to shorter wavelengths (Figures 3.2 and 3.3) and the feature at $2.3 \mu \mathrm{m}$ skews more to shorter wavelengths than the feature at $2.5 \mu \mathrm{m}$.

\subsubsection{TIR spectra of pure calcite and dolomite with varying grain size}

TIR reflectance spectra of pure powdered calcite and dolomite are characterized by the two prominent vibrational absorption features at 11.5 and $14 \mu \mathrm{m}$ (Figure 3.4). The graphs show that change in grain size influences spectral shape, reflectance value, and absorption feature characteristics of both calcite and dolomite. Overall reflectance and 
depth of absorption bands decrease with increasing grain size fraction for both features. The spectral features of calcite and dolomite become poorly defined as grain size fraction increases, particularly between 125 and $500 \mu \mathrm{m}$ grain sizes. Additionally, the doublet at $11.75 \mu \mathrm{m}$ and peaks at 12 and $13.50 \mu \mathrm{m}$ disappear gradually with increasing grain size fraction, whereas the peak at $11.25 \mu \mathrm{m}$ becomes more pronounced.

(a)
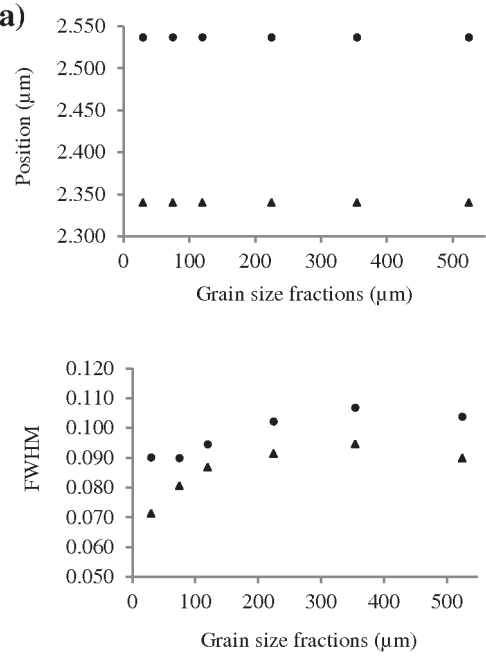

(b)
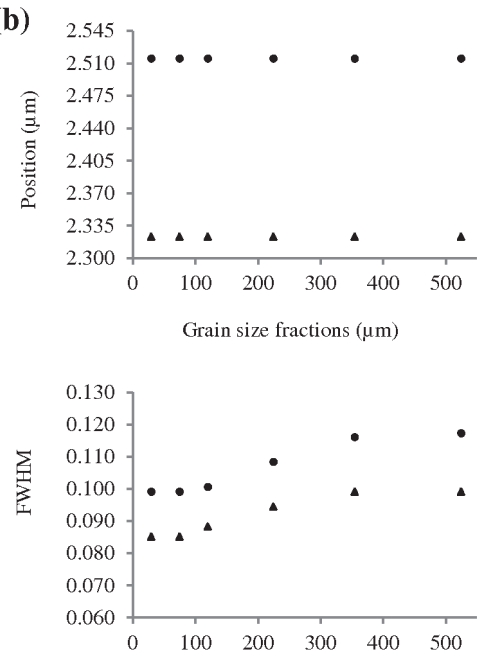

Grain size fractions $(\mu \mathrm{m})$
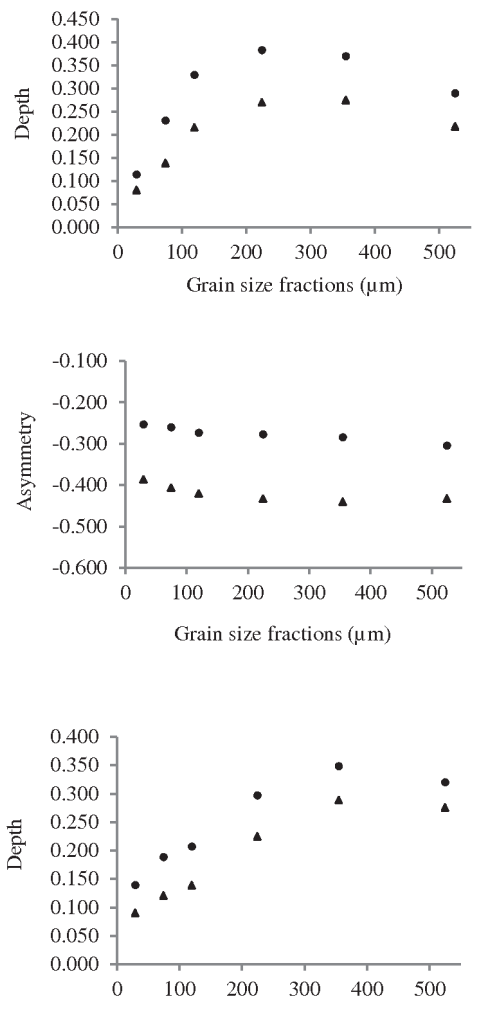

Grain size fractions $(\mu \mathrm{m})$

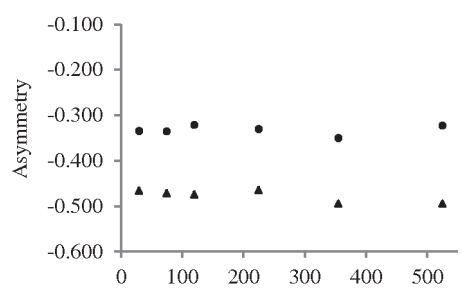

Grain size fractions $(\mu \mathrm{m})$

Figure 3.3: Absorption feature parameters of pure powdered (a) calcite and (b) dolomite as a function of grain size obtained from the spectral features at $2.3(\mathbf{\Lambda})$ and $2.5 \mu \mathrm{m}(\bullet)$, shown in Figure 3.2. 

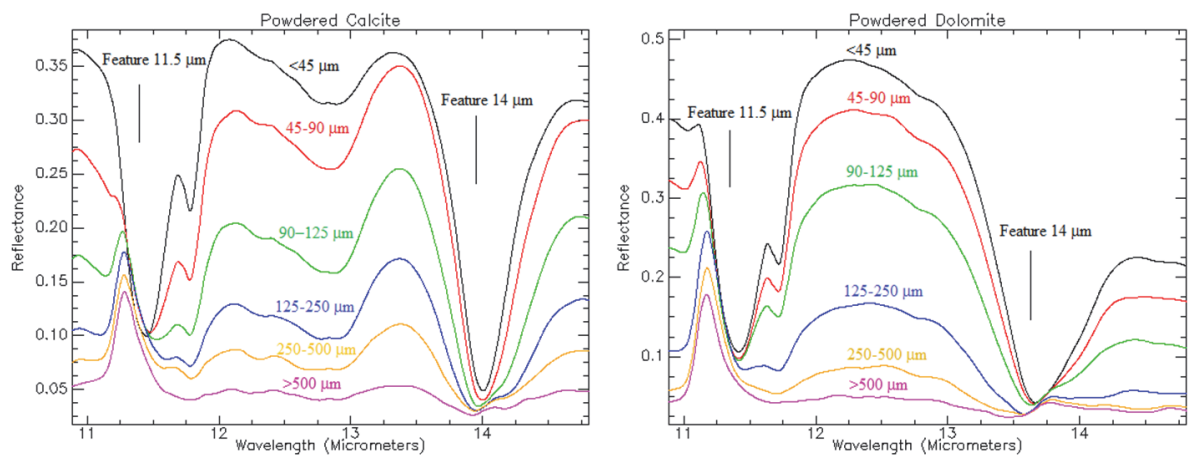

Figure 3.4: Reflectance spectra of pure powdered calcite and dolomite for each grain size fraction in the thermal infrared (TIR) wavelength region. The center of absorption band position is affected by grain size.

Absorption band position, FWHM, and asymmetry also vary with grain size fraction. The position shifts to longer wavelengths for the $11.5 \mu \mathrm{m}$ feature $(11.451-$ $11.600 \mu \mathrm{m}$ for calcite and $11.417-11.527 \mu \mathrm{m}$ for dolomite) and to shorter wavelengths for the $14 \mu \mathrm{m}$ feature (14.006-13.919 $\mu \mathrm{m}$ for calcite and 13.662-13.438 $\mu \mathrm{m}$ for dolomite), from fine to coarse grain size fraction (Figures 3.4 and 3.5). The FWHM increases with increasing grain size fraction of calcite and dolomite. The asymmetry of the features has a positive value which tends to skew to longer wavelengths as grain size increases (Figure 3.4).
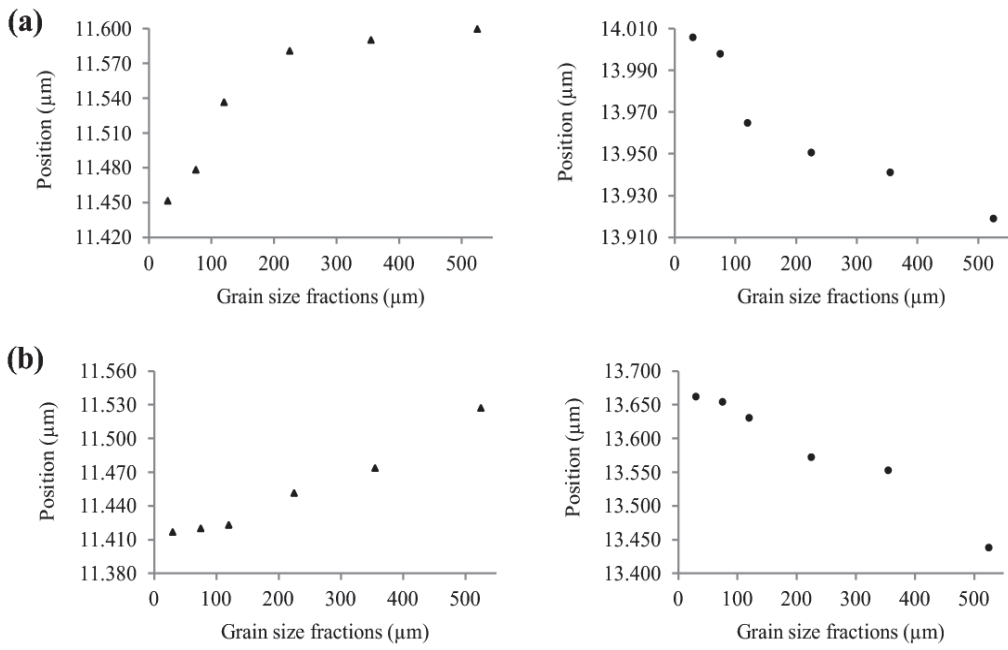

Figure 3.5: Absorption band positions of pure powdered (a) calcite and (b) dolomite in the TIR wavelength region as a function of grain size (features at $11.5(\boldsymbol{\Delta})$ and $14 \mu \mathrm{m}$ $(\bullet)$ ), shown in Figure 3.4. 

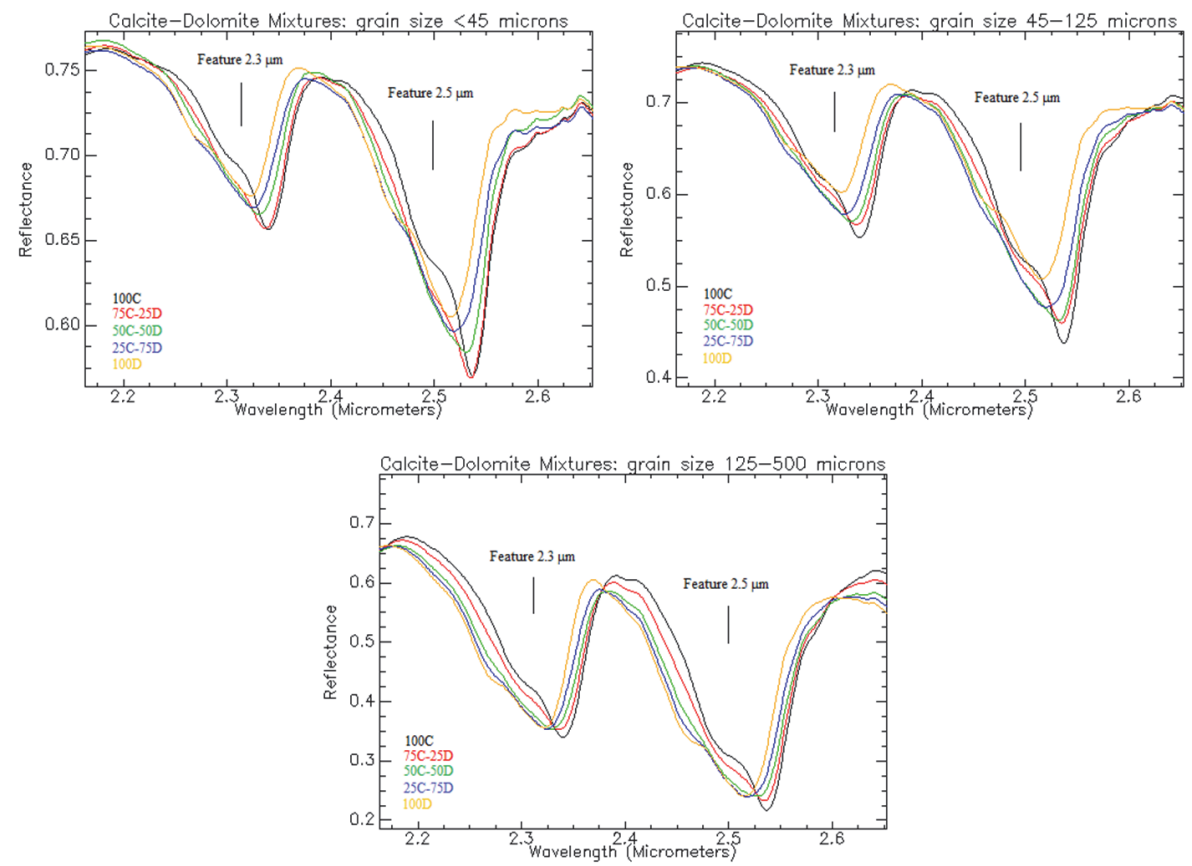

Figure 3.6: Spectral features of calcite-dolomite mixtures for each grain size fraction in the SWIR wavelength region. Position of absorption bands is a function of calcite content in the sample. $(\mathrm{C}=$ calcite and $\mathrm{D}=$ dolomite, prefix numbers showing the mineral contents in percent).

\subsubsection{SWIR spectra of mixed calcite and dolomite with varying mineral contents}

Reflectance spectra of calcite-dolomite mixtures in the SWIR wavelength region used in absorption feature analysis are shown in Figure 3.6. The graphs show that reflectance intensity and spectral characteristics change with different calcite and dolomite contents and grain size. Overall reflectance tends to decrease with increasing grain size fraction. The 2.3 and $2.5 \mu \mathrm{m}$ absorption bands shift in position as a result of different calcite or dolomite contents in the sample (Figure 3.7). These band positions of calcite-dolomite mixtures in the SWIR region are centered within the wavelength range of 2.323-2.340 $\mu \mathrm{m}$ and 2.515-2.537 $\mu \mathrm{m}$, from the band position of pure dolomite to pure calcite. Absorption band positions of the mineral mixtures also subtly displace with grain size fraction, especially when calcite content increases from $25 \%$ to $75 \%$.

Absorption band depth, FWHM, and the asymmetry of both features also vary slightly with changing carbonate mineral content (Figure 3.7). For each grain size fraction, the depth of absorption bands increases with increased calcite content. Coarse grain size gives deeper absorption features than fine grain size. The FWHM decreases when more than $25 \%$ of calcite is in the sample. The asymmetry of features has a negative value which tends to skew to shorter wavelengths. 
(a)
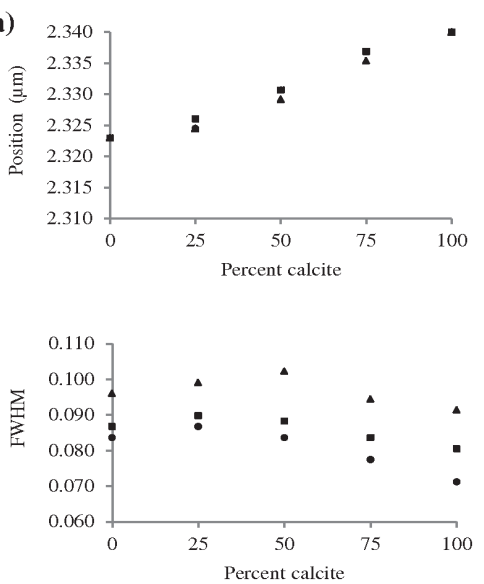

(b)
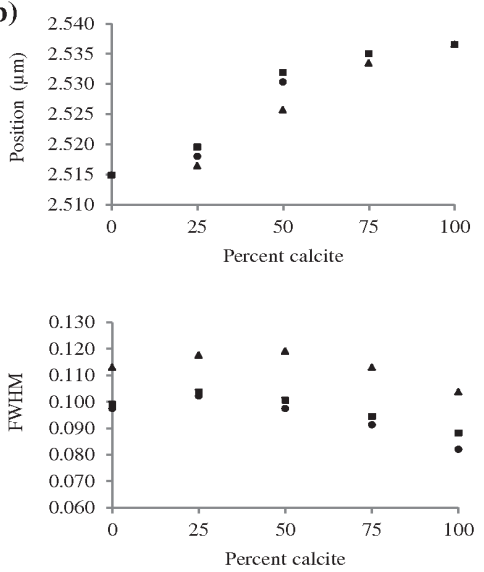
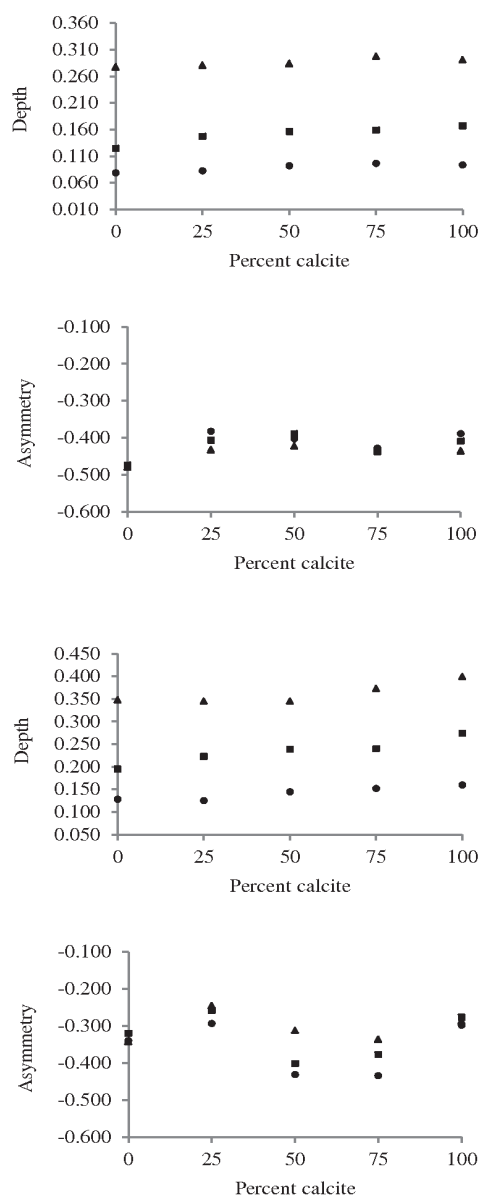

Figure 3.7: SWIR absorption feature parameters of calcite-dolomite mixtures for each grain size fraction (grain size: $<45 \mu \mathrm{m}(\bullet), 45-125 \mu \mathrm{m}(\mathbf{\bullet})$, and 125-500 $\mu \mathrm{m}(\mathbf{\Lambda})$ ) obtained from (a) feature at $2.3 \mu \mathrm{m}$ and (b) feature at $2.5 \mu \mathrm{m}$, shown in Figure 3.6.

\subsubsection{TIR spectra of mixed calcite and dolomite with varying mineral contents}

Figure 3.8 shows reflectance spectra of calcite-dolomite mixtures in the TIR wavelength region, for each grain size fraction. The graphs show that spectral shapes and absorption feature characteristics of both features (11.5 and $14 \mu \mathrm{m})$ vary with changing calcite and dolomite contents. Overall reflectance decreases with increasing calcite content and grain size fraction. The thermal infrared spectra of calcite-dolomite mixtures exhibit a relatively flat spectral curve when grain size fractions are in the range of 125 to $500 \mu \mathrm{m}$. 

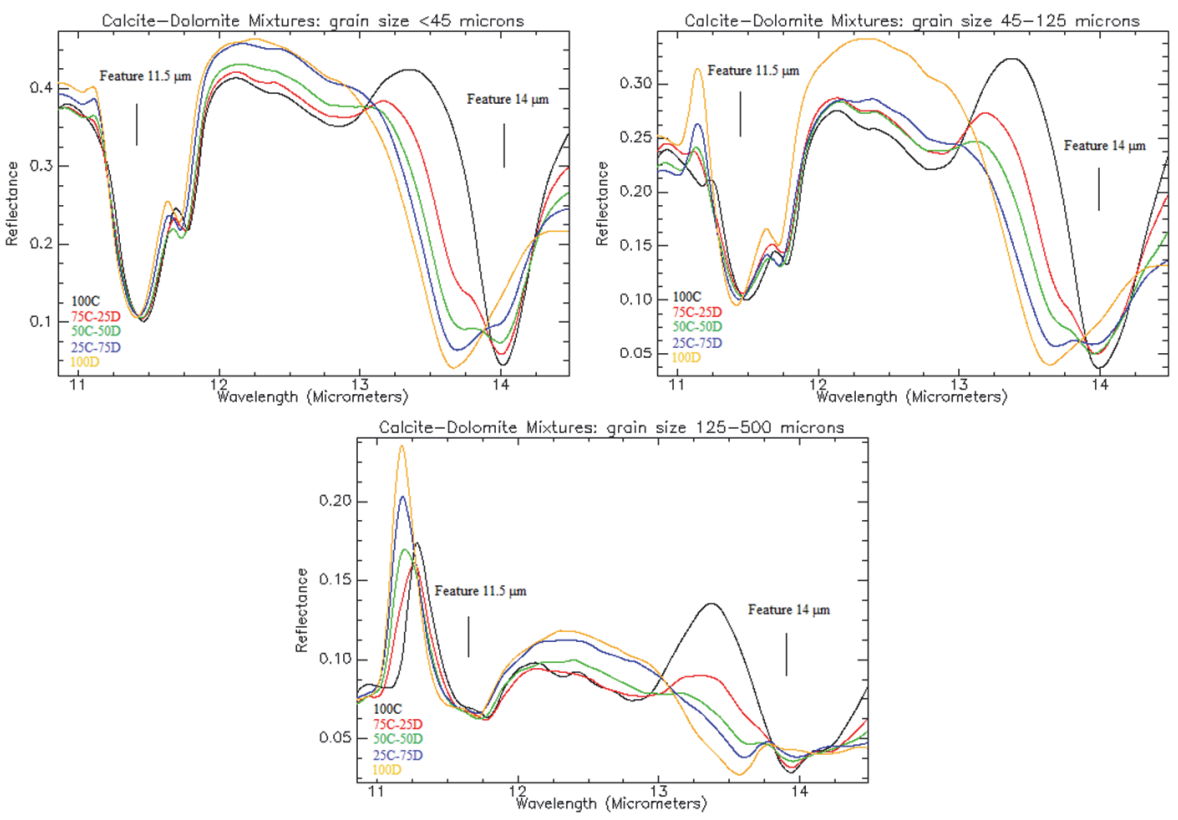

Figure 3.8: TIR spectral features of calcite-dolomite mixtures for each grain size fraction. Position of absorption bands is a function of the calcite content in the sample. $(\mathrm{C}=$ calcite and $\mathrm{D}=$ dolomite, prefix numbers showing the mineral contents in percent).
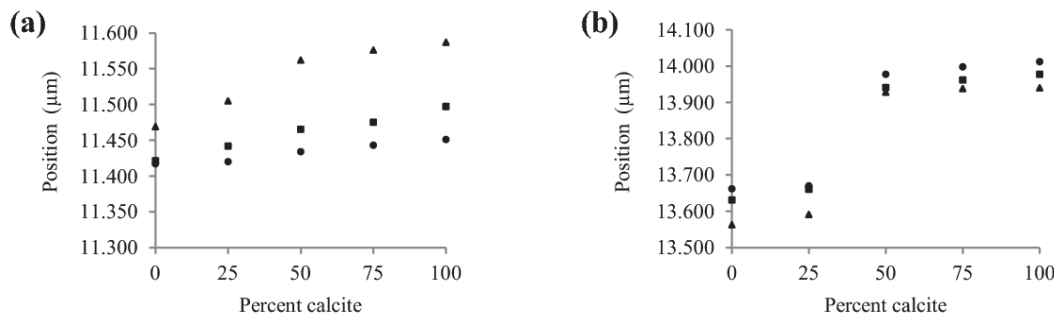

Figure 3.9: Absorption band positions of calcite-dolomite mixtures in the TIR region for each grain size fraction (grain size: $<45 \mu \mathrm{m}(\bullet), 45-125 \mu \mathrm{m}(\boldsymbol{\bullet})$, and $125-500 \mu \mathrm{m}$ (A)) obtained from (a) feature at $11.5 \mu \mathrm{m}$ and (b) feature at $14 \mu \mathrm{m}$, shown in Figure 3.8 .

The position of absorption bands of both features depends on the calcite content and grain size composing the sample, where the band positions range from that of pure dolomite to pure calcite or change to longer wavelengths as calcite content increases (Figure 3.9). These band positions of calcite-dolomite mixtures in the TIR region are centered within the wavelength range of 11.417-11.451 $\mu \mathrm{m}$ and $13.662-14.006 \mu \mathrm{m}$ for grain size $<45 \mu \mathrm{m}, 11.421-11.497 \mu \mathrm{m}$ and $13.631-13.977 \mu \mathrm{m}$ for grain size $45-125 \mu \mathrm{m}$, and $11.469-11.578 \mu \mathrm{m}$ and $13.563-13.940 \mu \mathrm{m}$ for grain size $125-500 \mu \mathrm{m}$. Absorption band depth, FWHM, and asymmetry of the features also vary with calcite content 
(Figure 3.8). The features tend to have positive asymmetry which skews to longer wavelengths.

\subsection{Discussions}

\subsubsection{Effect of grain size}

Varying grain size in carbonate samples influences spectral shape and thus absorption feature characteristics in the SWIR and TIR wavelength regions. Particularly, reflectance and depth of absorption bands change (Figures 3.2 and 3.4). The studies by van der Meer (1995), Gaffey (1986), and Crowley (1986) also show that the reflectance and depth of absorption bands of these minerals in SWIR spectra are affected by grain size. Coarse grain size fractions absorb more electromagnetic radiation penetrating to the grain surface than fine grain size associated with thickness of the grain or internal optical path of the grain (Clark \& Roush, 1984; Salisbury et al., 1987) according to Lambert-Beer's Law, typical of transparent material (Salisbury et al., 1987), and roughness of the grain surface (Crowley, 1986).

The presence of carbonate ion in a mineral or rock is characterized by several fundamental vibrational bands in the SWIR (Clark, 1999; Clark et al., 1990; Gaffey, 1986; Hunt \& Salisbury, 1971) and TIR (Clark, 1999; Clark et al., 1990; Salisbury et al., 1987) regions. The two prominent absorption features in SWIR reflectance spectra of calcite and dolomite (Figure 3.2) are caused by overtones and combination tones of internal vibrational processes of carbonate ions (Clark, 1999; Clark et al., 1990; Gaffey, 1986; Hunt \& Salisbury, 1971). In TIR spectra (Figure 3.4), the two diagnostic absorption features are generated by two vibrational bending modes of carbonate ions, which are out-of-plane bends for the feature at $11.5 \mu \mathrm{m}$ and in-plane bends for the feature at $14 \mu \mathrm{m}$ (Clark, 1999; Clark et al., 1990; Salisbury et al., 1987).

The position of absorption bands for both features in pure powdered calcite and dolomite spectra in the SWIR wavelength region appeared invariant to grain size fraction (Figure 3.3), confirming results reported by van der Meer (1995) and Gaffey (1986). Although the center of the absorption band position is not influenced by grain size, the band positions are centered at a slightly different wavelength, when compared to previous studies (Baissa et al., 2011; Gaffey, 1986; Hunt \& Salisbury, 1971; van der Meer, 1995). Gaffey (1986) revealed that using different spectroscopic instruments and methods to calculate band position may result in changing the center of the band position. In this study, we used an advance hyperspectral spectrometer with very high spectral resolution for reflectance spectra measurement, so that it could be the reason why our result is slightly different from others. The FWHM and asymmetry of the features at 2.3 and $2.5 \mu \mathrm{m}$ in the SWIR region varied with grain size fraction (Figures 3,2 and 3,3), which is in contrast to what has been published in prior studies (Gaffey, 1986; van der Meer, 1995). Here it was stated that the width and asymmetry of absorption features, and the number of absorption bands are not changing or invariant 
with particle size (Gaffey, 1986; van der Meer, 1995). In addition, the FWHM for both absorption features is wider for dolomite than for calcite.

The band position of both features in the TIR wavelength region appeared to be dependent on grain size fraction of the sample (Figure 3.4). The center of the band position changed slightly at different wavelengths, confirming results of previous studies (Huang \& Kerr, 1960; Ji et al., 2009; Lane \& Christensen, 1997; Reig et al., 2002; Salisbury et al., 1987). Reflectance intensity of band shoulders on the left and right sides of both features at 11.5 and $14 \mu \mathrm{m}$ decreased considerably more than for the band centers, when the grain size becomes coarser in the sample. Therefore, it influences spectral shapes and absorption feature characteristics. As grain size affects the shape of absorption features (Salisbury et al., 1987), it may also affect band position. The absorption band depth, FWHM, and asymmetry of the TIR carbonate features also varied with grain size, but the feature parameters were difficult to analyze given the weak nature of spectral features at larger grain sizes, especially between 125 and $500 \mu \mathrm{m}$ grain sizes.

\subsubsection{Effect of mineral mixing}

Varying quantity of calcite and dolomite in the sample affects absorption band position in the SWIR and TIR wavelength regions. Work reported by van der Meer (1995) for carbonate band positions in SWIR spectra of calcite-dolomite mixtures shows the same trends found in the course of this study. Gaffey (1985) also reported that absorption band position in calcite and dolomite spectra displaces with changed chemical composition such as increased $\mathrm{Mg}$ content in calcite and $\mathrm{Fe}$ content in dolomite. However, the absorption band position displaced also with grain size, especially when the calcite content in the samples increases from $25 \%$ to $75 \%$ (Figure 3.7), although the band position did not shift in the SWIR spectra of pure powdered calcite and dolomite (Figure 3.3). This effect may be caused by the mixing of calcite and dolomite in the sample, which is dominated by one of the two carbonate minerals or "pilling effect" of the fine grains in the sample (Hunt \& Salisbury, 1971). The FWHM of the $2.5 \mu \mathrm{m}$ feature in mixed mineral spectra is wider than the $2.3 \mu \mathrm{m}$ feature (Figure 3.7), which is the same as the FWHM of pure calcite and dolomite spectral features (Figure 3.3), most likely due to stronger vibrational absorption at $2.5 \mu \mathrm{m}$ (Hunt \& Salisbury, 1971).

The absorption band position of calcite-dolomite mixtures in the TIR was not only dependent on mineral contents, but also on grain size (Figure 3.9). Absorption features may be affected by grain size and multiple scattering effects (Salisbury et al., 1987). The absorption band depth, FWHM, and asymmetry of the features also varied with calcite content (Figure 3.8). These characteristics show the same pattern as pure calcite or dolomite feature characteristics (Figure 3.4), when the quantity of calcite-dolomite mixtures composing a sample is dominated by one of those minerals. It was also difficult to analyze due to less pronounced spectral features with increased grain size. 


\subsubsection{Mineralogical mapping applications}

Results of this study indicate that absorption band positions of the two prominent carbonate features in the SWIR and TIR wavelength regions are distinctive of carbonate minerals with different grain size and mineral content (Figures 3.3, 3.5, 3.7 and 3.9). Previous research has revealed that the two prominent carbonate features in the SWIR (Baissa et al., 2011; Gaffey, 1986; Hunt \& Salisbury, 1971; van der Meer, 1995) and TIR (Clark, 1999; Huang \& Kerr, 1960; Salisbury et al., 1987) regions are essential to distinguish between calcite and dolomite, as they contain the strongest vibrational absorption features of carbonate ions. Therefore, these features are useful for identifying pure and mixed calcite and dolomite as well as estimating the relative abundances of both minerals in a synthetic sample or rock. Previous research has demonstrated that distinctive spectral reflectance characteristics in the near infrared through laboratory experiment and remote sensing imagery can assist in identification of carbonate minerals and dolomitization patterns (van der Meer, 1996a, 1998; Windeler \& Lyon, 1991). Van der Meer (1995) stated that estimation of the calcite-dolomite ratio from spectra could be done using diagnostic absorption features around 2.30-2.34 $\mu \mathrm{m}$, of which the exact position is dependent on the relative amounts of calcite and dolomite. Consequently, knowledge of these precise absorption band positions may be applied to analysis of hyperspectral remote sensing imagery for mapping carbonate minerals and dolomitization patterns in limestones.

\subsection{Conclusions}

Absorption feature characteristics and reflectance values of pure and mixed calcite and dolomite spectra in the SWIR and TIR wavelength regions were influenced by grain size and carbonate mineral content. Absorption band positions of both features in these wavelength regions were displaced slightly as observed in previous studies. The positions of SWIR calcite features at $2.340 \mu \mathrm{m}$ and $2.537 \mu \mathrm{m}$ and dolomite features at $2.323 \mu \mathrm{m}$ and $2.515 \mu \mathrm{m}$ were invariant to grain size. The FWHM and asymmetry of the calcite and dolomite spectral features at 2.3 and $2.5 \mu \mathrm{m}$ in the SWIR region varied with grain size fraction, in contrast to what has been published in prior studies that the width and asymmetry of absorption features, and the number of absorption bands are not changing or invariant with particle size. In the TIR region, the positions depended on grain size and shifted to longer wavelength for the feature at $11.5 \mu \mathrm{m}$ and to shorter wavelength for the feature at $14 \mu \mathrm{m}$ from fine to coarse grain size fractions. The positions of both features of calcite-dolomite mixtures in the SWIR and TIR wavelength regions were determined by the calcite or dolomite content composing the sample. The positions of the features in the SWIR region were centered within the wavelength range of 2.323-2.340 $\mu \mathrm{m}$ and 2.515-2.537 $\mu \mathrm{m}$. In the TIR region, however, the absorption band positions of the calcite-dolomite mixtures not only depended on mineral content, but also on grain size in the sample. Knowledge of these detailed feature characteristics can increase the accuracy of spectral identifications of pure and mixed calcite and 
dolomite with different grain size and carbonate mineral content, which is of particular use for assessments of dolomitization patterns in limestones.

This study has contributed to understanding the effects of grain size and mineral mixtures on the spectral absorption feature characteristics in the SWIR and TIR wavelength regions, which will help in improving mineral identification on the earth's surface using hyperspectral remote sensing. 


\section{Determination of carbonate rock chemistry using laboratory-based hyperspectral imagery $^{3}$}

${ }^{3}$ This chapter has been published as: Zaini, N., van der Meer, F., van der Werff, H., 2014. Determination of carbonate rock chemistry using laboratory-based hyperspectral imagery. Remote Sensing 6, 4149-4172. 


\subsection{Introduction}

Carbonate rocks are one of the important and abundant constituents of materials on the earth surface. This is because the rocks not only possess natural resources, such as valuable minerals and including fossil fuels, but also contain history of the earth surface environments in the past (Blatt et al., 1972; Pettijohn, 1975). Thus, identification and quantification of the abundances and proportions of carbonate minerals on the rock surfaces is essential for minerals exploration and understanding petroleum geology characterization. The rocks are constituted by a mosaic of minerals and naturally complex geologic mixtures, such as intimate mixtures, grain size variations, weathered constituents, and alteration products (Blatt et al., 1972; Pettijohn, 1975). Those mixtures can create a major obstacle to mineralogic identification (Clark, 1999; Kruse, Lefkoff, \& Dietz, 1993; Mustard \& Pieters, 1987), particularly determining the proportions of mineral mixtures. Conventional methods to identify carbonate minerals in rock samples include X-ray diffraction (XRD) (Bishop et al., 2011; Gaffey, 1986; Kaplan et al., 2013; Sepulcre et al., 2009), scanning electron microscopy (SEM) (Kaplan et al., 2013; Lein, 2004), different thermal analysis (DTA) (Kaplan et al., 2013), thin section analysis (Forbes et al., 2010; Vincent et al., 2011), staining method (Dickson, 1965; Friedman, 1959; Hitzman, 1999; Kato et al., 2003), and others. However, most of these methods incur costly techniques and time consuming in terms of sample preparation and analysis. A promising approach, which is fast, inexpensive, non-destructive and can achieve a higher degree of accuracy in identification and estimation of the abundance of carbonate mineral mixtures, is hyperspectral imaging spectroscopy techniques.

The recent developments of laboratory-based imaging spectrometry sensors such as HyLogging $^{\mathrm{TM}}$, HySpex, SisuROCK, and SisuCHEMA hyperspectral imagers, which integrated the sophisticated digital imaging of airborne hyperspectral sensor technologies with the highest spectroscopic resolution of field and laboratory spectrometers, have generated a new type of hyperspectral imagery that can be used for identifying geologic mixtures of surface mineralogy (Baissa et al., 2011; Haest et al., 2012a, 2012b; Murphy et al., 2014; Specim, 2007). These spectrometers can acquire hyperspectral images of powdered or hand specimen samples for a wide variety of applications including chemical imaging, pharmaceutical, and mineralogical identification. These relatively novel datasets present new opportunities for analysis of the complex mixtures of surface mineralogy. However, the datasets have not been fully explored in determining mineral mixtures and estimating the proportions of these minerals on a hand specimen of rock or geologic sample (Baissa et al., 2011; Murphy et al., 2014). Therefore, the application of higher resolution hyperspectral imagery that enables the determination of the abundance of naturally mixed minerals on rock surfaces is still challenging.

This analysis uses higher resolution hyperspectral imagery of the SisuCHEMA hyperspectral scanner to determine and estimate the abundance of mineral mixtures on hand specimens of fresh carbonate rock surfaces. It is also complemented by 
geochemical analysis of spot measurements obtained by a portable X-ray fluorescence (PXRF) analyzer for identifying mineral chemistry of the rocks. The spectrometer, which was originally designed for chemical imaging, is an automatic hyperspectral imaging instrument for rapid scanning and analysis of various samples in laboratory (Specim, 2007). It acquires imagery of the sample mounted on its imaging tray using a push-broom hyperspectral sensor. The instrument can be equipped with a shortwave infrared (SWIR) sensor. In this regard, the higher resolution SisuCHEMA imagery provides an additional spatial detail to spectral information of surface feature characteristics in image pixels. It allows further determination of mineral assemblages or mixtures and estimation of the relative mineral abundances on the carbonate rock surfaces using various spectral recognition algorithms.

In order to extract compositional information of mineralogy based on their spectral characteristics in hyperspectral imaging data, a number of well-developed spectral classification approaches are commonly used. These consist of wavelength position analysis (Clark \& Roush, 1984; Kruse, Lefkoff, \& Dietz, 1993; Rodger et al., 2012), spectral angle mapper (SAM) (Kruse, Lefkoff, Boardman, et al., 1993), and linear spectral unmixing (LSU) (Adams et al., 1993; Boardman, 1989). The approaches have various advantages of spectral classification algorithms, as well as relatively accurate methods in identifying minerals from image spectra. These methods have also been used extensively for mapping surface mineralogy of hyperspectral data in different geological samples or areas (Baissa et al., 2011; Hecker et al., 2008; Kruse, Lefkoff, Boardman, et al., 1993; Kruse, Lefkoff, \& Dietz, 1993; Murphy et al., 2012; Murphy et al., 2014; Riaza \& Muller, 2010; van der Meer, 2006). Wavelength position analysis approach is sensitive to band position shift and noisier spectral responses (Murphy et al., 2014; Rodger et al., 2012), which is determined from a polynomial fit (Rodger et al., 2012) of continuum-remove spectra (Clark \& Roush, 1984; Kruse, Lefkoff, \& Dietz, 1993). SAM, a spectral similarity measure (Kruse, Lefkoff, Boardman, et al., 1993), is insensitive to illumination and albedo differences (Aspinall et al., 2002; Hecker et al., 2008; Murphy et al., 2012; van der Meer, 2006). LSU provides an interesting alternative approach to mixing problem of pixel spectra (Adams et al., 1993; Boardman, 1989). It can derive fractional abundances for selected endmembers within a pixel. Thus, detection of the exact absorption wavelength position and unique spectral shape is a key factor for direct identification of surface mineralogy (Clark et al., 1990; Hunt, 1977; Hunt \& Salisbury, 1970, 1971; Kruse, Lefkoff, \& Dietz, 1993).

The SWIR reflectance spectra $(1.0-2.5 \mu \mathrm{m})$ are rich in mineral spectral signatures. Within this spectral range, the diagnostic absorption features are determined by the occurrence of water $\left(\mathrm{H}_{2} \mathrm{O}\right)$, hydroxyl $(\mathrm{OH})$, carbonate $\left(\mathrm{CO}_{3}\right)$, and sulfate $\left(\mathrm{SO}_{4}\right)(\mathrm{Clark}$ et al., 1990; Hunt, 1977; Hunt \& Salisbury, 1970, 1971). Spectral absorption feature characteristics of minerals vary, depending on the chemical composition, structural arrangement, and bonding characteristics (Clark, 1999; Povarennykh, 1978; van der Meer, 1995). Hence, these feature characteristics can be used for discriminating one mineral from the other. Carbonate minerals, such as calcite $\left(\mathrm{CaCO}_{3}\right)$ and dolomite 
$\left(\mathrm{CaMg}\left(\mathrm{CO}_{3}\right)_{2}\right)$, are the most common constituents of carbonate rocks (Blatt et al., 1972; Pettijohn, 1975). They have two prominent absorption features in the SWIR region centered within the wavelength ranges of $2.530-2.541 \mu \mathrm{m}$ and $2.333-2.340 \mu \mathrm{m}$ and 2.503-2.520 $\mu \mathrm{m}$ and 2.312-2.323 $\mu \mathrm{m}$, respectively (Baissa et al., 2011; Clark et al., 1990; Crowley, 1986; Gaffey, 1986; Hunt \& Salisbury, 1971; Kurz et al., 2012; van der Meer, 1995; Zaini et al., 2012). Those absorption features are caused by vibrational processes of the carbonate ions $\left(\mathrm{CO}_{3}^{2-}\right)$ (Clark et al., 1990; Gaffey, 1986; Hunt \& Salisbury, 1971). Moreover, the positions of absorption features of calcite-dolomite mixtures in the SWIR region were determined by the calcite or dolomite content in the carbonate samples (van der Meer, 1995; Zaini et al., 2012). Absorption feature characteristics of these minerals are also influences by particle size (Crowley, 1986; Gaffey, 1986; van der Meer, 1995; Zaini et al., 2012), texture (Crowley, 1986), porosity (Gaffey, 1986), and mineral impurities (Crowley, 1986; Gaffey, 1986; van der Meer, 1995). The presence of clay minerals in intimate mixture with carbonates is usually indicated by a vibrational absorption feature around $2.20 \mu \mathrm{m}$ and $2.30 \mu \mathrm{m}$ due to the combination of the $\mathrm{OH}$ stretch with the $\mathrm{Al}-\mathrm{OH}$ and $\mathrm{Mg}-\mathrm{OH}$ bending modes, respectively (Clark et al., 1990; Hunt, 1977; Hunt \& Salisbury, 1970).

The objectives of this chapter are to (i) estimate the chemical composition and the relative abundance of carbonate minerals on the rock surfaces using wavelength position, SAM and LSU approaches, (ii) assess the accuracy of these classification methods for identification of surface mineralogy, and (iii) find relationship between mineral chemistry and mineral spectral characteristics in determining mineral constituents of rocks. The advent of higher resolution hyperspectral data provided by the SisuCHEMA SWIR sensor could potentially help to solve the problem of determining the relative abundance of mineral mixtures composing rocks or geologic samples.

\subsection{Materials and Methods}

\subsubsection{SisuCHEMA hyperspectral data}

The data used in this study were higher resolution hyperspectral imagery of carbonate rocks acquired by the SisuCHEMA hyperspectral imager of Spectral Imaging Ltd. (SPECIM), Finland (Specim, 2007). We used the SWIR hyperspectral sensor, which acquires images with 320 spatial pixels per line at a spatial resolution of 0.21 $\mathrm{mm}$. The imaging sensor is configured to record continuous spectral information from $970 \mathrm{~nm}$ to $2500 \mathrm{~nm}$ with 256 spectral bands at an average full width at half maximum (FWHM) of $6.23 \mathrm{~nm}$ and spectral resolution of $10 \mathrm{~nm}$ (Specim, 2007). Samples are scanned on a moving imaging tray under similar illumination conditions by using SPECIM's diffused line illumination unit. The scanner is integrated with a computer workstation as shown in Figure 4.1 taken from (Agus, 2011) that allows acquiring and saving spectral image in real-time using the ChemaDAQ data acquisition software. An internal standard reference target is used for calibration measurement before each 
sample scan. It results in automatically calibrated image data to reflectance. Its higher spatial and spectral resolution allows the SisuCHEMA to record distinctive spectral absorption features in the SWIR wavelength region, which can be applied to study mineralogical components on rock or geological surfaces.

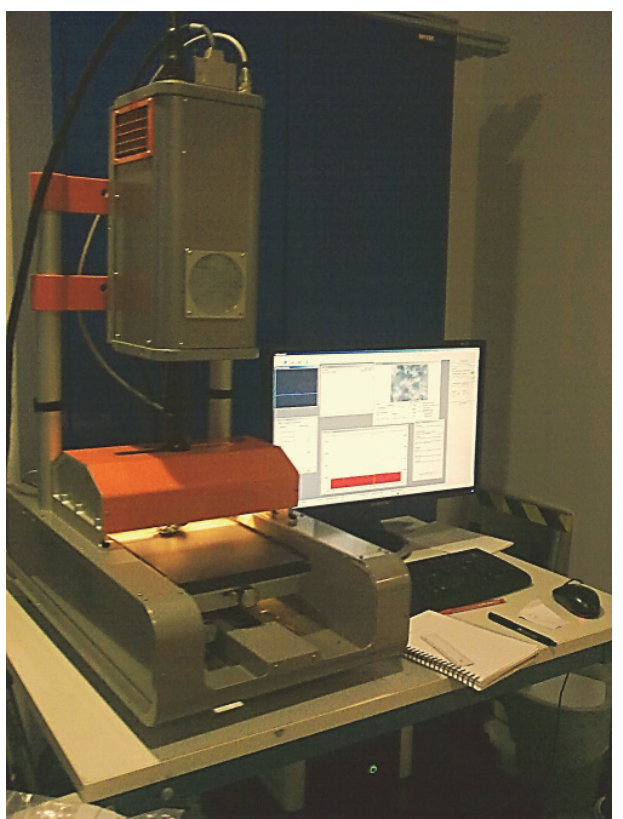

Figure 4.1: An integrated system of SisuCHEMA hyperspectral scanner (Agus, 2011).
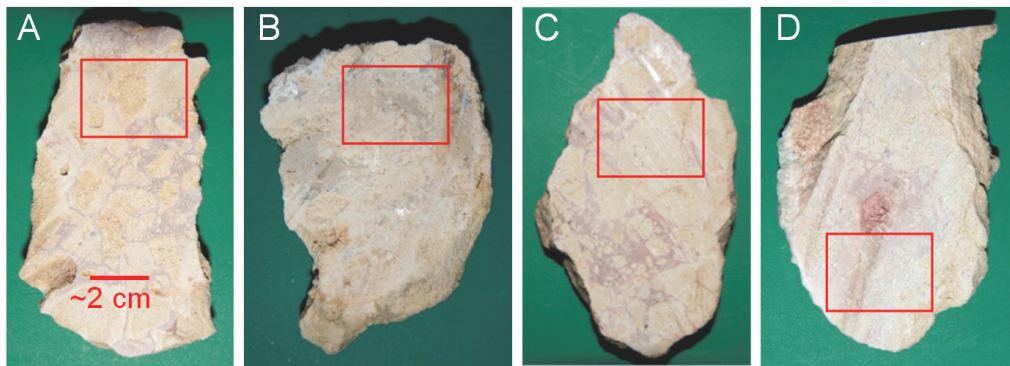

Figure 4.2: Fresh surfaces of carbonate rock samples, with red rectangles pointing out areas of selected SisuCHEMA images.

The rocks imaged were hand specimens of fresh carbonate rock surfaces (Figure 4.2). These rocks were collected from the Bédarieux mining area, which is an open and partly active dolomite mine in the Hérault department of Languedoc-Roussillon region, southern France. The samples are originating from the Jurrassic-Bathomien formation and their composition becomes sandier from west to east (Bogdanoff et al., 1984). A total of four rock samples (samples A, B, C, and D) were imaged, referred to as images $\mathrm{A}, \mathrm{B}, \mathrm{C}$, and D. These rocks were chosen and assessed visually based on the physical 
appearance of their carbonate mineral compositions. For the purposes of this study, the spatial and spectral subset hyperspectral images of carbonate rocks (Figure 4.3), with 15,756 spatial pixels (156 samples-101 lines) selected carefully over a smooth area of the rock surfaces (red rectangles, Figure 4.2), and a spectral range between $2100 \mathrm{~nm}$ and $2400 \mathrm{~nm}$ (Figure 4.4), were used. The ENVI software package version 4.7 (ITT, 2010) was used to process the images

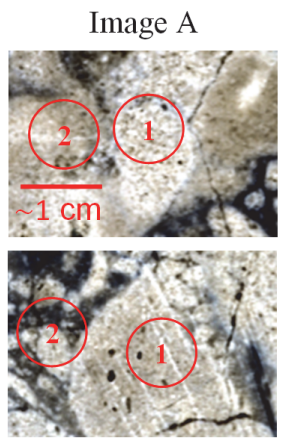

Image $\mathrm{C}$

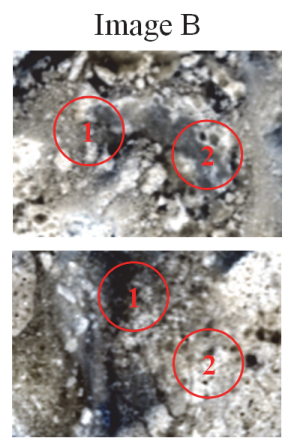

Image D

Figure 4.3: Selected SisuCHEMA images A, B, C, and D of carbonate rocks (bands 200, 205, and 210) with locations of two portable X-ray fluorescence (PXRF) spot measurements (red circles).
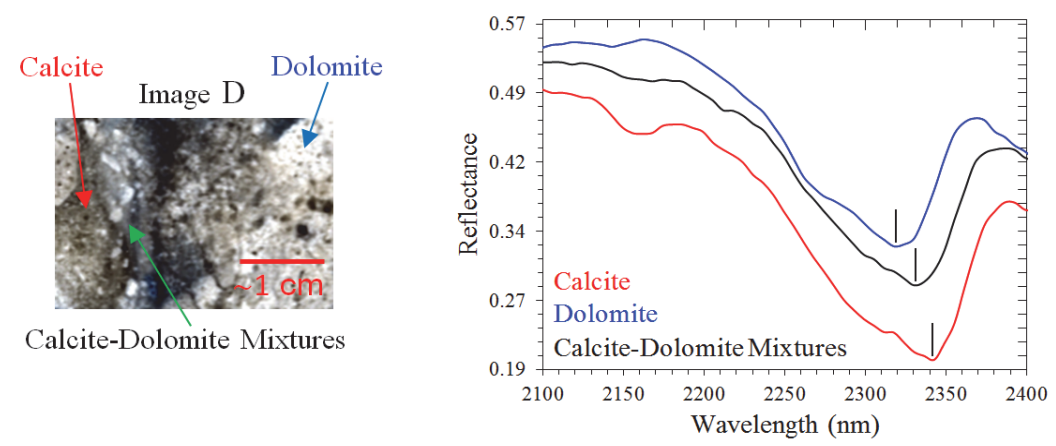

Figure 4.4: Example of SisuCHEMA spectra (right) of calcite (red curve), dolomite (blue curve) and calcite-dolomite mixtures (black curve) derived from different pixel locations of image D (left). The curves show shift in wavelength position of carbonate absorption feature.

\subsubsection{PXRF geochemical analysis}

The major and minor element concentrations of collected carbonate rock samples were measured using a portable X-ray fluorescence (PXRF), the Niton XL3t GOLDD+ from Thermo Fisher Scientific Inc. The PXRF was also equipped with a CCD camera for accurate positioning and documenting the measurement spots. This instrument offers a rapid and non-destructive measurement for determining and investigating elemental concentrations on rocks or geologic samples (Thermo Scientific, 2010). For analyzing 
geologic samples, the analyzer was set up using mining mode option to operate excitation filters that optimize the analyzers' sensitivity for various elements. The "High Range" filter is used to optimize Ba through Ag. The "Main Range" filter provides optimum sensitivity for the elements Mn through Bi. The "Low Range" filter is used to optimize the sensitivity for the elements from Ti to Cr. The "Light Range" filter is available only with He-purged (Thermo Scientific, 2010). Helium purge is required to enhance detection and the quality of measurement of light elements from $\mathrm{Mg}$ to $\mathrm{Cl}$.

Samples in the laboratory were placed on a sample compartment over the window frame of the sensor. Two PXRF spot measurements with an $8 \mathrm{~mm}$ diameter spot size were taken from each fresh carbonate rock surface within the selected area of SisuCHEMA images (Figure 4.3). The PXRF in mining mode setting is calibrated for a silicate dominated rock matrix. Some pure carbonate samples were analyzed to check the calibration in this mode and an over estimation of up to $10 \%$ was observed for $\mathrm{Ca}$ and $\mathrm{Mg}$. As the samples used in this research consist of a mixture of calcite and dolomite, the last of which the $\mathrm{Ca} / \mathrm{Mg}$ proportion is not known, it was not possible to establish a correction factor for these elements in the PXRF results. It is assumed that the measured $\mathrm{Ca}$ and $\mathrm{Mg}$ concentrations are proportionally correct. The lower limits of detection were approximately less than $0.02 \%$ for elements $\mathrm{K}, \mathrm{Al}$, and $\mathrm{Cl}$ (Table 4.1 ).

Table 4.1: Elemental concentrations of the rock samples derived from portable X-ray fluorescence (PXRF) spot measurements (in percent). Some elements have lower limits of detection (LOD).

\begin{tabular}{cccccccccc}
\hline $\begin{array}{c}\text { PXRF Spots } \\
\text { Code }\end{array}$ & $\mathrm{Ca}$ & $\mathrm{Mg}$ & $\mathrm{Ba}$ & $\mathrm{Fe}$ & $\mathrm{K}$ & $\mathrm{Al}$ & $\mathrm{Si}$ & $\mathrm{Cl}$ & $\mathrm{S}$ \\
\hline $\mathrm{A} 1$ & 24.47 & 6.54 & 0.02 & 0.08 & $<$ LOD & 0.09 & 0.22 & 0.02 & 0.08 \\
$\mathrm{~A} 2$ & 31.66 & 7.10 & 0.03 & 0.07 & $<$ LOD & 0.08 & 0.13 & $<$ LOD & 0.04 \\
$\mathrm{~B} 1$ & 35.05 & 4.56 & 0.02 & 0.03 & $<$ LOD & $<$ LOD & 0.11 & $<$ LOD & 0.04 \\
$\mathrm{~B} 2$ & 31.96 & 4.90 & 0.02 & 0.01 & $<$ LOD & 0.08 & 0.11 & 0.04 & 0.02 \\
C1 & 26.13 & 7.95 & 0.02 & 0.01 & $<$ LOD & 0.07 & 0.18 & 0.05 & 0.11 \\
C2 & 30.65 & 6.79 & 0.02 & 0.08 & $<$ LOD & 0.10 & 0.16 & 0.05 & 0.03 \\
D1 & 34.66 & 5.50 & 0.02 & 0.10 & 0.03 & 2.31 & 2.58 & 0.07 & 0.02 \\
D2 & 31.51 & 7.43 & 0.03 & 0.03 & $<$ LOD & 0.51 & 0.63 & 0.06 & 0.07 \\
\hline
\end{tabular}

\subsubsection{Spectral classification approaches of the SisuCHEMA imagery}

\subsubsection{Laboratory spectral endmembers}

In image classification and compositional identification of hyperspectral remotely sensed data, image pixels represented by reflectance spectra of exhibited surface mineralogy are classified on the basis of reference spectra or known spectral endmembers of minerals (Kruse, Lefkoff, \& Dietz, 1993). These endmembers are derived from field or laboratory spectra or the purest spectral image pixels or from published standard spectral libraries (Kruse, Lefkoff, Boardman, et al., 1993; van der Meer \& de Jong, 2000). For classification of the selected SisuCHEMA images, we used pure and mixed laboratory spectral endmembers of powdered calcite and dolomite synthetic samples in the wavelength range of 2100 to $2400 \mathrm{~nm}$ with grain size fractions 
between $125 \mu \mathrm{m}$ and $500 \mu \mathrm{m}$ (Figure 4.5). The synthetic sample preparations and spectral measurements of the pure and physical mixed calcite and dolomite were essentially those described by Zaini et al. (2012). The carbonate compositions of these calcite-dolomite mixture spectral endmembers were ranging from pure calcite to pure dolomite. The spectra and absorption feature characteristics from these laboratory synthetic samples (Zaini et al., 2012) were also used in the spectral absorption feature analysis, and compositional mineral quantification of the images by identifying absorption wavelength position of the spectral image pixels.
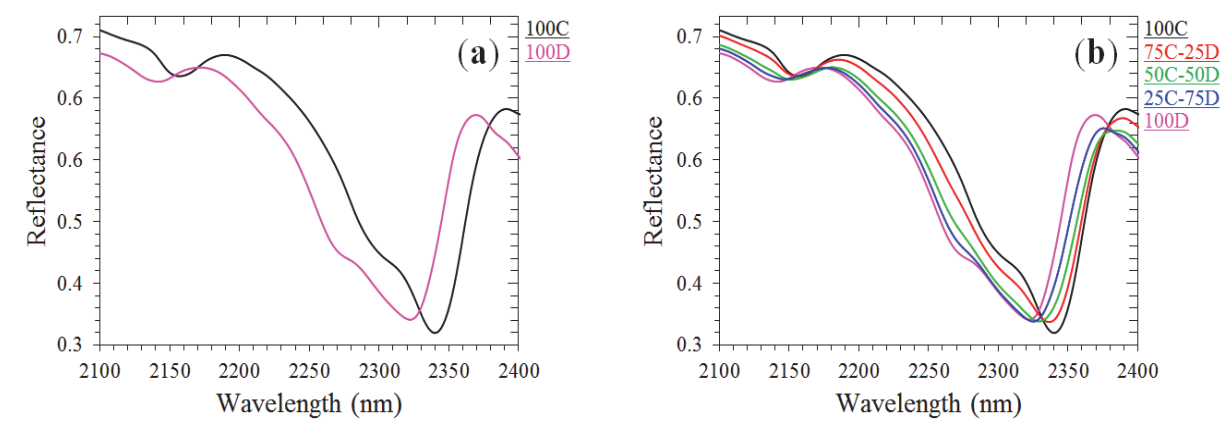

Figure 4.5: Laboratory spectral endmembers of (a) pure and (b) mixed calcite and dolomite synthetic samples $(\mathrm{C}=$ calcite and $\mathrm{D}=$ dolomite, prefix numbers showing the mineral contents in percent) (Modified after Zaini et al. (2012)).

\subsubsection{Absorption wavelength position}

Mineral reflectance spectra in the SWIR wavelength region contain a number of diagnostic absorption features, which are essential for compositional quantifying and distinguishing surface mineralogy. As absorption wavelength position of spectral features of minerals exhibits distinctive characteristics of their chemical compositions and molecular bonds (Clark, 1999). The absorption wavelength position calculated from continuum-removed spectra (Clark \& Roush, 1984; Kruse, Lefkoff, \& Dietz, 1993) is defined as the wavelength at which the maximum absorption or minimum reflectance of an absorption feature occurred (Kruse, Lefkoff, \& Dietz, 1993; van der Meer, 1995). The detail illustration of absorption feature characteristic definitions is given in previous studies (Kruse, Lefkoff, \& Dietz, 1993; Zaini et al., 2012).

In order to determine the relative abundances of mineral mixtures on the selected SisuCHEMA imagery using wavelength position analysis approach, the hyperspectral imagery was processed using Hyperspectral Python (HypPy) software package version 2.6 (Bakker, 2012) through the following procedures. Firstly, we followed a method developed by Rodger et al. (2012) to calculate wavelength position of a prominent absorption feature in image spectra within the wavelength range of 2100 to $2400 \mathrm{~nm}$. A continuum removal was then applied to the spectra within the selected wavelength range and followed by interpolation. A second order polynomial fit is modeled to three data points of minimum reflectance in the continuum-removed spectra. The wavelength 
position of the minimum and depth of absorption feature was determined on the fitting polynomial curve or the resulting interpolated parabola. This process produced an image with two bands for every pixel consisted of the interpolated wavelength position of the minimum of the prominent absorption feature and the depth of the feature, respectively. The wavelength position image of band one was used to derive wavelength position of mineralogy on the image pixels. Finally, the proportion or percentage estimation of carbonate mineral mixtures on the classified wavelength position image was counted manually. It was calculated by dividing the number of pixels of each mineral class by the total number of pixels in the image and then multiplied by a hundred.

\subsubsection{Spectral angle mapper}

Spectral Angle Mapper (SAM) is a spectral matching approach that compares the spectral similarity between reflectance spectra from image pixels and reference reflectance spectra with known material constituents (Kruse, Lefkoff, Boardman, et al., 1993). The spectral similarity is measured by calculating the angle between these spectra, which are characterized as vectors in space with n-dimensions equal to the number of bands. The angle of spectral vectors indicates a match of these spectra, where a smaller angle represents a closer match to the reference spectra. SAM only considers the vector directions in comparison of these spectral vectors, not their vector lengths, which are insensitive to illumination and albedo differences (Aspinall et al., 2002; Hecker et al., 2008; Kruse, Lefkoff, Boardman, et al., 1993; Murphy et al., 2012; van der Meer, 2006). Although SAM algorithm has been widely used for classifying surface mineralogy of hyperspectral imagery in various environmental and geological conditions (Baissa et al., 2011; Hecker et al., 2008; Murphy et al., 2012; Riaza \& Muller, 2010; van der Meer, 2006), its dependency on average match of the entire reference spectra has leaded to a certain extent of ambiguity in classification results (Hecker et al., 2008; van der Meer, 2006).

SAM classification was performed for the selected SisuCHEMA images of the fresh rock surfaces with a spectral subset of 2100 to $2400 \mathrm{~nm}$ using the laboratory spectra of calcite-dolomite mixtures of synthetic samples (Zaini et al., 2012) as endmembers with known mineralogical compositions (Figure 4.5b). The maximum angle used in the classification, such as single value or multiple values assigned to each spectral endmember of dataset, was defined by user in order to determine a closer match between the endmember spectral vectors and the image pixel vectors. We performed two SAM classifications with a value of 0.1 and 0.2 (in radians), which was used as a threshold angle for each laboratory spectral endmember. ENVI basic statistics showed the percentage estimation of mineral abundances or proportions of carbonate mineral mixtures of each classified endmember in the classified image. 


\subsubsection{Linear spectral unmixing}

Linear Spectral Unmixing (LSU) is a sub-pixel model algorithm assuming the reflectance at each pixel of the image to be a linear combination of the reflectance of each material (or spectral endmember) present within the pixel (Adams et al., 1993; Boardman, 1989). LSU uses the spectral characteristics of materials for determining the relative abundances of materials depicted in multispectral or hyperspectral imagery. But the number of endmembers used in this classification method must not be more than the number of spectral bands (Adams et al., 1993; Boardman, 1989). Based on user-selected spectral endmember materials extracted directly from the image or standard library, the proportional fraction of the pixel that contains the endmember material corresponding to the image was calculated using least squares techniques (Settle \& Drake, 1993). Thus, the approach can estimate the abundance values of each endmember for every pixel.

The unmixing algorithm was run for the selected SisuCHEMA images with a spectral subset of 2100 to $2400 \mathrm{~nm}$ using the laboratory spectral endmembers of the pure carbonate synthetic samples (Zaini et al., 2012) (Figure 4.5a) to quantify carbonate mineral compositions on the hand specimens of carbonate rocks. A unit sum unconstrained and constrained unmixing was applied to classify these hyperspectral images. In the constrained method, we defined the weight of a sum-to-unity constraint on the abundance fractions with a default value of 1.0. The results of the unmixing classification were generally presented as grey-scale images with values from 0.0 to 1.0. The pixels with values of 0.0 were displayed as pure black, whereas the pixels with values of 1.0 were displayed as pure white representing higher mineral abundances and a perfect match to the endmember. The pixels having values above 1.0 or below 0.0 indicated the reference endmembers used for the classification were probably poor match, or other endmembers have to be included in the analysis (ITT, 2010). ENVI classification results also produce an RMS error image that can be used to evaluate pixels of omitted or incorrect endmembers. The proportion or percentage estimation of carbonate mineral mixtures on the classified unmixing image was calculated manually. It was computed by dividing the number of pixels having the same fraction value by the total number of pixels in the image and then multiplied by a hundred.

\subsection{Results}

\subsubsection{Identification of carbonate mineral mixtures}

To identify carbonate mineral mixtures and estimate the relative mineral abundances on the fresh carbonate rock surfaces, three spectral analysis techniques, such as absorption wavelength position, SAM, and LSU, have been applied to the SisuCHEMA hyperspectral images. The results in the following subsections show the relative abundances and distributions of mineral surface components estimated using these spectral methods. Generally, classification results indicate that samples B and D are 
composed of more heterogeneous carbonate mineral mixtures than samples $\mathrm{A}$ and $\mathrm{C}$ (Figures 4.6-4.8).

\subsubsection{Wavelength position classification results}

Figure 4.6a shows variation distributions and abundances of carbonate mineral mixtures on the four carbonate rock surfaces classified by analyzing absorption wavelength positions in the SWIR spectra $(2100-2400 \mathrm{~nm})$ of the selected SisuCHEMA images. Absorption feature analysis of the spectral image pixels indicates that images A and $\mathrm{C}$ are formed mainly of dolomite (blue pixels (100D), Figure 6a); while images B and $\mathrm{D}$ are constituted predominantly of calcite-dolomite mixtures with different compositions of carbonate mineral contents (green (25C-75D), yellow (50C-50D) and red (75C-25D) pixels, Figure 4.6a). Wavelength position of dolomite (100D) is centered within the range of 2313-2323 nm. Absorption wavelength positions for various compositions of calcite-dolomite mixtures are centered within the range of 2324-2327 $\mathrm{nm}, 2328-2333 \mathrm{~nm}$, and $2334-2337 \mathrm{~nm}$ for $25 \%$ calcite-75\% dolomite (25C-75D), 50\% calcite-50\% dolomite (50C-50D), and 75\% calcite-25\% dolomite (75C-25D) mixtures, respectively. Calcite $(100 \mathrm{C})$ represented by cyan color in the classified images $\mathrm{B}$ and $\mathrm{D}$ (Figure 4.6a) is distinguished from dolomite by the presence of a carbonate feature within the wavelength range of 2338-2341 nm.

(a) Image A
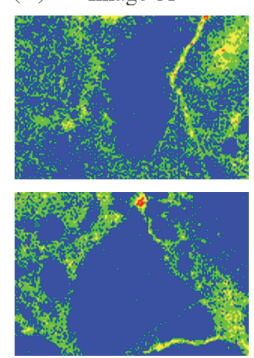

Image $\mathrm{C}$
Image B

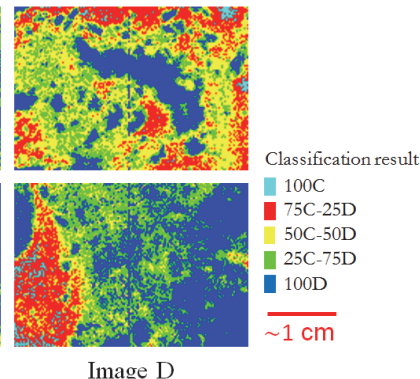

(b)

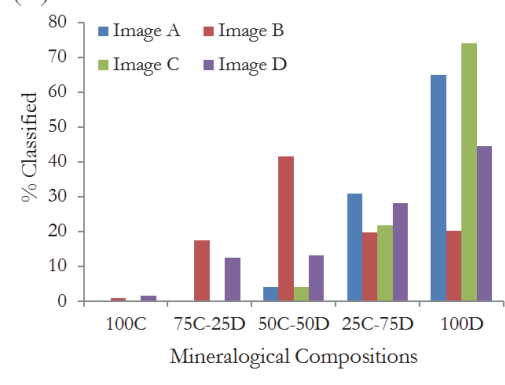

Figure 4.6: (a) Wavelength position images, showing the variability carbonate mineral mixtures. (b) Estimated proportion of classified minerals derived from the images. $(\mathrm{C}=$ calcite and $\mathrm{D}=$ dolomite, prefix numbers showing the mineral contents in percent).

The proportion estimation of carbonate mineral mixtures composing the rock samples based on the wavelength position analysis is shown in Figure 4.6b. It is obvious that the classified images of the rock samples are constituted by different proportions of carbonate mineral compositions. The wavelength position image $\mathrm{A}$ is dominated by abundant $100 \mathrm{D}$ of $64.94 \%$ and abundant $25 \mathrm{C}-75 \mathrm{D}$ of $30.80 \%$. The classified image $\mathrm{B}$ is dominated by 50C-50D with the relative mineral abundances of $41.50 \%$ and also contains small abundances of $100 \mathrm{C}$ of $0.94 \%$. The relative mineral abundance estimation of image $\mathrm{C}$ is almost the same as the image $\mathrm{A}$, where abundant $100 \mathrm{D}$ 
dominates the sample with a proportion of $73.97 \%$. The classified image D is dominated by abundant $100 \mathrm{D}$ of $44.48 \%$ and abundant $25 \mathrm{C}-75 \mathrm{D}$ of $28.24 \%$ and also contains small abundances of $100 \mathrm{C}$ of $1.66 \%$.

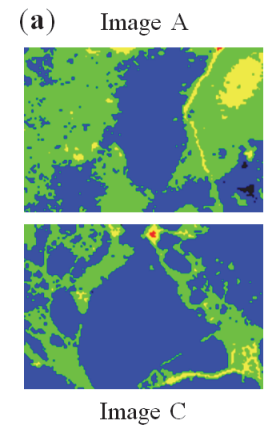

(c) Image A

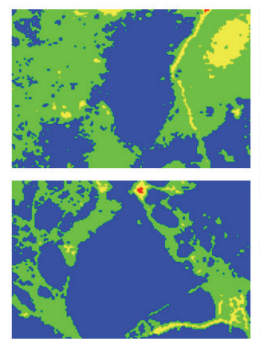

Image C
Image B

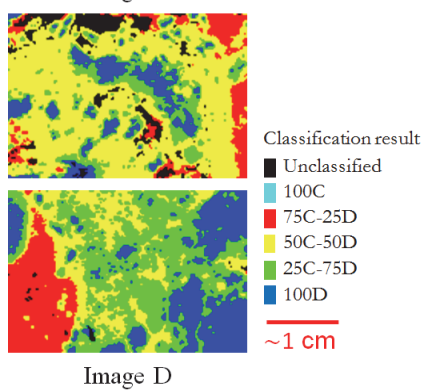

Image B

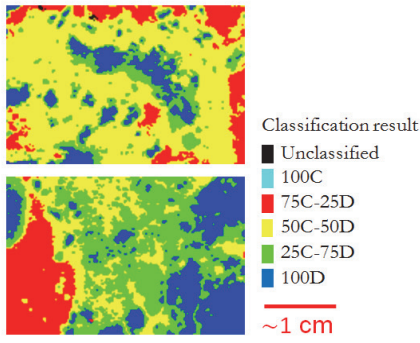

Image D

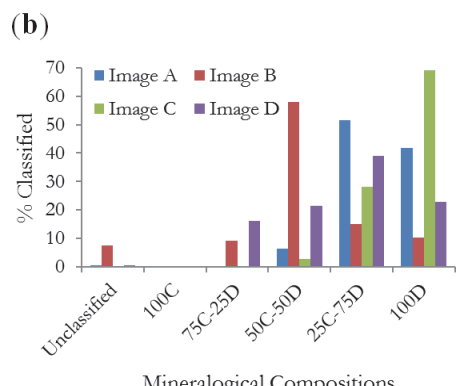

Mineralogical Compositions

(d)

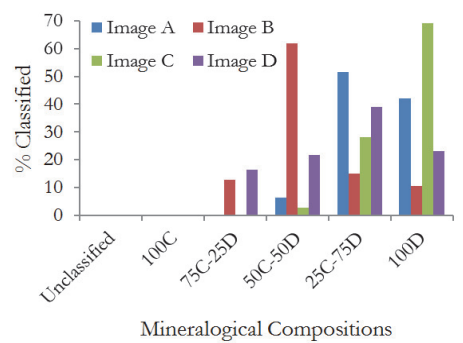

Figure 4.7: SAM classification results: (a) SAM images using a 0.1 radians threshold angle, (b) estimated proportion of classified minerals derived from (a) images, (c) SAM images using a 0.2 radians threshold angle, (d) estimated proportion of classified minerals derived from (c) images. The classification images illustrate roughly similar carbonate mineral abundances in different threshold angles. $(\mathrm{C}=$ calcite and $\mathrm{D}=$ dolomite, prefix numbers showing the mineral contents in percent).

\subsubsection{SAM classification results}

The classified SisuCHEMA images of the rock samples resulting from the SAM algorithm using the laboratory endmembers of mixed carbonate synthetic samples (Zaini et al., 2012) and a 0.1 and 0.2 radians threshold are shown in Figure 4.7a,c. The SAM abundance images for both threshold angles illustrate the same overall spatial distribution of carbonate minerals and slightly different proportions of these mineral mixtures due to more unclassified pixels in the SAM images of 0.1 threshold angle. Some carbonate mineral mixtures distributed over the image pixels are unclassified for both approaches (Figure 4.7a,c), such as the relative small abundances of $100 \mathrm{C}$ in the images B and D.

Figure $4.7 \mathrm{~b}, \mathrm{~d}$ shows proportion estimation of carbonate mineral mixtures on the rock samples using the SAM classification method for different threshold angles. These graphs illustrate that the relative abundance of carbonate minerals in the resulting 
images slightly increase with increasing threshold angle from 0.1 to 0.2 radians. It is caused by increasing the number of classified pixels in the images. The abundance images A are dominated mostly by abundant 25C-75D of $51.61 \%$ and abundant $100 \mathrm{D}$ with a slight different proportion which is of $41.74 \%$ in the 0.1 threshold image and $42.09 \%$ in the 0.2 threshold image. The classified images B show the same dominant abundant 50C-50D composing the sample, but the proportions of this carbonate mineral are $58.12 \%$ in the 0.1 threshold image and $61.77 \%$ in the 0.2 threshold image due to a significant amount of unclassified pixels of $7.43 \%$ in the 0.1 threshold image. The classified images $\mathrm{C}$ present equal proportions of carbonate mineral mixtures for both threshold angles, which are dominated by abundant 100D of $69.12 \%$. The abundance images D for both threshold angles contain mainly abundant 25C-75D of around 39\%.

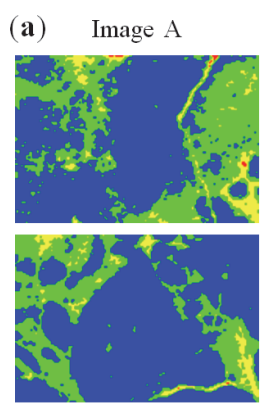

Image C

(c) Image A
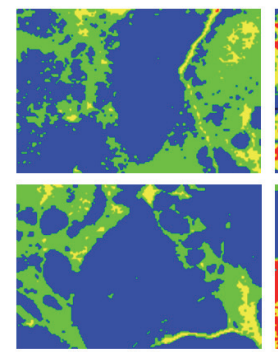

Image $C$
Image B

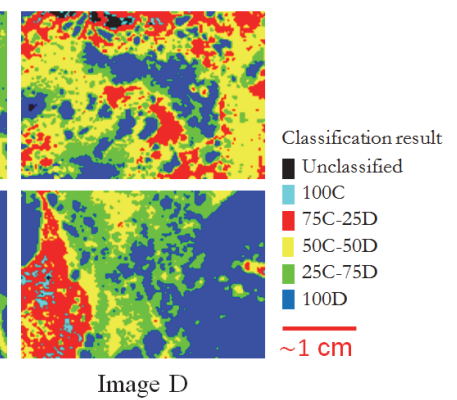

Image B

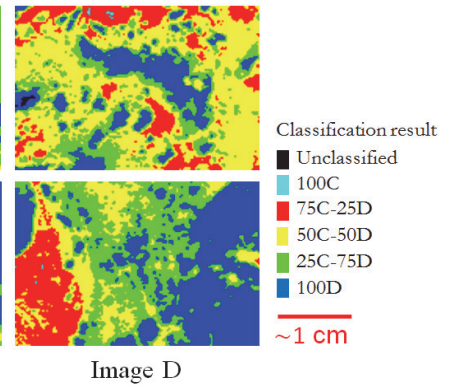

(b)

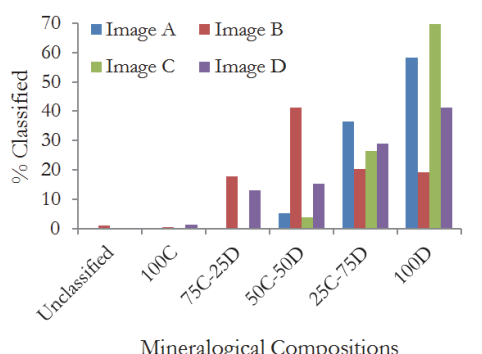

(d)

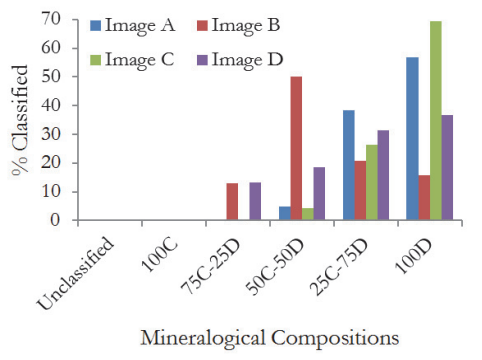

Figure 4.8: LSU classification results: (a) unconstrained dolomite endmember images, (b) estimated proportion of classified minerals derived from the unconstrained images,

(c) constrained dolomite endmember images using a 1.0 default value of weight, and

(d) estimated proportion of classified minerals derived from the constrained images. The classification images present a slight variability of carbonate fractional abundances in different unmixing approaches. $(\mathrm{C}=$ calcite and $\mathrm{D}=$ dolomite, prefix numbers showing the mineral contents in percent).

\subsubsection{LSU classification results}

Figure 4.8a,c shows LSU classification images of the selected SisuCHEMA data using the laboratory endmembers of pure carbonate synthetic samples (Zaini et al., 2012) as the reference spectra and unconstrained and constrained unmixing algorithms. 
The LSU images show variations of spatial distribution and abundance of carbonate mineral mixtures between unconstrained and constrained unmixing algorithms. The small abundant $100 \mathrm{C}$ in the images B and D is roughly classified by those unmixing methods with different proportions. The LSU results also exhibit a number of unclassified pixels (black pixels, Figure 4.8a,c). In this case, pixels having values above 1.0 or below 0.0 consider as the unclassified pixels.

The estimation of relative mineral abundances of the carbonate samples derived from the unconstrained and constrained dolomite endmember images is shown in Figure $4.8 \mathrm{~b}, \mathrm{~d}$. The abundance images $\mathrm{A}$ are dominated by abundant $100 \mathrm{D}$ with a slight different proportion which is of $58.18 \%$ in the unconstrained image and $56.78 \%$ in the constrained image. The unconstrained image B shows relatively similar proportions of carbonate mineral mixtures as the constrained image B. These classified images are dominated by carbonate abundances of 50C-50D, but the proportions of this carbonate mineral are about $9 \%$ higher in the constrained image than the unconstrained image. The unconstrained and constrained images $\mathrm{C}$ classify the same dominant mineral abundance, which is abundant 100D of around $69 \%$. However, the small proportion of abundant 75C-25D (Red pixels, Figure 4.8c) is unclassified in the constrained image C. The unconstrained and constrained images $\mathrm{D}$ are constituted mainly by abundant $100 \mathrm{D}$ and abundant $25 \mathrm{C}-75 \mathrm{D}$, whereas the proportions of abundant $100 \mathrm{D}$ are around $5 \%$ higher in the unconstrained image than the constrained image. In addition, although both unmixing algorithms identify the presence of small abundant $100 \mathrm{C}$ in the images $\mathrm{D}$, these approaches estimate the abundant $100 \mathrm{C}$ in different proportions, which are $1.41 \%$ for the unconstrained image and $0.04 \%$ for the constrained image.

\subsubsection{Comparison of the image classification approaches}

Figure 4.9 shows comparison of the relative estimated abundance of carbonate mineral mixtures on the rock samples derived from the classified images (Figures 4.6a, $4.7 \mathrm{a}, \mathrm{c}$ and $4.8 \mathrm{a}, \mathrm{c})$ by applying various spectral recognition methods. It shows that the proportion estimation of these minerals varies between the spectral classification approaches (Figure 4.9), but overall the classified mineral distributions on the rock samples are almost at the same general areas (Figures 4.6a, 4.7a,c and 4.8a,c).

The wavelength position analysis approach of the SisuCHEMA image spectra well characterizes the carbonate mineral mixtures and estimates the proportions of these carbonate minerals on the rock surfaces. In comparison to the wavelength position classifier, the SAM and LSU algorithms tend to produce some misclassified and unclassified pixels of carbonate mineral mixtures (Figures 4.7a,c and 4.8a,c). The small abundant 100C in the images B and D (Figure 4.7a,c) is to be unclassified by the SAM algorithm. These small proportions of unclassified pixels from the SAM and LSU results are excluded from comparison of the classification methods. Hence, we only consider and analyze the proportions of five carbonate mineral mixtures consisted of $100 \mathrm{C}, 75 \mathrm{C}-25 \mathrm{D}, 50 \mathrm{C}-50 \mathrm{D}$, 25C-75D, and 100D for comparison and accuracy assessment of these classification methods. 
(a) Sample A

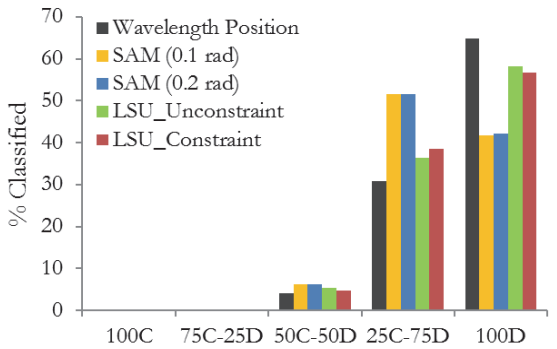

(c) Sample C

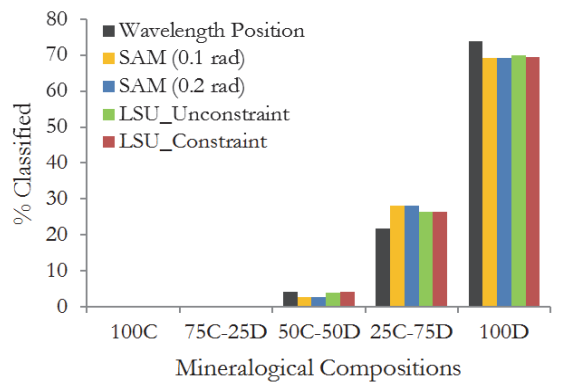

(b) Sample B

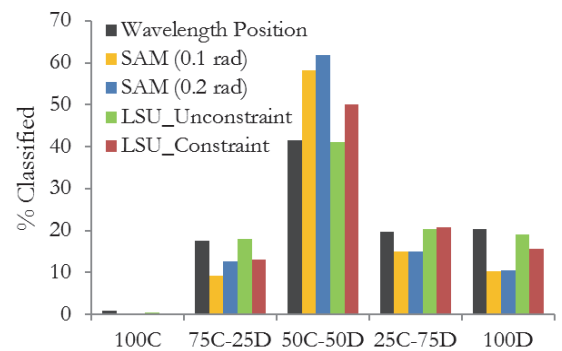

(d) Sample D

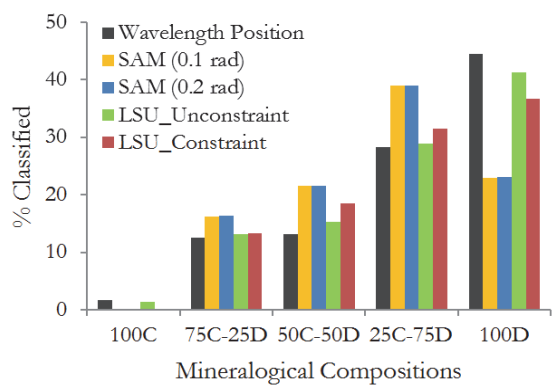

Figure 4.9: Histograms comparing proportion estimation of carbonate mineral mixtures of three spectral analysis techniques applied to the selected SisuCHEMA images. Samples (a) A, (b) B, (c) C, and (d) D. Classification results of carbonate mineral abundances differ slightly from one approach to another for a given image.

The proportions of carbonate mineral mixtures of $25 \mathrm{C}-75 \mathrm{D}$ and $100 \mathrm{D}$ estimated from the SAM results of images A differ approximately $21 \%$ and $23 \%$ from the wavelength position classification result, respectively (Figure $4.9 \mathrm{a}$ ). The proportion differences of these carbonate compositions in images A result in around $6 \%$ for the unconstrained and $8 \%$ for constrained LSU methods, as compared to the wavelength position result (Figure 4.9a). The resulting proportion of 50C-50D from the SAM results of images $\mathrm{B}$ differs roughly $17 \%$ from the wavelength position result, and the unconstrained and constrained LSU results exhibit a difference of $0.30 \%$ and $8.67 \%$, respectively (Figure 4.9b). The proportions of carbonate mineral mixtures derived from the SAM and LSU results of images $C$ are nearly the same as the wavelength position result (Figure 4.9c). SAM classification results of images D illustrate that the proportions of $25 \mathrm{C}-75 \mathrm{D}$ and $100 \mathrm{D}$ differ approximately $11 \%$ and $21 \%$ from the wavelength position result, respectively, while the proportion differences of these compositions in images D result in less than 3\% for the unconstrained and 7\% for constrained LSU methods (Figure $4.9 d)$. 
Table 4.2: Confusion matrix of the classified carbonate mineral mixtures by comparing spectral angle mapper (SAM) and linear spectral unmixing (LSU) results with wavelength position results. Samples (a) A, (b) B, (c) C, and (d) D. (C = calcite and D = dolomite, prefix numbers showing the mineral contents in percent).

\section{(a) Sample A}

$\operatorname{SAM}(0.1 \mathrm{rad})$

\begin{tabular}{|c|r|r|r|r|r|}
\hline & $100 \mathrm{C}$ & $75 \mathrm{C}-25 \mathrm{D}$ & $50 \mathrm{C}-50 \mathrm{D}$ & $25 \mathrm{C}-75 \mathrm{D}$ & $100 \mathrm{D}$ \\
\hline $100 \mathrm{C}$ & 0 & 0 & 0 & 0 & 0 \\
\hline $75 \mathrm{C}-25 \mathrm{D}$ & 0 & 30.77 & 0 & 0 & 0 \\
\hline $50 \mathrm{C}-50 \mathrm{D}$ & 0 & 69.23 & 68.82 & 10.26 & 0.34 \\
\hline $25 \mathrm{C}-75 \mathrm{D}$ & 0 & 0 & 24.12 & 71.35 & 44.40 \\
\hline $100 \mathrm{D}$ & 0 & 0 & 7.07 & 18.39 & 55.26 \\
\hline \multicolumn{7}{|c|}{ Overall classification accuracy: $60.74 \%$} \\
\hline
\end{tabular}

$\operatorname{SAM}(0.2 \mathrm{rad})$

\begin{tabular}{|c|r|r|r|r|r|}
\hline & $100 \mathrm{C}$ & $75 \mathrm{C}-25 \mathrm{D}$ & $50 \mathrm{C}-50 \mathrm{D}$ & $25 \mathrm{C}-75 \mathrm{D}$ & $100 \mathrm{D}$ \\
\hline $100 \mathrm{C}$ & 0 & 0 & 0 & 0 & 0 \\
\hline $75 \mathrm{C}-25 \mathrm{D}$ & 0 & 30.77 & 0 & 0 & 0.01 \\
\hline $50 \mathrm{C}-50 \mathrm{D}$ & 0 & 69.23 & 68.09 & 10.20 & 0.34 \\
\hline $25 \mathrm{C}-75 \mathrm{D}$ & 0 & 0 & 23.86 & 70.90 & 44.31 \\
\hline $100 \mathrm{D}$ & 0 & 0 & 8.05 & 18.90 & 55.34 \\
\hline \multicolumn{5}{|c|}{ Overall classification accuracy: $60.64 \%$} \\
\hline
\end{tabular}

\section{(b) Sample B}

$\operatorname{SAM}(0.1 \mathrm{rad})$

\begin{tabular}{|c|r|r|r|r|r|}
\hline & $100 \mathrm{C}$ & $75 \mathrm{C}-25 \mathrm{D}$ & $50 \mathrm{C}-50 \mathrm{D}$ & $25 \mathrm{C}-75 \mathrm{D}$ & $100 \mathrm{D}$ \\
\hline $100 \mathrm{C}$ & 0 & 0 & 0 & 0 & 0 \\
\hline $75 \mathrm{C}-25 \mathrm{D}$ & 96.00 & 54.57 & 4.78 & 0.03 & 0 \\
\hline $50 \mathrm{C}-50 \mathrm{D}$ & 4.00 & 45.43 & 93.20 & 71.48 & 6.22 \\
\hline $25 \mathrm{C}-75 \mathrm{D}$ & 0 & 0 & 2.00 & 25.81 & 45.10 \\
\hline $100 \mathrm{D}$ & 0 & 0 & 0.02 & 2.67 & 48.68 \\
\hline \multicolumn{7}{|c|}{ Overall classification accuracy: 63.47\% } \\
\hline \multicolumn{7}{|c}{} \\
\hline
\end{tabular}

$\operatorname{SAM}(0.2 \mathrm{rad})$

\begin{tabular}{|c|r|r|r|r|r|}
\hline & $100 \mathrm{C}$ & $75 \mathrm{C}-25 \mathrm{D}$ & $50 \mathrm{C}-50 \mathrm{D}$ & $25 \mathrm{C}-75 \mathrm{D}$ & $100 \mathrm{D}$ \\
\hline $100 \mathrm{C}$ & 0 & 0 & 0 & 0 & 0 \\
\hline $75 \mathrm{C}-25 \mathrm{D}$ & 94.04 & 55.54 & 4.94 & 0.03 & 0 \\
\hline $50 \mathrm{C}-50 \mathrm{D}$ & 5.96 & 44.46 & 93.10 & 71.44 & 6.16 \\
\hline $25 \mathrm{C}-75 \mathrm{D}$ & 0 & 0 & 1.93 & 25.73 & 44.68 \\
\hline $100 \mathrm{D}$ & 0 & 0 & 0.03 & 2.79 & 49.16 \\
\hline \multicolumn{7}{|c|}{ Overall classification accuracy: 63.41\% } \\
\hline
\end{tabular}

LSU (Unconstraint)

\begin{tabular}{|c|r|r|r|r|r|}
\hline & $100 \mathrm{C}$ & $75 \mathrm{C}-25 \mathrm{D}$ & $50 \mathrm{C}-50 \mathrm{D}$ & $25 \mathrm{C}-75 \mathrm{D}$ & $100 \mathrm{D}$ \\
\hline $100 \mathrm{C}$ & 0 & 0 & 0 & 0 & 0 \\
\hline $75 \mathrm{C}-25 \mathrm{D}$ & 0 & 53.85 & 2.58 & 0.02 & 0 \\
\hline $50 \mathrm{C}-50 \mathrm{D}$ & 0 & 30.77 & 37.84 & 8.84 & 1.50 \\
\hline $25 \mathrm{C}-75 \mathrm{D}$ & 0 & 15.38 & 57.60 & 59.20 & 24.18 \\
\hline $100 \mathrm{D}$ & 0 & 0 & 1.98 & 31.94 & 74.32 \\
\hline \multicolumn{5}{|c|}{ Overall classification accuracy: 68.12\% } \\
\hline
\end{tabular}

\section{LSU (Constraint)}

\begin{tabular}{|c|r|r|r|r|r|}
\hline & $100 \mathrm{C}$ & $75 \mathrm{C}-25 \mathrm{D}$ & $50 \mathrm{C}-50 \mathrm{D}$ & $25 \mathrm{C}-75 \mathrm{D}$ & $100 \mathrm{D}$ \\
\hline $100 \mathrm{C}$ & 0 & 0 & 0 & 0 & 0 \\
\hline $75 \mathrm{C}-25 \mathrm{D}$ & 0 & 15.38 & 0.15 & 0 & 0 \\
\hline $50 \mathrm{C}-50 \mathrm{D}$ & 0 & 76.92 & 53.50 & 6.70 & 0.58 \\
\hline $25 \mathrm{C}-75 \mathrm{D}$ & 0 & 7.69 & 45.14 & 64.27 & 25.84 \\
\hline $100 \mathrm{D}$ & 0 & 0 & 1.22 & 29.03 & 73.58 \\
\hline \multicolumn{5}{|c|}{ Overall classification accuracy: $69.83 \%$} \\
\hline
\end{tabular}

LSU (Unconstraint)

\begin{tabular}{|c|r|r|r|r|r|}
\hline & $100 \mathrm{C}$ & $75 \mathrm{C}-25 \mathrm{D}$ & $50 \mathrm{C}-50 \mathrm{D}$ & $25 \mathrm{C}-75 \mathrm{D}$ & $100 \mathrm{D}$ \\
\hline $100 \mathrm{C}$ & 5.60 & 2.65 & 0.02 & 0 & 0 \\
\hline $75 \mathrm{C}-25 \mathrm{D}$ & 88.80 & 66.41 & 14.16 & 0.93 & 0.09 \\
\hline $50 \mathrm{C}-50 \mathrm{D}$ & 4.80 & 30.36 & 68.33 & 36.78 & 2.36 \\
\hline $25 \mathrm{C}-75 \mathrm{D}$ & 0.80 & 0.57 & 16.47 & 45.45 & 21.61 \\
\hline $100 \mathrm{D}$ & 0 & 0 & 1.03 & 16.83 & 75.93 \\
\hline \multicolumn{7}{|c|}{ Overall classification accuracy: $64.49 \%$} \\
\hline
\end{tabular}

LSU (Constraint)

\begin{tabular}{|c|r|r|r|r|r|}
\hline & $100 \mathrm{C}$ & $75 \mathrm{C}-25 \mathrm{D}$ & $50 \mathrm{C}-50 \mathrm{D}$ & $25 \mathrm{C}-75 \mathrm{D}$ & $100 \mathrm{D}$ \\
\hline $100 \mathrm{C}$ & 4.58 & 0.40 & 0 & 0 & 0 \\
\hline $75 \mathrm{C}-25 \mathrm{D}$ & 90.20 & 56.93 & 5.23 & 0.19 & 0 \\
\hline $50 \mathrm{C}-50 \mathrm{D}$ & 4.58 & 42.57 & 82.02 & 41.28 & 2.43 \\
\hline $25 \mathrm{C}-75 \mathrm{D}$ & 0.65 & 0.11 & 12.65 & 51.43 & 26.76 \\
\hline $100 \mathrm{D}$ & 0 & 0 & 0.09 & 7.10 & 70.81 \\
\hline \multicolumn{5}{|c|}{ Overall classification accuracy: 68.55\% } \\
\hline
\end{tabular}


Table 4.2: (continued)

(c) Sample C

SAM (0.1 rad)

\begin{tabular}{|c|r|r|r|r|r|}
\hline & $100 \mathrm{C}$ & $75 \mathrm{C}-25 \mathrm{D}$ & $50 \mathrm{C}-50 \mathrm{D}$ & $25 \mathrm{C}-75 \mathrm{D}$ & $100 \mathrm{D}$ \\
\hline $100 \mathrm{C}$ & 0 & 0 & 0 & 0 & 0 \\
\hline $75 \mathrm{C}-25 \mathrm{D}$ & 0 & 50.00 & 0.31 & 0 & 0 \\
\hline $50 \mathrm{C}-50 \mathrm{D}$ & 0 & 50.00 & 35.31 & 5.03 & 0.10 \\
\hline $25 \mathrm{C}-75 \mathrm{D}$ & 0 & 0 & 59.84 & 74.67 & 12.70 \\
\hline $100 \mathrm{D}$ & 0 & 0 & 4.53 & 20.31 & 87.20 \\
\hline \multicolumn{7}{|c|}{ Overall classification accuracy: 82.31\% } \\
\hline
\end{tabular}

$\operatorname{SAM}(0.2 \mathrm{rad})$

\begin{tabular}{|c|r|r|r|r|r|}
\hline & $100 \mathrm{C}$ & $75 \mathrm{C}-25 \mathrm{D}$ & $50 \mathrm{C}-50 \mathrm{D}$ & $25 \mathrm{C}-75 \mathrm{D}$ & $100 \mathrm{D}$ \\
\hline $100 \mathrm{C}$ & 0 & 0 & 0 & 0 & 0 \\
\hline $75 \mathrm{C}-25 \mathrm{D}$ & 0 & 47.37 & 0.31 & 0 & 0 \\
\hline $50 \mathrm{C}-50 \mathrm{D}$ & 0 & 47.37 & 35.31 & 5.03 & 0.10 \\
\hline $25 \mathrm{C}-75 \mathrm{D}$ & 0 & 0 & 59.84 & 74.67 & 12.70 \\
\hline $100 \mathrm{D}$ & 0 & 5.26 & 4.53 & 20.31 & 87.20 \\
\hline \multicolumn{7}{|c|}{ Overall classification accuracy: $82.31 \%$} \\
\hline
\end{tabular}

(d) Sample D

SAM (0.1 rad)

\begin{tabular}{|c|r|r|r|r|r|}
\hline & $100 \mathrm{C}$ & $75 \mathrm{C}-25 \mathrm{D}$ & $50 \mathrm{C}-50 \mathrm{D}$ & $25 \mathrm{C}-75 \mathrm{D}$ & $100 \mathrm{D}$ \\
\hline $100 \mathrm{C}$ & 0 & 0 & 0 & 0 & 0 \\
\hline $75 \mathrm{C}-25 \mathrm{D}$ & 100 & 95.32 & 21.11 & 0.09 & 0 \\
\hline $50 \mathrm{C}-50 \mathrm{D}$ & 0 & 4.68 & 66.41 & 38.03 & 3.66 \\
\hline $25 \mathrm{C}-75 \mathrm{D}$ & 0 & 0 & 12.34 & 59.20 & 46.50 \\
\hline $100 \mathrm{D}$ & 0 & 0 & 0.15 & 2.68 & 49.84 \\
\hline \multicolumn{7}{|c|}{ Overall classification accuracy: 59.48\% } \\
\hline
\end{tabular}

$\operatorname{SAM}(0.2 \mathrm{rad})$

\begin{tabular}{|c|r|r|r|r|r|}
\hline & $100 \mathrm{C}$ & $75 \mathrm{C}-25 \mathrm{D}$ & $50 \mathrm{C}-50 \mathrm{D}$ & $25 \mathrm{C}-75 \mathrm{D}$ & $100 \mathrm{D}$ \\
\hline $100 \mathrm{C}$ & 0 & 0 & 0 & 0 & 0 \\
\hline $75 \mathrm{C}-25 \mathrm{D}$ & 100 & 95.28 & 21.16 & 0.11 & 0 \\
\hline $50 \mathrm{C}-50 \mathrm{D}$ & 0 & 4.72 & 66.30 & 37.93 & 3.65 \\
\hline $25 \mathrm{C}-75 \mathrm{D}$ & 0 & 0 & 12.35 & 59.06 & 46.45 \\
\hline $100 \mathrm{D}$ & 0 & 0 & 0.19 & 2.90 & 49.89 \\
\hline \multicolumn{7}{|c|}{ Overall classification accuracy: 59.48\% } \\
\hline
\end{tabular}

LSU (Unconstraint)

\begin{tabular}{|c|r|r|r|r|r|}
\hline & 100C & $75 \mathrm{C}-25 \mathrm{D}$ & $50 \mathrm{C}-50 \mathrm{D}$ & $25 \mathrm{C}-75 \mathrm{D}$ & $100 \mathrm{D}$ \\
\hline $100 \mathrm{C}$ & 0 & 0 & 0 & 0 & 0 \\
\hline $75 \mathrm{C}-25 \mathrm{D}$ & 0 & 0 & 0.31 & 0.03 & 0 \\
\hline $50 \mathrm{C}-50 \mathrm{D}$ & 0 & 68.42 & 41.88 & 8.37 & 0.30 \\
\hline $25 \mathrm{C}-75 \mathrm{D}$ & 0 & 31.58 & 56.25 & 71.99 & 11.16 \\
\hline $100 \mathrm{D}$ & 0 & 0 & 1.56 & 19.61 & 88.54 \\
\hline \multicolumn{7}{|c|}{ Overall classification accuracy: $82.92 \%$} \\
\hline
\end{tabular}

LSU (Constraint)

\begin{tabular}{|c|r|r|r|r|r|}
\hline & $100 \mathrm{C}$ & $75 \mathrm{C}-25 \mathrm{D}$ & $50 \mathrm{C}-50 \mathrm{D}$ & $25 \mathrm{C}-75 \mathrm{D}$ & $100 \mathrm{D}$ \\
\hline $100 \mathrm{C}$ & 0 & 0 & 0 & 0 & 0 \\
\hline $75 \mathrm{C}-25 \mathrm{D}$ & 0 & 0 & 0 & 0 & 0 \\
\hline $50 \mathrm{C}-50 \mathrm{D}$ & 0 & 94.74 & 48.13 & 8.92 & 0.22 \\
\hline $25 \mathrm{C}-75 \mathrm{D}$ & 0 & 5.26 & 50.94 & 73.47 & 11.30 \\
\hline $100 \mathrm{D}$ & 0 & 0 & 0.94 & 17.61 & 88.48 \\
\hline \multicolumn{7}{|c|}{ Overall classification accuracy: $83.45 \%$} \\
\hline
\end{tabular}

LSU (Unconstraint)

\begin{tabular}{|c|r|r|r|r|r|}
\hline & $100 \mathrm{C}$ & $75 \mathrm{C}-25 \mathrm{D}$ & $50 \mathrm{C}-50 \mathrm{D}$ & $25 \mathrm{C}-75 \mathrm{D}$ & $100 \mathrm{D}$ \\
\hline $100 \mathrm{C}$ & 26.25 & 7.73 & 0.10 & 0 & 0 \\
\hline $75 \mathrm{C}-25 \mathrm{D}$ & 61.78 & 78.03 & 17.34 & 0.16 & 0 \\
\hline $50 \mathrm{C}-50 \mathrm{D}$ & 11.97 & 13.99 & 50.75 & 20.27 & 2.25 \\
\hline $25 \mathrm{C}-75 \mathrm{D}$ & 0 & 0.25 & 30.94 & 58.11 & 18.69 \\
\hline $100 \mathrm{D}$ & 0 & 0 & 0.87 & 21.46 & 79.06 \\
\hline \multicolumn{7}{|c|}{ Overall classification accuracy: 68.43\% } \\
\hline
\end{tabular}

LSU (Constraint)

\begin{tabular}{|c|r|r|r|r|r|}
\hline & $100 \mathrm{C}$ & $75 \mathrm{C}-25 \mathrm{D}$ & $50 \mathrm{C}-50 \mathrm{D}$ & $25 \mathrm{C}-75 \mathrm{D}$ & $100 \mathrm{D}$ \\
\hline $100 \mathrm{C}$ & 0.77 & 0.20 & 0 & 0 & 0 \\
\hline $75 \mathrm{C}-25 \mathrm{D}$ & 91.19 & 82.19 & 11.14 & 0 & 0 \\
\hline $50 \mathrm{C}-50 \mathrm{D}$ & 8.05 & 17.61 & 65.57 & 23.55 & 2.17 \\
\hline 25C-75D & 0 & 0 & 23.00 & 62.70 & 24.28 \\
\hline $100 \mathrm{D}$ & 0 & 0 & 0.29 & 13.75 & 73.55 \\
\hline \multicolumn{7}{|c|}{ Overall classification accuracy: 69.31\% } \\
\hline
\end{tabular}

The overall classification accuracies of carbonate mineral mixtures using these spectral analysis approaches are illustrated in Table 4.2. The results show that the classification accuracies of LSU images are slightly higher than SAM images when compared with wavelength position images. The classification accuracies of SAM results are almost the same for both threshold angles. It also indicates that the classification accuracies of constrained LSU results improve above $1 \%$ for images A and $\mathrm{B}$ and above $0.5 \%$ for images $\mathrm{C}$ and $\mathrm{D}$ when compared with unconstrained LSU results. The classification accuracies of the carbonate mixtures in image $\mathrm{C}$ using these spectral methods are around $80 \%$, while the other classified images (images A, B, and D) show an overall accuracy around $60 \%$. 
(a)

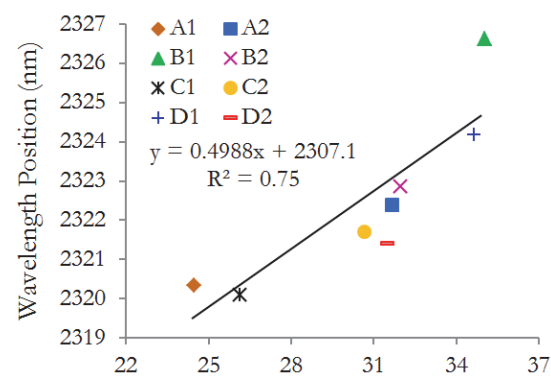

(b)

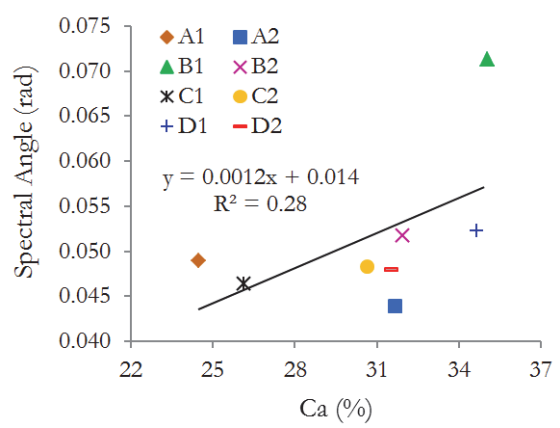

(c)

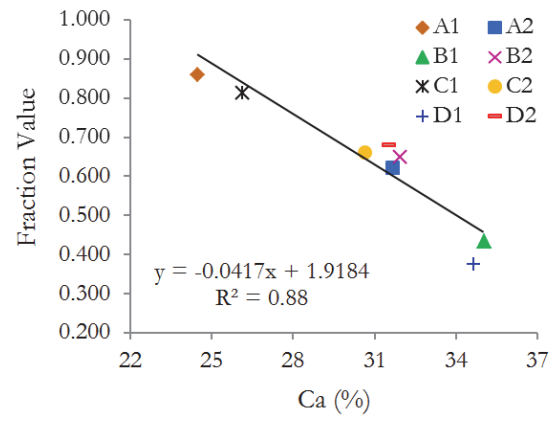

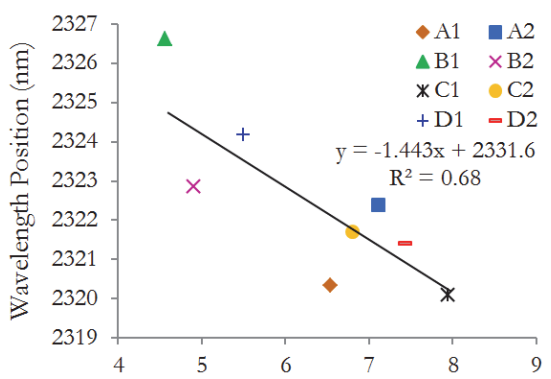
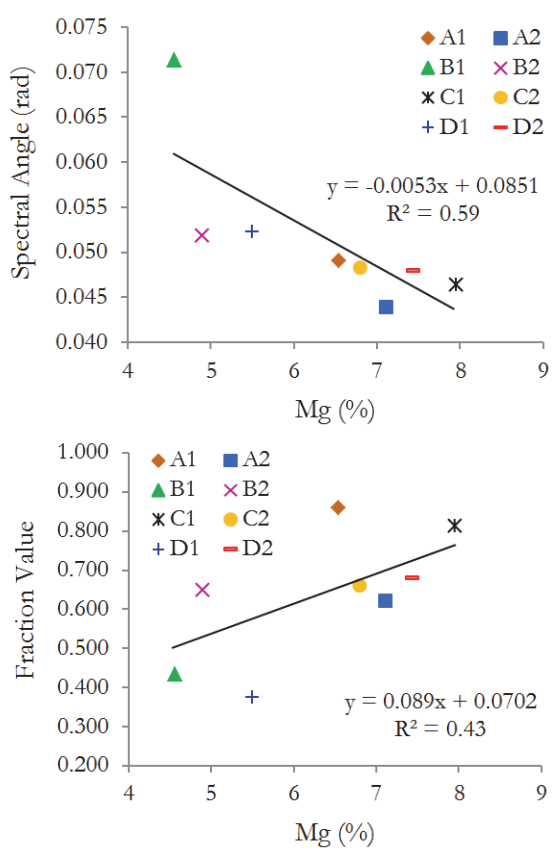

Figure 4.10: Correlation between major geochemical elements in the carbonate samples and the average of spectral parameter results of the classified images. Physical model relating $\mathrm{Ca}$ and $\mathrm{Mg}$ contents in the carbonate samples and spectral parameters derived from images classified by (a) wavelength position analysis, (b) and (c) SAM and unconstrained LSU methods for 100D images, respectively. These average spectral classification results were acquired on the same regions of interest (ROIs) of the PXRF spot measurements.

\subsubsection{PXRF geochemical analysis results}

Geochemical analysis of elements on the selected carbonate rock samples using a PXRF over two spot measurements for each sample is shown in Table 4.1. The PXRF laboratory analysis result shows that the samples contain mineralogical associations of major elements, such as $\mathrm{Ca}$ and $\mathrm{Mg}$ and trace elements such as $\mathrm{Ba}, \mathrm{Fe}, \mathrm{Al}, \mathrm{Si}, \mathrm{Cl}$, and $\mathrm{S}$ (Table 4.1). Element concentrations of $\mathrm{Sr}$ and $\mathrm{Ti}$ are mostly less than $30 \mathrm{ppm}$ and 55 ppm, respectively. These major and trace elements indicate that the rock samples are 
dominated by carbonate minerals with various compositions of mineral mixtures. Low concentrations of the trace elements such as $\mathrm{Fe}, \mathrm{Al}, \mathrm{Si}$, and $\mathrm{S}$ (Table 4.1) give possibly an indication of iron oxide, clay and sulfate mineral associations in the carbonate rocks.

It can also be seen on the correlation between major elemental concentrations and average spectral classification results (Figure 4.10) derived from the regions of interest (ROIs) of the classified images (Figures 4.6a, 4.7a and 4.8a) over the same areas as PXRF spot measurements (Figure 4.3). As illustrated in Figure 10a, an approximate linear relationship is observed between chemical contents and average wavelength positions of the classified images. However, some relationships between chemical contents and average spectral angles of SAM and fraction values of LSU are poorer than the former for both 100C and 100D images (Figure 4.10b,c and Table 4.3). Although there is a well-fitted correlation of $\mathrm{Ca}$ content with average mineral spectral parameters, this relation becomes a relatively weak with $\mathrm{Mg}$ content in the samples.

Table 4.3: Summary of the linear regression results from SAM and LSU classifications of images on the major geochemical elements $(\mathrm{Ca}$ and $\mathrm{Mg})$ in carbonate samples. Note that the average spectral classification results were acquired on the same regions of interest (ROIs) of the PXRF spot measurements.

\begin{tabular}{ccccccc}
\hline \multirow{2}{*}{$\begin{array}{c}\text { Spectral } \\
\text { Parameters }\end{array}$} & Classification & & \multicolumn{5}{c}{ Geochemical Parameters } \\
\cline { 4 - 7 } & Methods & Classified Images & & $\mathrm{Ca}$ & $\mathrm{Mg}$ \\
\cline { 4 - 7 } & & & $\mathrm{R}^{2}$ & Regression Equation & $\mathrm{R}^{2}$ & Regression Equation \\
\hline Spectral angle & SAM (0.1 rad) & $100 \mathrm{C}$ & 0.88 & $\mathrm{y}=-0.0031 \mathrm{x}+0.1795$ & 0.44 & $\mathrm{y}=0.0066 \mathrm{x}+0.0417$ \\
\hline Fraction value & LSU-Unconstraint & $100 \mathrm{C}$ & 0.70 & $\mathrm{y}=0.0231 \mathrm{x}-0.4855$ & 0.64 & $\mathrm{y}=-0.0674 \mathrm{x}+0.6541$ \\
\hline Fraction value & LSU-Constraint & $100 \mathrm{C}$ & 0.54 & $\mathrm{y}=0.0196 \mathrm{x}-0.4041$ & 0.61 & $\mathrm{y}=-0.0634 \mathrm{x}+0.6026$ \\
\hline Fraction value & LSU-Constraint & $100 \mathrm{D}$ & 0.91 & $\mathrm{y}=-0.037 \mathrm{x}+1.8083$ & 0.50 & $\mathrm{y}=0.0835 \mathrm{x}+0.1404$ \\
\hline
\end{tabular}

The average band positions shift towards longer wavelength in the SWIR region with increasing $\mathrm{Ca}$ content, but the average band positions shift towards shorter wavelength in the SWIR with increasing Mg content (Figure 4.10a). It reveals that the wavelength positions depend on $\mathrm{Ca}$ and $\mathrm{Mg}$ contents in the samples. Definite patterns are not observed between the spectral angles of 100D rule images and $\mathrm{Ca}$ and $\mathrm{Mg}$ contents (Figure 4.10b). The average dolomite abundances (fraction values) of the unconstrained unmixing 100D images decrease with increasing $\mathrm{Ca}$ content and vice versa for $\mathrm{Mg}$ content (Figure 4.10c). It indicates that higher fractions represent the dominancy of dolomite, which is related to increasing $\mathrm{Mg}$ content in the samples.

\subsection{Discussions}

Results of this study indicated that differences in carbonate mineral mixtures identification and proportion estimation of these minerals of the rock samples depend on spectral classification approaches, user-selected parameters, and match between reference spectra and image spectra (Figure 4.9). However, the overall spatial 
distribution of carbonate mineral mixtures classified by the three spectral analysis approaches (Figures 4.6a, 4.7a,c and 4.8a,c) has nearly the same pattern on the rock surfaces. Geochemical results analysis also demonstrated a high correlation between chemical contents and spectroscopic results, proving various compositional mineral mixtures identification in the samples (Figure 4.10 and Table 4.3).

The absorption wavelength position analysis approach is sensitive to slight changes of carbonate minerals composition, even in areas with "noisier" spectral responses. The accurate determination of wavelength position improves by applying a polynomial fit to the continuum-removed spectra (Murphy et al., 2014; Rodger et al., 2012). It should be noted that absorption features of the SWIR carbonate spectra may be affected by the result of varying grain sizes (Crowley, 1986; Gaffey, 1986; van der Meer, 1995; Zaini et al., 2012), weathering, and mixing with organic matters forming a coating on carbonate particles (Crowley, 1986; van der Meer, 1995) and iron (Gaffey, 1986; van der Meer, 1995) in carbonate samples. Nevertheless, the wavelength position approach can identify carbonate mineral mixtures based on spectral characteristics. Thus, occurrence of prominent absorption feature in the SWIR spectra around 2300-2350 nm due to vibrational processes of the carbonate ions $\left(\mathrm{CO}_{3}^{2-}\right)$ (Clark et al., 1990; Gaffey, 1986; Hunt \& Salisbury, 1971; van der Meer, 1995) can be used to distinguish carbonate mineral mixtures in the rock samples (Clark et al., 1990; Gaffey, 1986; Hunt \& Salisbury, 1971; van der Meer, 1995; Zaini et al., 2012). The band positions of both pure and mixed calcite and dolomite are centered within the range of carbonate wavelength positions observed in previous studies (Clark et al., 1990; Gaffey, 1986; Hunt \& Salisbury, 1971; van der Meer, 1995; Zaini et al., 2012). The carbonate mixture band positions are determined by the quantity of calcite and dolomite in the samples (van der Meer, 1995; Zaini et al., 2012).

The outcome of SAM and LSU classification methods demonstrates a number of misclassified and unclassified pixels of carbonate mineral mixtures (Figures 4.7 and 4.8), as compared to wavelength position approach (Figure 4.6). This may contribute to the difficulty in proportion estimation of carbonate mineral mixtures on the rock surfaces (Figure 4.9). Most probably it could be due to the spectral shape similarities of endmembers used for classification (Figure 4.5) or omitted endmember from analysis and mismatches between spectral endmembers and spectra of image pixels. As depicted in Table 4.2, the overall classification accuracies of LSU images are slightly higher than SAM images. SAM algorithms were relatively poor in accuracy to discriminate carbonate mineral mixtures between 100D and 25C-75D and between 100C and 75C-25D. These misclassifications may be influenced by very similar shape of the endmember spectra although their band positions of absorption features are centered at a slightly different wavelength. Previous studies have also described that SAM algorithm is not searching for diagnostic mineral absorption features, but it depends on average match of the entire reference spectra (Hecker et al., 2008; van der Meer, 2006) and it is insensitive to illumination and albedo differences (Aspinall et al., 2002; Hecker et al., 2008; Murphy et al., 2012; van der Meer, 2006). 
Furthermore, despite the fact that the shape of spectral endmembers of pure calcite and dolomite is similar to each other with a slight shift absorption band position, the unconstrained and constrained LSU algorithms provide a good agreement in carbonate mineral mixtures identification on the selected SisuCHEMA images. It indicated that the unknown spectrum at each pixel of the images may be formed by a linear combination of the reference spectrum or endmember. The results of linear unmixing processes depend on the combination of the correlation between spectral minerals forming the mixture and the endmembers used in analysis (Kruse, Lefkoff, \& Dietz, 1993; van der Meer \& de Jong, 2000). Generally the LSU algorithms show a relative similar mineral mixtures distribution and proportion estimation of carbonate compositions to wavelength position approach. The constrained LSU results achieved slightly higher classification accuracies than the unconstrained LSU results, by comparing with wavelength position results. The differences in overall classification accuracy may be linked to more unclassified pixels in the unconstrained results, particularly in the images B and D (Figure 4.8a). However, wavelength position analysis and LSU classification methods require knowledge of spectral mixture characteristics and further preprocessing of the data to estimate the proportion of the mixed minerals on the selected SisuCHEMA images.

The PXRF geochemical analysis results of the rock samples (Table 4.1) also confirm and prove the presence of carbonate mineral mixtures with various compositions. As the major element concentrations of $\mathrm{Ca}$ and $\mathrm{Mg}$ are lower than their stoichiometric values in pure calcite and dolomite. These major and trace elements can help to characterize mineralogic assemblages of carbonate rocks, which agree with results of previous studies (Barber, 1974; Robinson, 1980; Thompson et al., 1970; Wolf et al., 1967). The results from Figure 4.10 and Table 4.3 show that using the wavelength of minimum absorption through the wavelength position approach provides the best predictive value for inverting $\mathrm{Ca}$ and $\mathrm{Mg}$ chemistry to spectral parameters. Both the spectral angle (through SAM) and the fractional abundance (through LSU) overall performance is poorer than wavelength position approach. However, they showed acceptable results for individual chemical elements inversion. It should be noted that the LSU outperforms the SAM. This is attributed to the fact that the endmembers used are correlated and this works in favor of the LSU algorithm, which uses this dependency while the SAM assumes the endmembers are independent. In other words, in SAM endmembers are tested one at the time against pixel spectra, but in LSU all endmembers are used simultaneously in the inversion of the model. It can be envisaged that if the collinearity between the endmembers decreases by including more endmembers or less correlated endmembers (van der Meer \& Jia, 2012) and this improves the performance of LSU over SAM although in the present study this could not be tested. As a result, the finding of this study could be implemented to determine naturally mixed minerals and estimate the proportions of minerals on rock surfaces using laboratory-based hyperspectral data, confirming results of previous studies (Baissa et al., 2011; Haest et al., 2012a, 2012b; Murphy et al., 2014). 


\subsection{Conclusions}

This study for the first time presents the use of SisuCHEMA hyperspectral imagery to identify the chemical composition of naturally mixed minerals and estimate the relative mineral abundances in hand specimens of carbonate rocks. We demonstrate how to derive the chemical composition (Ca-Mg ratio) of carbonate minerals at a pixel (e.g., sub-grain) level using spectral analysis methods from the image pixel spectra. Classified images created using wavelength position, spectral angle mapper (SAM), and linear spectral unmixing (LSU) were used to spatially map calcite-dolomite mixtures with various carbonate mineral compositions and proportions. The wavelength position approach enables to determine all compositional variations of carbonate mineral mixtures in the rock samples when compared to the SAM and LSU approaches.

The relationship between major geochemical elements $(\mathrm{Ca}$ and $\mathrm{Mg})$ and average spectral parameters (wavelength position, spectral angle of SAM, and fraction value of LSU) also proves the presence of various carbonate mixtures with different mineralogical compositions on the rock surfaces. Our study indicates that the wavelength position approach is a more stable, standardized and reproducible technique for determining the carbonate mineral chemistry from the image pixel spectra than the SAM and LSU methods. For future research, the established correlation between geochemical elements and wavelength position (physical models) can be used for inverse modeling of hyperspectral imagery in estimating the chemical composition of carbonate minerals on rock surfaces. In a practical sense, understanding of the carbonate mineral chemistry contributes to the developing a frame-work for the cement industry in assessing the purity and the chemical composition of carbonate minerals. 
5. An alternative quality control technique for mineral chemistry analysis of Portland cement-grade limestone using shortwave infrared spectroscopy ${ }^{4}$

\footnotetext{
${ }^{4}$ This chapter has been published as: Zaini, N., van der Meer, F., van Ruitenbeek, F., de Smeth, B., Amri, F., Lievens, C., 2016. An alternative quality control technique for mineral chemistry analysis of Portland cement-grade limestone using shortwave infrared spectroscopy. Remote Sensing 8, 950.
} 


\subsection{Introduction}

The manufacturing process and quality of Portland cement are directly controlled by the chemistry of the raw materials used. Therefore, it is essential to select raw materials that have the correct chemical composition. The composition and properties of Portland cement clinker show that it is made by blending different raw materials, which are predominantly a mix of calcareous and argillaceous materials (Chatterjee, 1983; Ghosh, 1983; Meade, 1926; Taylor, 1997). To correct any desired composition deficiencies, it may be necessary to add minor proportions of additive or corrective constituents, which may be a siliceous, aluminous, or ferruginous material or a combination of those materials, into the raw mix. However, the proportional estimation of the additive or corrective constituents depends on the compositional characteristics of the calcareous material as the main component in the raw mix (Chatterjee, 1983; Ghosh, 1983; Meade, 1926; Taylor, 1997).

The main naturally available calcareous material on the earth's surface, as well as the preferred source of lime or calcium oxide $(\mathrm{CaO})$ to make clinker, is limestone (Chatterjee, 1983; Ghosh, 1983; Meade, 1926; Taylor, 1997). The suitability and availability of this carbonate rock in very large amounts are vital for the production of clinker. Limestone is a sedimentary rock mostly containing calcium carbonate $\left(\mathrm{CaCO}_{3}\right)$, normally in the form of calcite (Blatt et al., 1972; Pettijohn, 1975). The rock may also contain various amounts of mineralogical associations, such as dolomite $\left(\mathrm{CaMg}\left(\mathrm{CO}_{3}\right)_{2}\right)$, siderite $\left(\mathrm{FeCO}_{3}\right)$, magnesite $\left(\mathrm{MgCO}_{3}\right)$, goethite $(\mathrm{FeO}(\mathrm{OH}))$, quartz $\left(\mathrm{SiO}_{2}\right)$, clays (kaolinite $\left(\mathrm{Al}_{2} \mathrm{Si}_{2} \mathrm{O}_{5}(\mathrm{OH})_{4}\right)$, montmorillonite $\left((\mathrm{Na}, \mathrm{Ca})_{0.33}(\mathrm{Al}, \mathrm{Mg})_{2}\left(\mathrm{Si}_{4} \mathrm{O}_{10}\right)\right)$, illite $\left.\left(\left(\mathrm{K}, \mathrm{H}_{3} \mathrm{O}\right)(\mathrm{Al}, \mathrm{Mg}, \mathrm{Fe})_{2}(\mathrm{Si}, \mathrm{Al})_{4} \mathrm{O}_{10}\left[(\mathrm{OH})_{2},\left(\mathrm{H}_{2} \mathrm{O}\right)\right]\right)\right)$, halides (fluorite $\left(\mathrm{CaF}_{2}\right)$ and halite $(\mathrm{NaCl})$ ), phosphates (hydroxylapatite $\left(\mathrm{Ca}_{5}\left(\mathrm{PO}_{4}\right)_{3} \mathrm{OH}\right)$, fluorapatite $\left(\mathrm{Ca}_{5}\left(\mathrm{PO}_{4}\right)_{3} \mathrm{~F}\right)$, and chlorapatite $\left(\mathrm{Ca}_{5}\left(\mathrm{PO}_{4}\right)_{3} \mathrm{Cl}\right)$ ), sulphates (gypsum $\left(\mathrm{CaSO}_{4} \cdot 2 \mathrm{H}_{2} \mathrm{O}\right)$, barite $\left(\mathrm{BaSO}_{4}\right)$, alunite $\left(\mathrm{KAl}_{3}\left(\mathrm{SO}_{4}\right)_{2}(\mathrm{OH})_{6}\right)$, celestite $\left.\left(\mathrm{SrSO}_{4}\right)\right)$, and sulphides (pyrite $\left(\mathrm{FeS}_{2}\right)$ and realgar $\left.\left(\mathrm{As}_{4} \mathrm{~S}_{4}\right)\right)$ (Blatt et al., 1972; Pettijohn, 1975). Moreover, the mineralogical and chemical compositions of the rock depend on its mode of origin and depositional environment (Blatt et al., 1972; Ghosh, 1983; Pettijohn, 1975), which have a definite implication on the cement manufacturing process (Ghosh, 1983). Carbonate rock that is suitable in the manufacturing of Portland cement should contain specific chemical compositions, such as $44-52 \% \mathrm{CaO}, 3-3.5 \% \mathrm{MgO}, 0.6 \%$ (maximum) $\mathrm{Na}_{2} \mathrm{O}$ and $\mathrm{K}_{2} \mathrm{O}, 0.6-0.8 \%$ (maximum) $\mathrm{SO}_{3}, 0.25-0.6 \%$ (maximum) $\mathrm{P}_{2} \mathrm{O}_{5}, 1.3 \% \mathrm{TiO}_{2}, 0.5 \% \mathrm{Mn}_{2} \mathrm{O}_{3}$, and $\mathrm{SiO}_{2}, \mathrm{Al}_{2} \mathrm{O}_{3}$, and $\mathrm{Fe}_{2} \mathrm{O}_{3}$ in proportions suitable for cement manufacturing (Chatterjee, 1983; Meade, 1926; Taylor, 1997). The occurrence of some of those minor chemical constituents and trace elements in amounts exceeding the standard, for instance, $\mathrm{MgO}, \mathrm{SO}_{3}, \mathrm{P}_{2} \mathrm{O}_{5}, \mathrm{TiO}_{2}, \mathrm{Na}_{2} \mathrm{O}$, $\mathrm{K}_{2} \mathrm{O}, \mathrm{Cl}, \mathrm{Cu}, \mathrm{Pb}, \mathrm{Zn}, \mathrm{Cr}$, and others, are deleterious to the production and utilization of clinker (Chatterjee, 1983; Galan et al., 2015; Gineys et al., 2010; Gineys et al., 2011; Horkoss et al., 2011; Ichikawa \& Kanaya, 1997; Li et al., 2014; Maki et al., 1992; Meade, 1926; Taylor, 1997, 1999). 
Various techniques have been employed to characterize and control the chemical compositions of cement materials and products. Such techniques include X-ray fluorescence (XRF) (Fernandez et al., 2011; Mazouzi et al., 2014; Wu et al., 2012), energy dispersive X-ray spectroscopy (EDS) (De Weerdt et al., 2015; Irassar et al., 2003; Pipilikaki et al., 2008; Tosun et al., 2009), electron probe microanalysis (EPMA) (Bertron et al., 2009; Ifka et al., 2014; Kurokawa et al., 2013; Taylor \& Newbury, 1984), and inductively coupled plasma optical emission spectrometer (ICP-OES) (Frias et al., 1994; Marjanovic et al., 2000; Potgieter \& Maljanovic, 2007; Silva et al., 2002). However, these methods are expensive and time consuming for sample preparation and analysis. An alternative approach that is much simpler and faster than these conventional techniques is infrared spectroscopy. This spectroscopic method uses shortwave infrared (SWIR) spectral absorption feature properties, such as the wavelength position and depth of absorption feature (Kruse, Lefkoff, \& Dietz, 1993; van der Meer, 2004), to identify and estimate the relative abundances of SWIR rangeactive minerals and their compositions suitable for the manufacturing of cement clinker from hand specimens of fresh carbonate rock surfaces. The spectroscopic method can also be combined with X-ray fluorescence (XRF) or geochemistry data to determine the chemical compositions of rocks. Infrared spectroscopy techniques have been utilized to characterize the chemistry of cement products and the hydration rate (Kocak \& Nas, 2014; Mollah et al., 2000; Perraki et al., 2010; Pipilikaki et al., 2008; Ylmen et al., 2010). However, their applications in determining the mineral chemistry and chemical compositions of cement raw materials, especially limestone or other calcareous materials, have not been completely explored. Previous studies have shown that the spectroscopic method complemented by geochemical analysis can identify and predict the composition and proportion of iron oxide and aluminum hydroxide (Al-clay) contents from drill core samples of channel iron ore (Haest et al., 2012a) and iron ore (Magendran \& Sanjeevi, 2014). Zaini et al. (2014) recently presented a laboratory hyperspectral imaging spectroscopy approach to derive the carbonate mineral chemistry or $\mathrm{Ca}-\mathrm{Mg}$ ratio from carbonate rock samples based on spectroscopic and geochemical parameters.

The SWIR reflectance spectra in the wavelength range of $1.0-2.5 \mu \mathrm{m}$ exhibit several diagnostic absorption features of mineral chemistries. These features are determined by the occurrence of hydroxyl $(\mathrm{OH})$, water $\left(\mathrm{H}_{2} \mathrm{O}\right)$, carbonate $\left(\mathrm{CO}_{3}\right)$, sulfate $\left(\mathrm{SO}_{4}\right)$, and typical cationic transitional vibrations present in phyllosilicates (e.g., $\mathrm{Al}-\mathrm{OH}$, $\mathrm{Mg}-\mathrm{OH}$, and Fe-OH bearing clay, mica and serpentine) (Clark et al., 1990; Hunt, 1977; Hunt \& Salisbury, 1970, 1971). The spectral absorption features of minerals are influenced by the chemical composition, structural arrangement, and bonding characteristics (Clark, 1999; Povarennykh, 1978; van der Meer, 1995). These spectral characteristics may allow for direct identification of surface mineralogy. Carbonate minerals, such as calcite $\left(\mathrm{CaCO}_{3}\right)$ and dolomite $\left(\mathrm{CaMg}\left(\mathrm{CO}_{3}\right)_{2}\right)$, have two distinctive absorption features in the SWIR wavelength region centered at 2.530-2.541 $\mu \mathrm{m}$ and $2.333-2.340 \mu \mathrm{m}$ and $2.503-2.520 \mu \mathrm{m}$ and $2.312-2.323 \mu \mathrm{m}$, respectively (Clark et al., 
1990; Crowley, 1986; Gaffey, 1986; Hunt \& Salisbury, 1971; Kurz et al., 2012; van der Meer, 1995; Zaini et al., 2012), due to the vibrational processes of carbonate ions $\left(\mathrm{CO}_{3}^{2-}\right)$ (Clark et al., 1990; Gaffey, 1986; Hunt \& Salisbury, 1971). The presence of clay and other phyllosilicate minerals in an intimate mixture with carbonates can be identified based on their vibrational absorption features around $2.20 \mu \mathrm{m}$ and $2.30 \mu \mathrm{m}$ (Clark et al., 1990; Hunt, 1977; Hunt \& Salisbury, 1970). These absorption features are caused by the combination of the $\mathrm{OH}$ stretch with the $\mathrm{Al}-\mathrm{OH}$ and $\mathrm{Mg}-\mathrm{OH}$ bending modes, respectively (Clark et al., 1990; Hunt, 1977; Hunt \& Salisbury, 1970).

The objective of the present chapter is to investigate the potential and accuracy of SWIR spectroscopy as an alternative quality control technique for chemical and mineralogical analyses of Portland cement-grade limestone in deriving and estimating the relative abundances and compositions of carbonate and clay mineral chemistries from carbonate rock samples. This is conducted by correlating the spectral absorption feature characteristics (wavelength position and depth of absorption feature) with a geochemical analysis of spot measurements on the rock surface.

\subsection{Materials and Methods}

\subsubsection{Carbonate rock samples}

The carbonate rock samples (Figure 5.1) used for this study were collected from two different locations, including (1) the Lhoknga limestone quarry, which is an open active limestone mine of PT. Lafarge Cement Indonesia, Aceh Besar, Indonesia. Two types of limestone samples, dark gray and light gray limestones (Figure 5.1a,b), were selected during fieldwork from 01 to 05 September 2014. The sedimentary rocks are from the Jurassic to Cretaceous-Raba Limestone formation of the Woyla group, which are composed of massive calcarenite and calcilutite and dark gray thin-bedded argillaceous and siliceous limestones (Barber \& Crow, 2005; Bennett et al., 1981). The second area is (2) the Bédarieux mining area, which is an open and partly active dolomite mine in the Hérault department of the Languedoc-Roussillon region, southern France (Zaini et al., 2014). The representative dolomitic limestone samples (Figure 5.1c) were selected during fieldwork in September 2008. These carbonate rocks are from the Jurassic-Bathomien formation, and their composition becomes sandier from west to east (Bogdanoff et al., 1984; Zaini et al., 2014). For the purpose of the present study, each carbonate rock type was grouped by five selective hand specimen samples. They consist of dark gray limestones (samples B20, B28, B33, B45, and B49), light gray limestones (samples B1, B26, B32, B36, and B41) and dolomitic limestones (samples F17, F18, F20, F23, and F26) (Figure 5.2).

\subsubsection{PXRF geochemical analysis}

The geochemical elements and oxide compositions of the selected limestone samples used for the quality control of cement raw material were analyzed using 
portable X-ray fluorescence (PXRF) with the Niton XL3t GOLDD+ from Thermo Fisher Scientific Inc. The geochemical characterizations consisted of the weight percentages of $\mathrm{CaO}, \mathrm{MgO}, \mathrm{SiO}_{2}, \mathrm{Al}_{2} \mathrm{O}_{3}, \mathrm{Fe}_{2} \mathrm{O}_{3}, \mathrm{SO}_{3}, \mathrm{~K}_{2} \mathrm{O}, \mathrm{TiO}_{2}$, and $\mathrm{P}_{2} \mathrm{O}_{5}$. To measure the carbonate rock samples, the instrument was set up using the same procedure as previous research (Zaini et al., 2014). Five PXRF spot measurements with an 8-mm diameter spot size were performed from the same locations as ASD spot measurements on both fresh surfaces of each limestone sample (Figure 5.2). The analyzer in the mining mode setting was calibrated for a silicate dominated rock matrix; hence, the $\mathrm{Ca}$ and $\mathrm{Mg}$ concentrations of pure carbonate samples showed an overestimation of up to $10 \%$ (Zaini et al., 2014). To overcome the instrument deficiency in acquiring these elemental concentrations, an inductively coupled plasma optical emission spectrometer (ICP-OES), Variant Liberty Series II, was used to correct the PXRF measurement results by analyzing some pure carbonate samples and limestone samples collected from the Lhoknga and Bédarieux mining areas, with a correction factor of 0.76 and 2.31 for the $\mathrm{Ca}$ and $\mathrm{Mg}$ PXRF values, respectively.
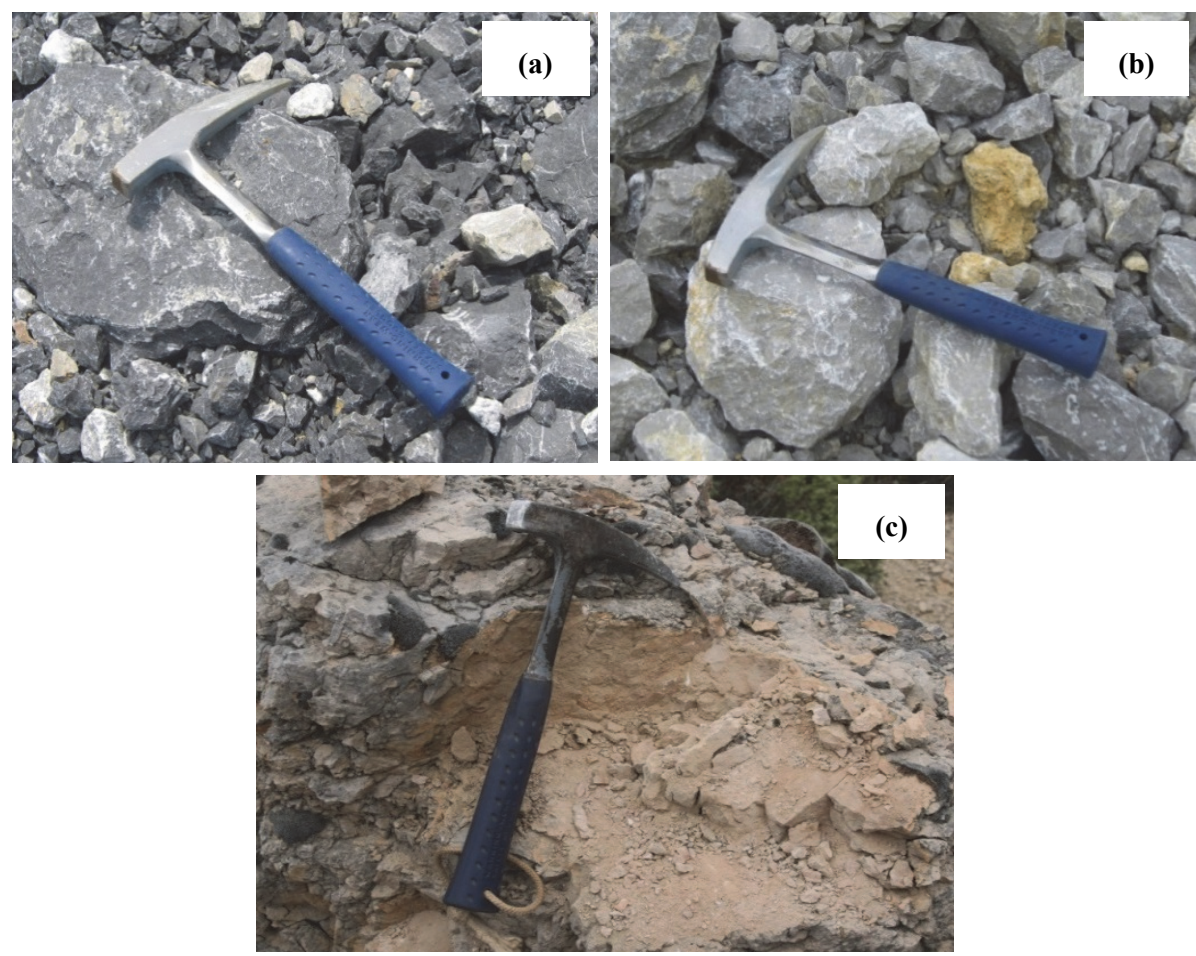

Figure 5.1: Carbonate rock samples: (a) dark gray and (b) light gray limestone samples collected from the Lhoknga limestone quarry of PT. Lafarge Cement Indonesia, Aceh Besar, Indonesia, and (c) dolomitic limestone sample collected from the Bédarieux dolomite mine, Hérault department of the Languedoc-Roussillon region, southern France. 

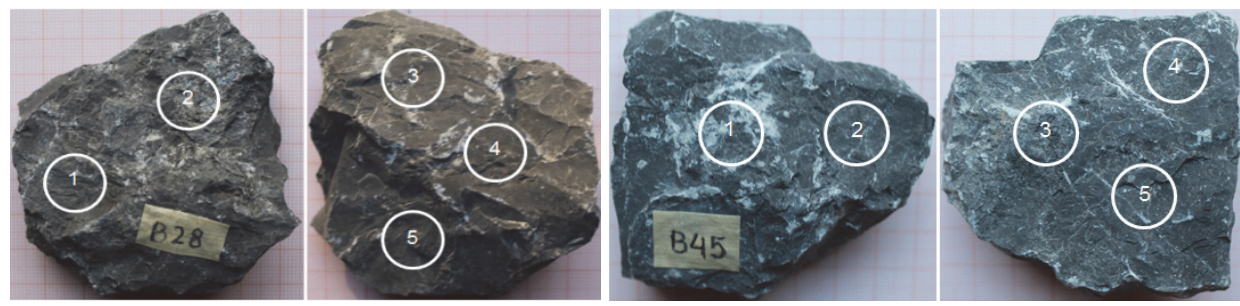

(a)
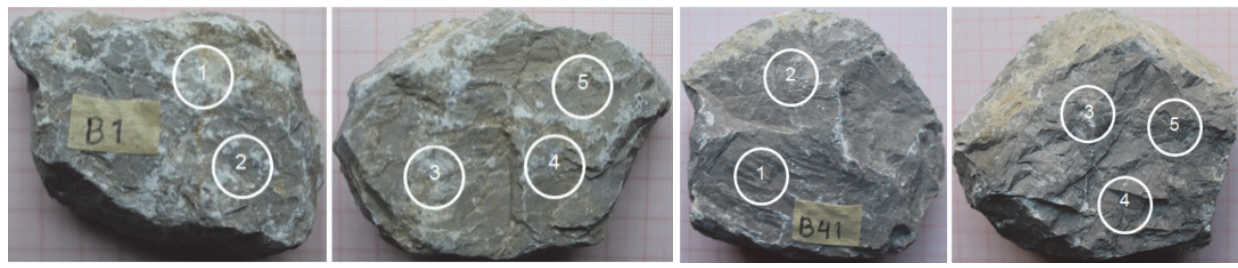

(b)
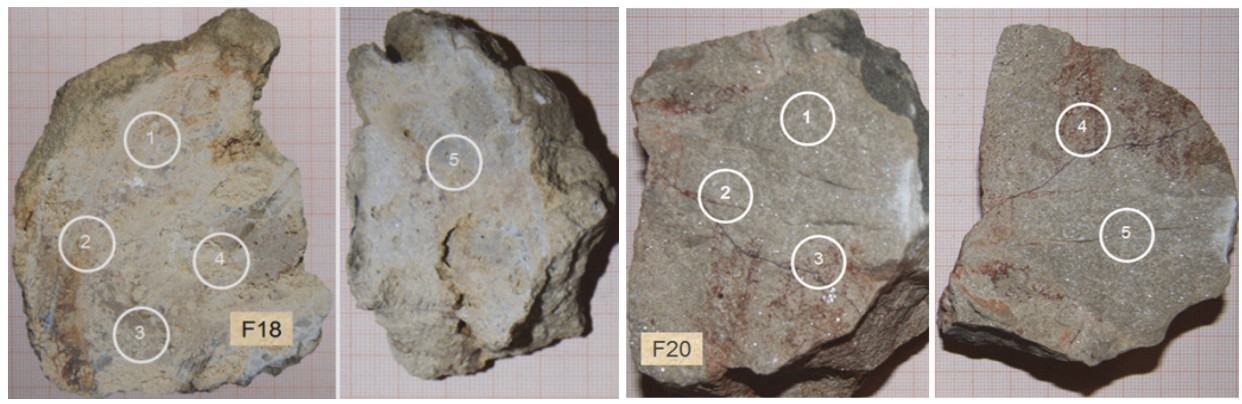

(c)

Figure 5.2: Examples of hand specimens of carbonate rock samples collected from the mines: (a) dark gray limestones (samples B28 and B45), (b) light gray limestones (samples B1 and B41) and (c) dolomitic limestones (samples F18 and F20), with white circles pointing out the locations of portable X-ray fluorescence (PXRF) and Analytical Spectral Device (ASD) spot measurements on both fresh surfaces of the rock samples.

\subsubsection{Carbonate rock spectral measurements}

A FieldSpec Pro Spectrometer from Analytical Spectral Devices (ASD) Inc., Boulder, CO, USA, was used to measure reflectance spectra of the carbonate rock samples from the visible/near infrared (VNIR) to the SWIR (350-2500 nm) wavelength regions. The spectrometer was equipped with a high-intensity light source that is integrated into a reflectance probe and a detector system, which consists of a 512channel silicon photodiode array for the VNIR spectral measurements (350-1000 nm) and a single thermoelectrically cooled indium gallium arsenide (InGaAs) detector to acquire the SWIR reflectance spectra (1000-2500 nm). A Spectralon (Labsphere, North Sutton, NH, USA) was used to calibrate the spectral measurements of each carbonate 
rock sample. The reflectance spectra of rock samples were measured using the ASD contact probe, where a probe window frame $2 \mathrm{~cm}$ in diameter was placed in direct contact with each of the five spot measurements on both fresh rock sample surfaces (Figure 5.2). Five reflectance spectra were acquired to obtain an average reflectance spectrum from each ASD spot measurement of limestone samples. A total of five average spectral data were derived from five spot measurements of each rock sample or twenty-five reflectance spectra were recorded from each carbonate rock type. Raw spectral data were corrected by applying splice correction using ViewSpecPro software. ENVI software package version 4.7 was used to build a spectral library and process the spectral data in the wavelength range of $2.100-2.400 \mu \mathrm{m}$.

\subsubsection{Determination of spectral feature parameters}

The SWIR reflectance spectra have several distinctive absorption features of surface mineralogy. These spectral features can be used to estimate the mineral abundances and chemical compositions of rock or geologic samples based on their spectral feature characteristics, such as the wavelength position and depth of absorption feature (Haest et al., 2012a; Magendran \& Sanjeevi, 2014; Murphy et al., 2014; Zaini et al., 2012, 2014). The position and depth of absorption feature were extracted from continuum-removed reflectance spectra (Clark \& Roush, 1984). The absorption wavelength position is defined as the wavelength at which the maximum absorption or minimum reflectance of an absorption feature occurred (Kruse, Lefkoff, \& Dietz, 1993; van der Meer, 2004). The depth of the absorption feature indicates the reflectance value at the shoulders minus the reflectance value at the position of the absorption wavelength (Kruse, Lefkoff, \& Dietz, 1993; van der Meer, 2004). Detailed definitions of the characteristics of the absorption feature are described in previous studies (Kruse, Lefkoff, \& Dietz, 1993; van der Meer, 2004; Zaini et al., 2012).

In this study, the carbonate $\left(\mathrm{CO}_{3}\right)$ and $\mathrm{Al}-\mathrm{OH}$ absorption features present in the SWIR reflectance spectra of limestone samples were analyzed. As mentioned previously, carbonate minerals, such as calcite $\left(\mathrm{CaCO}_{3}\right)$ and dolomite $\left(\mathrm{CaMg}\left(\mathrm{CO}_{3}\right)_{2}\right)$, and clay minerals, such as kaolinite $\left(\mathrm{Al}_{2} \mathrm{Si}_{2} \mathrm{O}_{5}(\mathrm{OH})_{4}\right)$ and illite $\left(\left(\mathrm{K}, \mathrm{H}_{3} \mathrm{O}\right)(\mathrm{Al}, \mathrm{Mg}, \mathrm{Fe})_{2}(\mathrm{Si}, \mathrm{Al})_{4} \mathrm{O}_{10}\left[(\mathrm{OH})_{2},\left(\mathrm{H}_{2} \mathrm{O}\right)\right]\right)$, have prominent vibrational absorption features in the SWIR wavelength region due to the vibrational processes of carbonate ions (Clark et al., 1990; Gaffey, 1986; Hunt \& Salisbury, 1971) and the combination of the $\mathrm{OH}$ stretch with the Al-OH and $\mathrm{Mg}-\mathrm{OH}$ bending modes (Clark et al., 1990; Hunt, 1977; Hunt \& Salisbury, 1970), respectively. Those mineral constituents are the main components of the raw materials of cement and play an important role in the manufacturing of Portland cement clinker (Chatterjee, 1983; Ghosh, 1983; Meade, 1926; Taylor, 1997). The presence of clay and other phyllosilicate minerals in selected rock samples was also confirmed using X-ray diffraction (XRD). The rock samples were pulverized and placed in acid. The acid-insoluble residue was filtered and dried and subsequently measured using the Bruker D2 Phaser XRD. However, there was very little material left after acid digestion on the powdered dolomitic limestone samples. 
The acid-insoluble residue came into contact with a filter paper and could not be separated. Hence, it yielded unreliable XRD results of clay and other phyllosilicate minerals in the dolomitic samples.

The wavelength position and depth of absorption feature of the mineral reflectance spectra were computed using Hyperspectral Python (HypPy) software package version 2.6 (Bakker, 2012). These spectral parameters were processed by following a routine procedure as described in Zaini et al. (2014). Firstly, we used a method developed by Rodger et al. (2012) to calculate wavelength position of a prominent absorption feature of carbonate $\left(\mathrm{CO}_{3}\right)$ and $\mathrm{Al}-\mathrm{OH}$ spectral features in the wavelength ranges of 2.125 $2.400 \mu \mathrm{m}$ and $2.170-2.250 \mu \mathrm{m}$, respectively. The depth of the absorption feature was determined by adapting an approach designated in previous studies (Kruse, Lefkoff, \& Dietz, 1993; van der Meer, 2004; Zaini et al., 2012). A continuum removal was then applied to the spectra within the selected wavelength range, followed by interpolation. A second-order polynomial fit was modeled to three data points of minimum reflectance in the continuum-removed spectra. The wavelength position of the minimum and depth of absorption feature were determined on the fitting polynomial curve or the resulting interpolated parabola. This process produced the wavelength position of the deepest absorption feature and the depth of the feature for each of the spectra. Finally, these spectral parameters were validated and correlated with PXRF geochemical analysis to derive the abundance and composition of the mineral chemistries from the SWIR continuum-removed spectra of the carbonate rock samples.

\subsection{Results}

\subsubsection{Geochemical characterization of the rock samples}

The geochemical characterization results of oxide compositions on the selected limestone samples over five PXRF spot measurements for each rock sample are shown in Table 5.1. The chemical analysis shows that calcium oxide $(\mathrm{CaO})$ is a major constituent, comprising approximately $50 \%$ by weight, and there is a very low amount of magnesium oxide $(\mathrm{MgO})$ in most of the Lhoknga limestone samples (samples B28, dark gray limestone and B41, light gray limestone). The results also show a significant elemental concentration of $\mathrm{SiO}_{2}$ and $\mathrm{Al}_{2} \mathrm{O}_{3}$ in the Lhoknga samples, especially the dark gray limestone sample (sample B28, Table 5.1). Thus, the quarried limestone samples contain a major amount of calcium carbonate, which is associated with clay and a mixture of other phyllosilicate minerals. In addition, the PXRF results (Table 5.1) indicate that the light gray limestone sample (sample B41) is purer than the dark gray limestone sample (sample $\mathrm{B} 28$ ) in terms of $\mathrm{CaO}, \mathrm{MgO}, \mathrm{Al}_{2} \mathrm{O}_{3}$, and $\mathrm{SiO}_{2}$ concentrations. In contrast, the selected dolomitic limestone sample from the Bédarieux dolomite mine (sample F20) contains major oxide elements of $\mathrm{CaO}$ and $\mathrm{MgO}$, with concentrations over $27 \%$ and $18 \%$ (Table 5.1), respectively. The high $\mathrm{MgO}$ concentration is attributed to a dominance of magnesium carbonate in the Bédarieux samples. The geochemical results (Table 5.1) also reveal a relative low elemental concentration of $\mathrm{SiO}_{2}$ and $\mathrm{Al}_{2} \mathrm{O}_{3}$ in the 
rock sample. Moreover, the Lhoknga and Bédarieux rock samples contain low proportions of other oxide elements, such as $\mathrm{Fe}_{2} \mathrm{O}_{3}, \mathrm{SO}_{3}, \mathrm{~K}_{2} \mathrm{O}$, and $\mathrm{TiO}_{2}$ (Table 5.1). The oxide concentration of $\mathrm{P}_{2} \mathrm{O}_{5}$ is mostly less than $0.1 \%$ for the dark gray and light gray limestone samples and almost $0 \%$ for the dolomitic limestone samples. These elements indicate possibly the presence of iron oxide, phosphate and sulfate mineral associations in the limestones. The relative abundance of mineral chemistries and compositions in the rock samples (Table 5.1) illustrate that the Lhoknga limestone samples can be specified as a good quality limestone for the manufacturing of Portland cement clinker (Chatterjee, 1983; Taylor, 1997) compared with the Bédarieux sample.

Table 5.1: Chemical composition of the selected limestone samples derived from five PXRF spot measurements on both fresh surfaces of each rock sample (wt\%) (Samples B28, dark gray limestone; B41, light gray limestone; and F20, dolomitic limestone). The geochemical analysis illustrates a considerable variability in oxide concentrations and compositions of the carbonate rock samples that relate to the sample quality for Portland cement manufacturing.

\begin{tabular}{cccccccccc}
\hline $\begin{array}{c}\text { PXRF } \\
\text { Spots } \\
\text { Code }\end{array}$ & $\mathrm{CaO}$ & $\mathrm{MgO}$ & $\mathrm{Al}_{2} \mathrm{O}_{3}$ & $\mathrm{SiO}_{2}$ & $\mathrm{Fe}_{2} \mathrm{O}_{3}$ & $\mathrm{~K}_{2} \mathrm{O}$ & $\mathrm{SO}_{3}$ & $\mathrm{TiO}_{2}$ & Sample Quality \\
\hline $\mathrm{B} 28-1$ & 46.736 & 0.501 & 2.984 & 4.463 & 0.345 & 0.373 & 0.197 & 0.148 & \\
$\mathrm{~B} 28-2$ & 45.023 & 1.228 & 8.674 & 14.289 & 0.440 & 1.166 & 0.230 & 0.572 & Good \\
$\mathrm{B} 28-3$ & 51.804 & 0 & 0.897 & 2.939 & 0.276 & 0.218 & 0.220 & 0.113 & (Chatterjee, 1983; Taylor, 1997) \\
$\mathrm{B} 28-4$ & 48.798 & 0.342 & 1.759 & 5.808 & 0.785 & 0.436 & 1.026 & 0.322 & \\
$\mathrm{~B} 28-5$ & 50.595 & 0.142 & 1.960 & 3.260 & 0.222 & 0.317 & 0.095 & 0.127 & Good \\
\hline $\mathrm{B} 41-1$ & 52.313 & 0 & 0.295 & 1.074 & 0.067 & 0.070 & 0.172 & 0.060 & \\
$\mathrm{~B} 41-2$ & 51.388 & 0 & 0.395 & 1.196 & 0.059 & 0.045 & 0.225 & 0.045 & (Chatterjee, 1983; Taylor, 1997) \\
$\mathrm{B} 41-3$ & 50.967 & 0.342 & 1.240 & 2.390 & 0.076 & 0.039 & 0 & 0.053 & \\
$\mathrm{~B} 41-4$ & 50.360 & 0.511 & 1.578 & 2.846 & 0.060 & 0.069 & 0 & 0.050 & Bad \\
$\mathrm{B} 41-5$ & 50.525 & 0 & 1.265 & 1.862 & 0.069 & 0.052 & 0 & 0.053 & 0 \\
\hline $\mathrm{F} 20-1$ & 27.635 & 21.941 & 0 & 0.169 & 0 & 0 & 0.172 & 0 & \\
$\mathrm{~F} 20-2$ & 29.132 & 21.239 & 0.079 & 0.182 & 0.034 & 0 & 0.192 & 0 & (Chatterjee, 1983; Taylor, 1997) \\
F20-3 & 28.606 & 18.086 & 0.711 & 0.958 & 0.107 & 0.023 & 0.162 & 0.020 & \\
F20-4 & 26.877 & 17.728 & 0.832 & 1.535 & 0.113 & 0 & 0.157 & 0.022 & \\
F20-5 & 29.442 & 20.174 & 0 & 0.237 & 0 & 0 & 0.140 & 0 & \\
\hline
\end{tabular}

\subsubsection{SWIR reflectance spectra of the rock samples}

The SWIR continuum removed reflectance spectra of the dark gray limestone samples (samples B28 and B45) derived from five ASD spot measurements on the rock surfaces are shown in Figure 5.3. The spectra exhibit dominant carbonate absorption with a prominent absorption feature of carbonate at $\sim 2.34 \mu \mathrm{m}$ due to the vibrational process of the carbonate ions $\left(\mathrm{CO}_{3}^{2-}\right)$ (Clark et al., 1990; Gaffey, 1986; Hunt \& Salisbury, 1971). This wavelength position and spectral shape indicate that calcite is more dominant than other carbonate minerals in the rock samples. The reflectance spectra (Figure 5.3) show weak Al-OH absorption feature at $\sim 2.20 \mu \mathrm{m}$, which suggests the presence of minor constituents of clays (e.g., montmorillonite and illite) and other phyllosilicates (e.g., muscovite) in the rock samples. This is caused by the combination of the $\mathrm{OH}$ stretch with the fundamental Al-OH bending mode (Clark et al., 1990; Hunt, 1977; Hunt \& Salisbury, 1970). However, it is difficult to differentiate between montmorillonite, illite and muscovite based only on the subtle or weak absorption feature at $\sim 2.20 \mu \mathrm{m}$. These 
phyllosilicate minerals exhibit relatively similar spectral shapes for the $\sim 2.20 \mu \mathrm{m} \mathrm{Al}-$ $\mathrm{OH}$ feature. The spectral curves also show variations of the absorption band depths for features at $\sim 2.20 \mu \mathrm{m}$ and $\sim 2.34 \mu \mathrm{m}$, which are probably correlated with changes in the relative abundances of phyllosilicate and carbonate minerals on the rock surfaces, respectively.
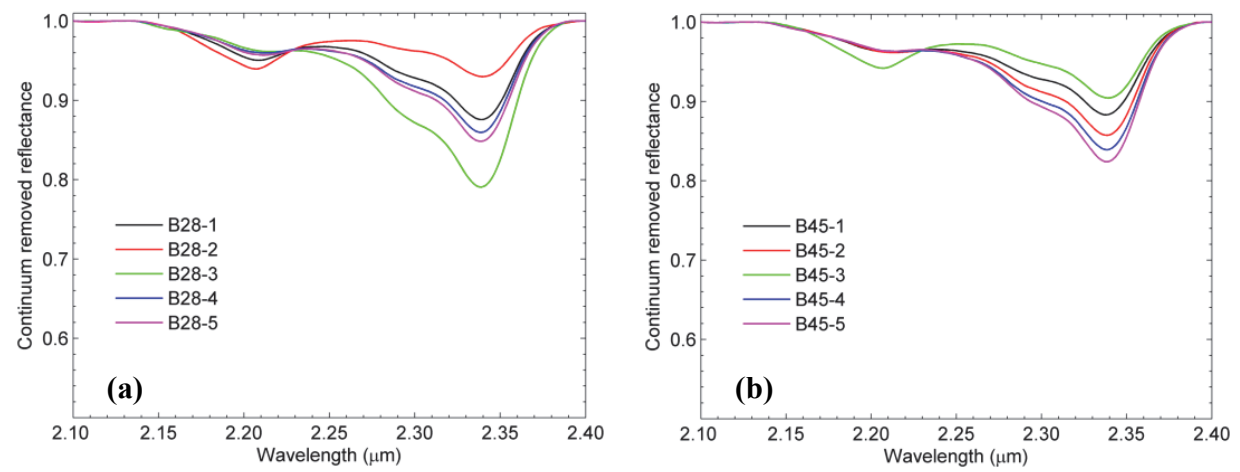

Figure 5.3: Continuum removed spectra of dark gray limestone samples: (a) sample B28 and (b) sample B45 derived from five ASD spot measurements on the rock sample surfaces in the SWIR wavelength region. The spectral curves exhibit variations of depths of absorption features at $\sim 2.20 \mu \mathrm{m}$ and $\sim 2.34 \mu \mathrm{m}$ corresponding to changes in mineral contents on the rock surfaces.

Figure 5.4 shows the SWIR continuum removed reflectance spectra of the light gray limestone samples (samples B1 and B41) derived from the five ASD spot measurements on the rock surfaces. The spectra exhibit strong and weak carbonate absorption features at $\sim 2.34 \mu \mathrm{m}$ and $\sim 2.16 \mu \mathrm{m}$, respectively, and a subtle Al-OH absorption feature centered at $\sim 2.20 \mu \mathrm{m}$. These carbonate features and spectral shapes are attributed to the relatively pure calcite in the rock samples. It can be seen obviously from Figures 5.3 and 5.4 that the depth of carbonate absorption feature at $\sim 2.34 \mu \mathrm{m}$ in the light gray limestone samples (samples B1 and B41) is deeper than that in dark gray limestone samples (samples B28 and B45) and vice versa for the depth of Al-OH absorption feature at $\sim 2.20 \mu \mathrm{m}$. This indicates that the light gray limestone samples contain more calcium carbonate mineral (calcite) than the dark gray limestone samples; moreover, the relative abundance of clay and other phyllosilicate minerals content is higher in the dark gray limestone samples than in the light gray limestone samples. 

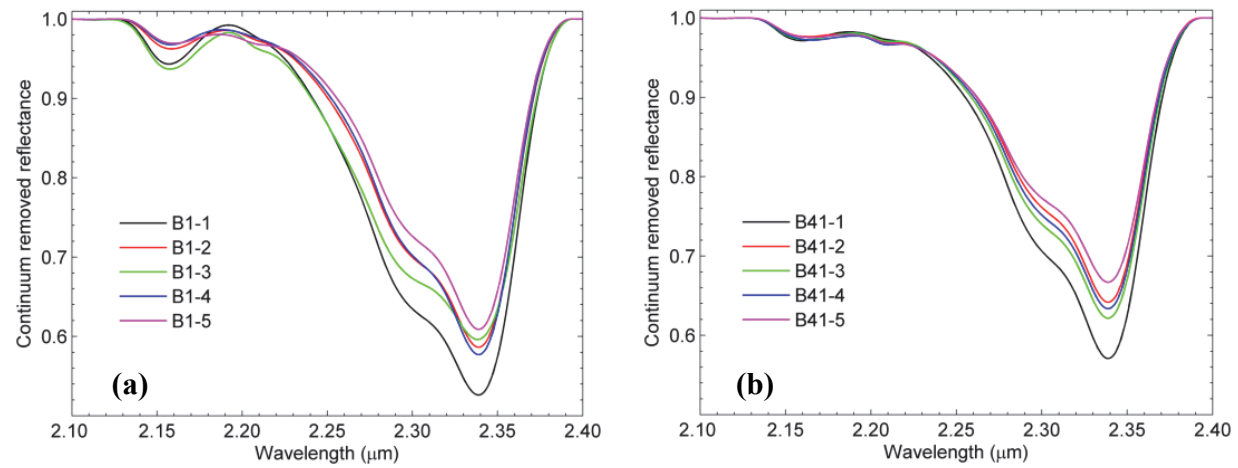

Figure 5.4: Continuum removed spectra of light gray limestone samples: (a) sample B1 and (b) sample B41 derived from five ASD spot measurements on the rock sample surfaces in the SWIR wavelength region, showing the variability in the depth of carbonate absorption feature at $\sim 2.34 \mu \mathrm{m}$.
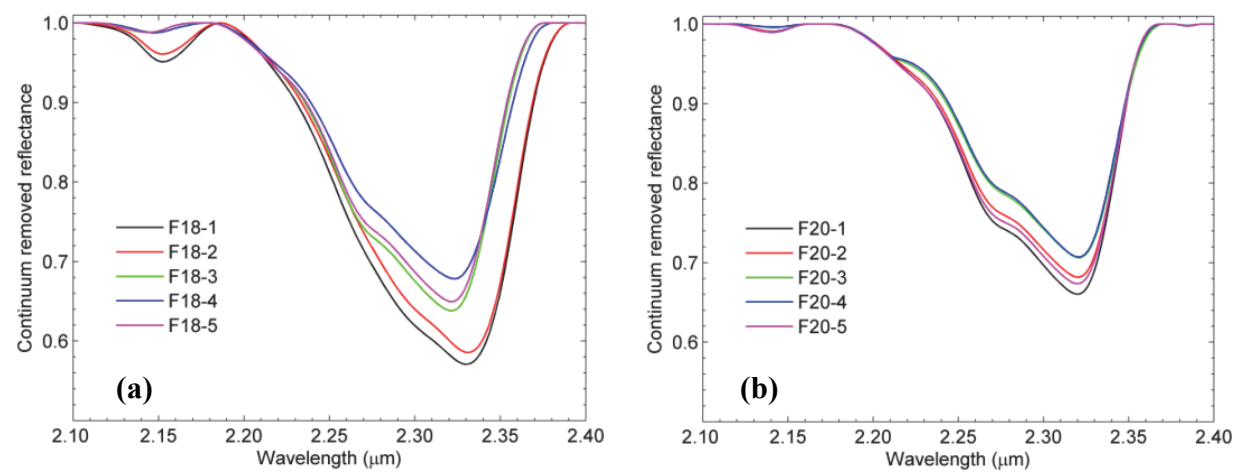

Figure 5.5: Continuum removed spectra of dolomitic limestone samples: (a) sample F18 and (b) sample F20 derived from five ASD spot measurements on the rock sample surfaces in the SWIR wavelength region, showing the variability in the wavelength position and depth of carbonate absorption feature at $\sim 2.32 \mu \mathrm{m}$.

The SWIR continuum removed reflectance spectra of the dolomitic limestone samples (samples F18 and F20) differ slightly in the wavelength position and depth of carbonate absorption feature at $\sim 2.32 \mu \mathrm{m}$ (Figure 5.5). The shifts in the position of an absorption feature at $\sim 2.32 \mu \mathrm{m}$ towards longer wavelengths as observed in the spectra of sample F18 (Figure 5.5a) are related to changes in the carbonate mineral compositions of the sample, depending on the proportion of calcite-dolomite mixtures. Strong and weak carbonate absorption features at $\sim 2.32 \mu \mathrm{m}$ and $\sim 2.15 \mu \mathrm{m}$ (Figure 5.5) indicate that the rock samples are dominated by magnesium carbonate and dolomite, respectively. In addition, it can be observed from Figure 5.5 that there is no obvious Al$\mathrm{OH}$ absorption feature at $\sim 2.20 \mu \mathrm{m}$ in the spectra, which suggests that the abundance of clay and other phyllosilicate mineral chemistries in the rock samples is insignificant to 
be determined spectroscopically, compared to the PXRF geochemical approach (Table 5.1).

(a)
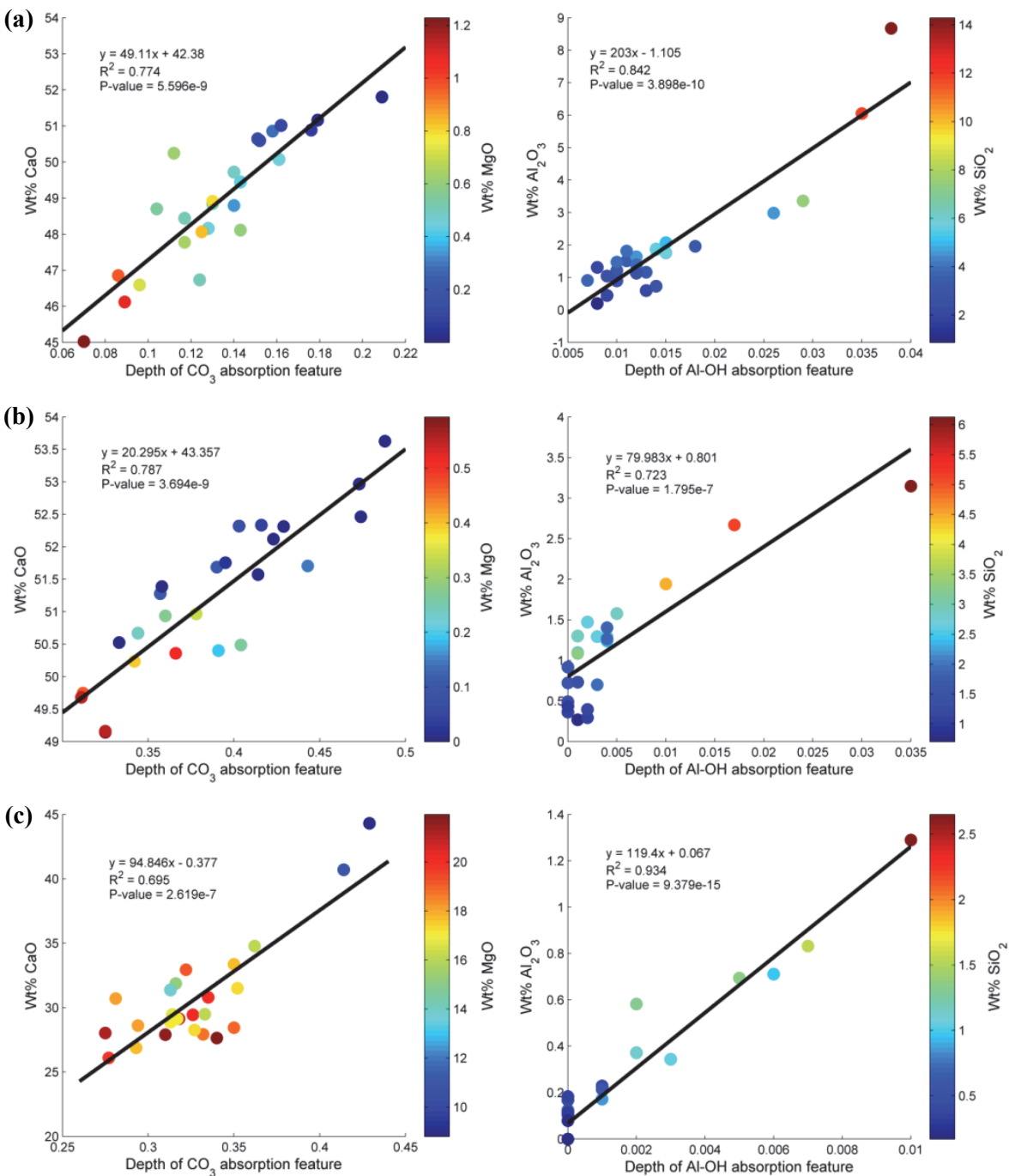

Figure 5.6: Correlation between spectral and geochemical characteristics derived from the same spot measurements of (a) dark gray limestone samples (samples B20, B28, B33, B45 and B49), (b) light gray limestone samples (samples B1, B26, B32, B36 and B41) and (c) dolomitic limestones samples (samples F17, F18, F20, F23 and F26). Physical models relating depths of carbonate features and $\mathrm{wt} \% \mathrm{CaO} \mathrm{PXRF}$ results, color coded with the $\mathrm{wt} \% \mathrm{MgO}$ results (left) and the depths of $\mathrm{Al}-\mathrm{OH}$ features and $\mathrm{wt} \% \mathrm{Al}_{2} \mathrm{O}_{3}$ PXRF results, color coded with the wt $\% \mathrm{SiO}_{2}$ results (right). 
(a)

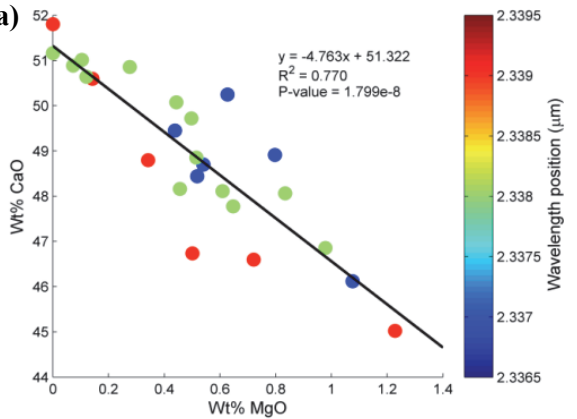

(b)

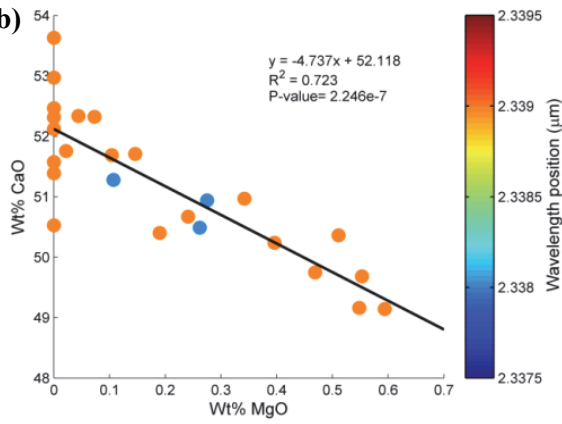

(c)

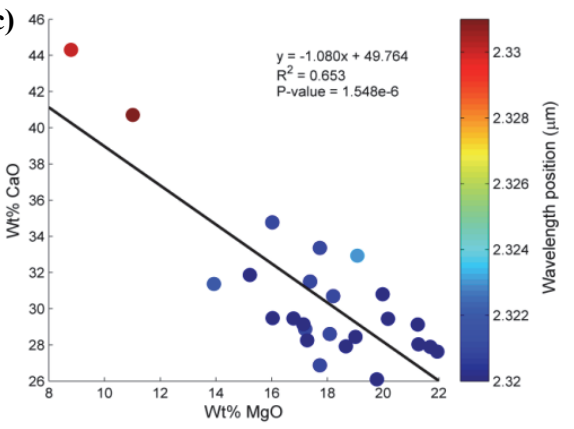

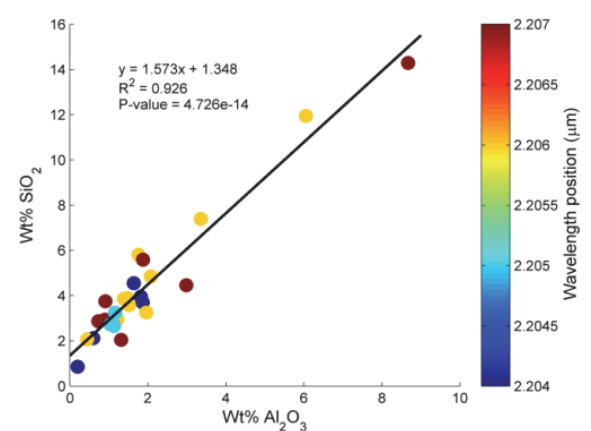
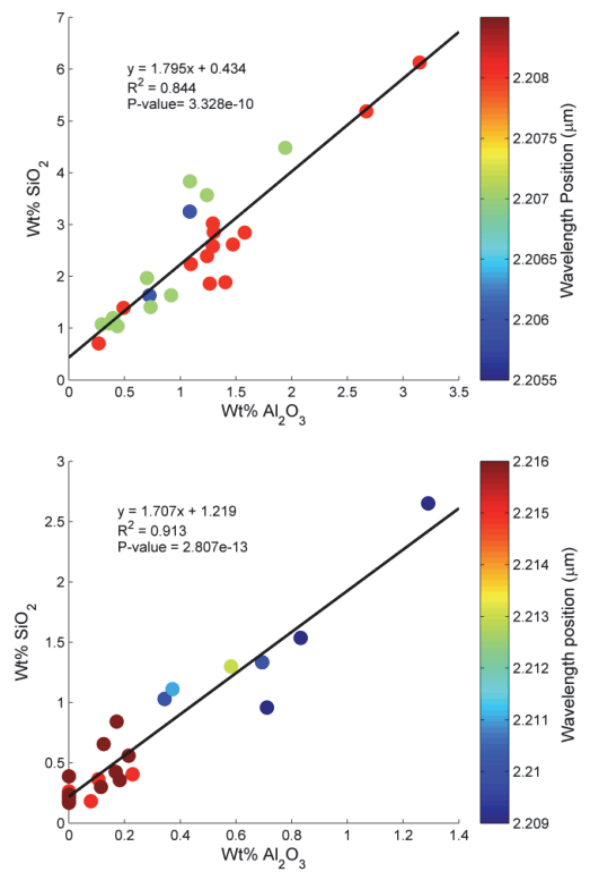

Figure 5.7: Geochemical charts of $\mathrm{CaO}$ vs. $\mathrm{MgO}$ (left) and $\mathrm{SiO}_{2}$ vs. $\mathrm{Al}_{2} \mathrm{O}_{3}$ (right) contents derived from PXRF spot measurements of (a) dark gray limestone samples (samples B20, B28, B33, B45 and B49), (b) light gray limestone samples (samples B1, B26, B32, B36 and B41) and (c) dolomitic limestones samples (samples F17, F18, F20, F23 and F26), color coded with the wavelength position of the carbonate and Al-OH absorption features.

\subsubsection{Estimation of mineral chemistry abundance and composition of the rock samples}

The spectroscopy and geochemistry results indicate that the depths of carbonate $\left(\mathrm{CO}_{3}\right)$ and Al-OH absorption features deepen with increasing relative abundances of carbonate $(\mathrm{CaO})$ and phyllosilicate $\left(\mathrm{Al}_{2} \mathrm{O}_{3}\right)$ mineral chemistries in the rock samples (Figure 5.6). The depths of $\mathrm{CO}_{3}$ and $\mathrm{Al}-\mathrm{OH}$ absorption features and the $\mathrm{wt} \% \mathrm{CaO}$ and 
$\mathrm{Al}_{2} \mathrm{O}_{3}$ contents in the rock samples have a relatively good correlation, with $\mathrm{R}^{2}=0.774$ and 0.842 for the dark gray limestone samples (Figure 5.6a), $\mathrm{R}^{2}=0.787$ and 0.723 for the light gray limestone samples (Figure 5.6b), and $\mathrm{R}^{2}=0.695$ and 0.934 for the dolomitic limestone samples (Figure 5.6c), respectively. Figure 6 shows that the depths of $\mathrm{CO}_{3}$ and $\mathrm{Al}-\mathrm{OH}$ absorption features vary between the limestone samples. Particularly for the depth of carbonate feature, the dark gray limestone samples tend to have lower band depth values than the light gray and dolomitic limestone samples. This is typical of opaque or organic materials, which can decrease the spectral reflectance value of the material (Crowley, 1986; Salisbury et al., 1987; van der Meer, 1995). However, the dark gray and light gray limestone samples contain more $\mathrm{CaO}$ and $\mathrm{Al}_{2} \mathrm{O}_{3}$ concentrations than the dolomitic limestone samples (Figure 5.6). The contents of $\mathrm{wt} \% \mathrm{CaO}$ in the samples are approximately $45-52 \%, 49-53 \%$, and $26-44 \%$ for the dark gray, light gray and dolomitic limestone samples, respectively.

The scatter plots shown in Figure 5.6 also indicate that $\mathrm{SiO}_{2}$ abundance is directly proportional to the $\mathrm{Al}_{2} \mathrm{O}_{3}$ content in the rock samples and vice versa for the relation between the $\mathrm{MgO}$ and $\mathrm{CaO}$ contents. As many clay minerals have $\mathrm{Al}$ octahedra and $\mathrm{Si}$ tetrahedra as their crystallographic framework (Brigatti et al., 2006), the correlation between $\mathrm{Al}_{2} \mathrm{O}_{3}$ and $\mathrm{SiO}_{2}$ indicates the presence of clay and other phyllosilicate minerals in the carbonate rocks. However, a number of spot measurements of light gray limestone samples and almost all dolomitic limestone samples do not have an $\mathrm{Al}-\mathrm{OH}$ absorption feature or are spectrally featureless at $\sim 2.20 \mu \mathrm{m}$ (depth of Al-OH feature $<0.005$; Figure 5.6b,c). These results show that the light gray limestone (Figure 5.6b) and dolomitic limestone (Figure 5.6c) samples contain less than $1.2 \%$ and $0.7 \%$ of wt $\%$ $\mathrm{Al}_{2} \mathrm{O}_{3}$, respectively as determined by the PXRF geochemical analyzer (Table 5.1). The very low amounts of $\mathrm{Al}_{2} \mathrm{O}_{3}$ in the dolomitic limestone point to very low percentages of clay and other phyllosilicate minerals in this particular rock, and these phyllosilicate mineral contents will therefore likely be below the detection limit of the infrared spectroscopy used.

Figure 5.7 shows the correlation between the $\mathrm{CaO}$ and $\mathrm{MgO}$ (left) and $\mathrm{SiO}_{2}$ and $\mathrm{Al}_{2} \mathrm{O}_{3}$ (right) contents in limestone samples, with the color-coded wavelength position of carbonate and $\mathrm{Al}-\mathrm{OH}$ absorption features. These analyses reveal that the proportions of these mineral chemistries in carbonate and phyllosilicate minerals are linearly related. The wavelength positions of mineral chemistries vary slightly with their compositions (Figure 5.7). For the dark gray and light gray limestone samples, the position of carbonate feature is approximately in the wavelength range of 2.337-2.339 $\mu \mathrm{m}$ (Figure $5.7 \mathrm{a}, \mathrm{b})$. The wavelength position is typical of calcium carbonate or calcite (Clark et al., 1990; Crowley, 1986; Gaffey, 1986; Hunt \& Salisbury, 1971; Kurz et al., 2012; van der Meer, 1995; Zaini et al., 2012), which is the dominant mineral in the rock samples. Nevertheless, the wavelength position of carbonate feature of the dolomitic limestone samples in the SWIR region is centered at 2.320-2.330 $\mu \mathrm{m}$ (Figure 5.7c), which is distinctive of dolomite (Clark et al., 1990; Crowley, 1986; Gaffey, 1986; Hunt \& Salisbury, 1971; Kurz et al., 2012; van der Meer, 1995; Zaini et al., 2012), with a wt\% 
$\mathrm{MgO}$ content of approximately 9-22\%. This indicates a larger dolomite or magnesium carbonate mineral content in the rock samples.

Moreover, the position of Al-OH absorption feature is approximately in the wavelength range of 2.205-2.208 $\mu \mathrm{m}$ for dark gray and light gray limestone samples (Figure 5.7a,b). The wavelength position suggests the presence of montmorillonite, illite or muscovite (Clark et al., 1990; Hunt \& Salisbury, 1970) in the rock samples. However, the wavelength position of Al-OH absorption feature of the dolomitic limestone samples is centered nearly at $2.210-2.216 \mu \mathrm{m}$ (Figure 5.7c), which is suggestive of montmorillonite, illite or muscovite (Clark et al., 1990; Hunt \& Salisbury, 1970) of slightly different chemical composition. The longer wavelength position of the $\mathrm{Al}-\mathrm{OH}$ feature indicates replacement of $\mathrm{Al}$ by $\mathrm{Fe}$ and $\mathrm{Mg}$ atoms in the crystal lattice of these minerals (Post \& Noble, 1993). The majority of dolomitic samples contain relatively low concentrations (less than $0.4 \%$ ) of $\mathrm{Al}_{2} \mathrm{O}_{3}$ (Figure 5.7c). As described above, some light gray and dolomitic limestone samples do not have an $\mathrm{Al}-\mathrm{OH}$ absorption feature or are spectrally featureless at $\sim 2.20 \mu \mathrm{m}$ (Figure 5.6b,c). X-ray diffraction analysis of selected rock samples also confirms the presence of minor constituents of Al-containing minerals in the form of montmorillonite, illite, and muscovite in the dark gray and light gray limestone samples (Figure A.1; appendix A).

\subsection{Discussions}

The PXRF geochemical analysis, SWIR reflectance spectra, and spectroscopic parameters of the limestone samples as shown in Table 5.1 and Figures 5.3, 5.4, 5.5, 5.6 and 5.7 indicate that the mineral abundance and chemical composition of the rock samples vary considerably. They depend on the type of limestone samples and the location of spot measurements on the rock surfaces. It seems that rough and porous surfaces within the area of spot measurements result in low elemental concentrations and reflectance intensity. The reason for this is probably that the incoming X-ray or electromagnetic radiation on the irregular surface will reflect diffusely, and only a few reflected radiations can reach the PXRF analyzer and spectroscopic sensors.

The results of this study (Table 5.1 and Figures 5.6 and 5.7) reveal that the proportions of oxide compositions, such as $\mathrm{CaO}, \mathrm{MgO}, \mathrm{Al}_{2} \mathrm{O}_{3}$, and $\mathrm{SiO}_{2}$, of dark gray and light gray limestone samples collected from the Lhoknga limestone quarry of PT. Lafarge Cement Indonesia, Aceh Besar, Indonesia, are qualitatively suitable for Portland cement manufacturing. These limestone samples can be categorized as Portland cement-grade limestone. The chemical concentrations and compositions of the rock samples meet the standard quality requirements of cement raw material used for the manufacturing of Portland cement clinker (Chatterjee, 1983; Meade, 1926; Taylor, 1997). However, the opposite is true for dolomitic limestone samples collected from the Bédarieux dolomite mine in the Hérault department of the Languedoc-Roussillon region, southern France. The proportions of the chemical compositions of the dolomitic limestone samples (Table 5.1 and Figures 5.6 and 5.7), especially the $\mathrm{wt} \% \mathrm{CaO}$ and 
$\mathrm{MgO}$ concentrations, are present in quantities lower and higher than are allowed by the specifications of cement raw material for Portland cement making (Chatterjee, 1983; Meade, 1926; Taylor, 1997), respectively. A high amount of MgO (above 2\%) in the cement clinker will generate the growth of periclase, which can restrict the reaction with water and consequently damage the hardened concrete (Taylor, 1997).

These results (Table 5.1 and Figures 5.6 and 5.7) also indicate that the light gray limestone sample is purer than its dark gray counterpart. Naturally, pure limestone is harder and has more massive structure than impure limestone. Its hardness influences the efficiency of the crushing and grinding process of the limestone sample to a fine powder to intimately mix with clay or shale before being transported to the kiln. The physical properties are another factor to be considered in determining the suitability of a limestone for Portland cement manufacturing. The clinkerization process (reactivity and burnability) of a raw meal may depend on its fineness (Ghosh, 1983; Meade, 1926; Taylor, 1997). The less pure limestones (dark gray limestone samples), which relate to $\mathrm{CaO}, \mathrm{MgO}, \mathrm{Al}_{2} \mathrm{O}_{3}$, and $\mathrm{SiO}_{2}$ contents, are more suitable for cement manufacturing in relation to the efficiency of the crushing and grinding process than the hard or pure limestones (light gray limestone samples).

The spectroscopic parameters, particularly the wavelength position and depth of absorption feature of carbonate and phyllosilicate minerals within the SWIR spectral ranges on fresh surfaces of limestone samples (Figures 5.6 and 5.7), also exhibit changes in the abundance and composition of these mineral chemistries. Previous researchers stated that the wavelength positions of carbonate minerals in the SWIR reflectance spectra are affected by the $\mathrm{Ca}$ and $\mathrm{Mg}$ contents (calcite-dolomite mixtures) in the samples (van der Meer, 1995; Zaini et al., 2012, 2014). Post and Noble (1993) observed that the wavelength position of clay absorption feature at $\sim 2.20 \mu \mathrm{m}$ depends on the relative content of $\mathrm{Al}$ in the sample. Haest et al. (2012a) and Magendran and Sanjeevi (2014) studied the correlation between the depth of Al-OH absorption feature and the content of $\mathrm{Al}_{2} \mathrm{O}_{3}$ in iron ore samples. They found that the spectroscopic and geochemical characteristics of clay mineral chemistry are linearly related. Furthermore, carbonate spectral feature characteristics are influenced by particle size (Crowley, 1986; Gaffey, 1986; van der Meer, 1995; Zaini et al., 2012), texture (Crowley, 1986), porosity (Gaffey, 1986) and mineral impurities (Crowley, 1986; Gaffey, 1986; van der Meer, 1995). Some scientists have attempted to analyze weathering effects on the infrared reflectance spectra of carbonate rocks (Younis et al., 1997; Yue et al., 2010). They found that the reflectance values, shape and spectral absorption features of carbonate minerals are affected by the weathering processes of the rocks.

The practical implications of the study with regard to the quality control of cement raw materials or characterization of Portland cement-grade limestones are as follows. A comparison of the spectroscopy and geochemistry parameters (Figure 5.6) illustrates a relatively good correlation between the depths of carbonate and $\mathrm{Al}-\mathrm{OH}$ absorption features and the abundance of carbonate $(\mathrm{CaO})$ and phyllosilicate $\left(\mathrm{Al}_{2} \mathrm{O}_{3}\right)$ mineral chemistries in the carbonate rock samples, respectively. The results show that the 
infrared spectroscopy within the SWIR wavelength range is an applicable technique for mineral chemistry analysis of Portland cement-grade limestones. Carbonate and clay mineral abundances in carbonate rock samples could be analyzed and estimated by applying these physical models (Figure 5.6) based on the spectroscopic parameter, especially the depth of absorption feature. This study confirms the results of previous studies (Kocak \& Nas, 2014; Mollah et al., 2000; Perraki et al., 2010; Pipilikaki et al., 2008; Ylmen et al., 2010) that used the infrared spectroscopy technique for characterizing the chemistry of cement products and hydration rate. These results also indicate that the SWIR spectroscopic approach can be used as a direct method for the characterization of other raw materials from a laboratory to real-time processes in the field or quarry. However, to implement this spectroscopic method on other limestones or rocks, some issues require further work. For instance, spectroscopic and geochemical characteristics should be derived from bulk measurements of the rock samples. It may provide a better interpretation of the method because the results of spot measurements on the rock surface are always at the mercy of the geological variation within a rock. Other spectral absorption feature parameters of carbonate and clay minerals should also be analyzed as alternative characteristics for identifying and estimating mineralogical variations and their compositions in rock.

\subsection{Conclusions}

Shortwave infrared (SWIR) spectroscopy in the 2.100-2.400 $\mu \mathrm{m}$ wavelength region is investigated in relation to the characterization of Portland cement-grade limestones to determine and estimate the chemical composition and mineral chemistry abundance on the carbonate rock surfaces. Spectral parameters, such as the wavelength position and depth of absorption feature derived from the SWIR continuum removed spectra fitted to the second-order polynomial curves, are helpful in analyzing and estimating carbonate $\left(\mathrm{CO}_{3}\right)$ and $\mathrm{Al}-\mathrm{OH}$ absorption features associated with $\mathrm{CaO}$ and $\mathrm{Al}_{2} \mathrm{O}_{3}$ contents and the compositions in the rock samples, respectively. The depths of these absorption features demonstrate a linear relationship with the contents of carbonate $(\mathrm{CaO})$ and phyllosilicate $\left(\mathrm{Al}_{2} \mathrm{O}_{3}\right)$ in the rock samples as determined by the portable X-ray fluorescence (PXRF) measurements. The wavelength positions of the $\mathrm{CO}_{3}$ and $\mathrm{Al}-\mathrm{OH}$ absorption features vary with the chemical compositions of the samples. The results showed that dark gray and light gray limestone samples are more suitable for manufacturing Portland cement clinker (Portland cement-grade limestone) than dolomitic limestone samples in terms of $\mathrm{CaO}, \mathrm{MgO}, \mathrm{Al}_{2} \mathrm{O}_{3}$, and $\mathrm{SiO}_{2}$ concentrations and compositions. The approach illustrates that SWIR spectroscopy within the selected wavelength range is an applicable technique for the chemical quality control of cement raw materials, particularly for determining the carbonate and clay mineral chemistries in the carbonate rock samples. 
6. Synthesis 


\subsection{Introduction}

Accurate and rapid determination and estimation of mineral chemistry and chemical composition of carbonate rocks is essential in various industrial sectors, especially the cement industry. The manufacturing process and their products quality are directly controlled by the mineralogical and chemical compositions of carbonate rocks, which are the main component of raw materials for making Portland cement clinker (Chatterjee, 1983; Ghosh, 1983; Meade, 1926; Taylor, 1997). Therefore, the suitability and availability of these sedimentary rocks in very large amounts are imperative to the production of cement clinker. Conventional analytical methods are well established for characterizing mineral chemistry of carbonate rocks. However, the majority of these traditional methods are a labor-intensive and time consuming process for sample preparation and analysis compared with infrared spectroscopy and hyperspectral imagery (hyperspectral imaging) approaches.

Near- and shortwave-infrared spectroscopy (Hunt \& Salisbury, 1971; Zaini et al., 2016) and hyperspectral imaging (imaging spectroscopy) (Baissa et al., 2011; Buckley et al., 2013; Green \& Schodlok, 2016; Kurz et al., 2013; Kurz et al., 2012; Mathieu et al., 2017; Murphy et al., 2016; Schodlok et al., 2016; Zaini et al., 2014) are recognized as advanced analytical methods for determining mineralogy and chemical information of carbonate rocks or geologic samples. These spectroscopic methods offer a nondestructive method and can be used outdoors for analyzing mineral chemistry of the rocks or samples based on their spectral absorption feature characteristics. Moreover, the technological improvements of hyperspectral imaging sensors have offered an opportunity to apply the imagery for mapping continuous spatial distribution patterns and compositional variations of surface mineralogy on geological area or outcrop mine faces (Buckley et al., 2013; Kruse et al., 2012; Kurz \& Buckley, 2016; Kurz et al., 2013; Kurz et al., 2012; Murphy \& Monteiro, 2013; Murphy et al., 2012; Murphy et al., 2014). However, compared to infrared spectroscopy and imaging spectroscopy, most of the conventional methods are impractical for field application, particularly during mineral chemistry exploration and measurement process in a quarry or geological site. This is because the analytical instruments require a specific requirement for sample preparation and acquisition of the data. Furthermore, these spectroscopic techniques cannot determine exactly chemical compositions or elemental concentrations of carbonate rocks, as are characterized by the classical analytical methods, such as X-ray fluorescence (XRF), energy dispersive X-ray spectroscopy (EDS) attached to scanning electron microscopy (SEM-EDS) and electron microprobe analysis (EMPA).

In the cement industry, X-ray diffraction (XRD) and XRF are two important analytical methods for determining and controlling mineralogical and chemical compositions in each stage of the cement production process, chain from the exploration of high quality raw materials in a quarry to the final cement products (Anderson et al., 2015). However, these conventional methods pose some obstacles to characterizing and analyzing a geologic sample. To overcome this constrain, infrared spectroscopy has 
provided a great potential and opportunity for the chemical quality control and the quantitative analysis of carbonate rocks as cement raw materials by combining spectroscopic data of field spectrometry with geochemical data of X-ray analyzer (XRF) (Zaini et al., 2016).

The general objective of the research presented in this thesis was to develop a methodology for determining and estimating the relative abundances and compositions of mineral chemistries from carbonate rocks using a combination approach of spectroscopy, geochemistry and hyperspectral imagery, particularly for the chemical quality control of carbonate rocks as cement raw materials. This chapter summarizes and elaborates on the main findings and outcomes of the research, which have been discussed previously in Chapters 3 to 5 with respect to the original research objectives. The objectives were defined as:

- To analyze the effects of grain size and calcite-dolomite mixtures on carbonate spectral absorption feature characteristics (Section 6.2).

- To estimate the relative abundance and chemical composition of carbonate minerals on the rock surfaces using SisuCHEMA hyperspectral imagery (Section $6.3)$.

- To investigate the potential and accuracy of shortwave infrared (SWIR) spectroscopy approach for chemical quality control of Portland cement-grade limestone (Section 6.4).

The following sections discuss the achievements related to the research objectives and summarize the results of carbonate rock chemistry characterization, specifically to determine and estimate the relative abundance of mineralogical and chemical compositions of carbonate rocks using a combination approach of spectroscopy, geochemistry and hyperspectral imagery. The last section of this chapter highlights the limitations and proposes recommendations for future research.

\subsection{Carbonate absorption feature characteristics}

The first objective of the research was to analyze carbonate absorption feature characteristics. In this thesis, the main focus of discussion on carbonate minerals was calcite $(\mathrm{CaCO} 3)$ and dolomite $(\mathrm{CaMg}(\mathrm{CO} 3) 2)$. These carbonate minerals are the predominant constituents of carbonate rocks (Blatt et al., 1972; Pettijohn, 1975). Thus, knowledge and understanding of calcite and dolomite reflectance spectra and their absorption feature characteristics are essential for identifying and analyzing mineral chemistry and composition of carbonate rocks. Spectral feature characteristics of calcite and dolomite in both the shortwave infrared (SWIR) and thermal infrared (TIR) wavelength regions, as a function of grain size and carbonate mineral mixtures were discussed in Chapter 3. The absorption feature characteristics analysis of carbonate reflectance spectra consisted of wavelength position, depth, full width at half maximum 
(FWHM), and asymmetry of absorption feature (Clark \& Roush, 1984; Kruse, Lefkoff, \& Dietz, 1993; van der Meer, 1995; van der Meer, 2004).

Carbonate minerals have two prominent spectral absorption features in the SWIR (features at 2.3 and $2.5 \mu \mathrm{m}$ ) and TIR (features at 11.5 and $14 \mu \mathrm{m}$ ) wavelength regions due to vibrational processes of the carbonate ions $\left(\mathrm{CO}_{3}^{2-}\right)$ (Clark, 1999; Clark et al., 1990; Gupta, 2003; Hunt \& Salisbury, 1971; Salisbury et al., 1987). These spectral features can be used to distinguish carbonates from other minerals. The results of Chapter 3 showed that absorption feature characteristics and reflectance values of pure calcite and dolomite spectra in the SWIR and TIR wavelength regions were influenced by grain size fraction (Figures 3.2 and 3.4). In the SWIR region, the absorption band positions of both features were centered at $2.340 \mu \mathrm{m}$ and $2.537 \mu \mathrm{m}$ for calcite and at $2.323 \mu \mathrm{m}$ and $2.515 \mu \mathrm{m}$ for dolomite (Figure 3.3). These SWIR band positions of the calcite and dolomite features were invariant to grain size fraction. The depth of absorption bands intensified with increasing grain size fraction of the calcite and dolomite features between 45 and $250 \mu \mathrm{m}$, and decreased when the grain size was greater than $250 \mu \mathrm{m}$. Overall reflectance values decreased with increasing grain size fraction of the sample. The FWHM and asymmetry of the calcite and dolomite spectral features at 2.3 and $2.5 \mu \mathrm{m}$ varied with particle size (Figure 3.3). The FWHM increased with increasing grain size fractions from 45 to $500 \mu \mathrm{m}$, but slightly decreased when grain size is larger than $500 \mu \mathrm{m}$ (Figure 3.3). The feature at $2.5 \mu \mathrm{m}$ was wider and deeper than the feature at $2.3 \mu \mathrm{m}$ for both carbonate minerals. The asymmetry of calcite and dolomite features has a negative value which tended to skew to shorter wavelengths (Figures 3.2 and 3.3) and the feature at $2.3 \mu \mathrm{m}$ skewed more to shorter wavelengths than the feature at $2.5 \mu \mathrm{m}$.

In the TIR wavelength region, the calcite and dolomite band positions of both features depended on grain size and shifted to longer wavelength for the feature at 11.5 $\mu \mathrm{m}$ and to shorter wavelength for the feature at $14 \mu \mathrm{m}$ from fine to coarse grain size fractions (Figure 3.5). Overall reflectance values and depth of absorption bands decreased with increasing grain size fraction for both carbonate features. The spectral features of calcite and dolomite became poorly defined as grain size fraction increased, particularly between 125 and $500 \mu \mathrm{m}$ grain sizes. The FWHM and asymmetry of the calcite and dolomite spectral features at 11.5 and $14 \mu \mathrm{m}$ also varied with grain size fraction (Figure 3.4). The width of calcite and dolomite features amplified with increasing particle size.

Chapter 3 also presents that absorption band position of both features of calcitedolomite mixtures in the SWIR and TIR wavelength regions were determined by the calcite or dolomite composition in the samples (Figures 3.6 and 3.8). The depth, FWHM, and asymmetry of the SWIR and TIR carbonate features also varied slightly with changing calcite or dolomite contents in the samples (Figure 3.7). The band positions of the carbonate features in the SWIR region were centered within the wavelength range of $2.323-2.340 \mu \mathrm{m}$ and $2.515-2.537 \mu \mathrm{m}$, from the band position of pure dolomite to pure calcite. In the TIR region, however, the absorption band positions 
of the calcite-dolomite mixtures not only depended on carbonate mineral composition, but also on grain size of the sample (Figure 3.9). The TIR spectra of mixed calcite and dolomite exhibited a relatively flat spectral curve for coarse grain size fractions in the range of 125 to $500 \mu \mathrm{m}$. This study has contributed to understand the effects of grain size and mineral mixtures on the spectral absorption feature characteristics of calcite and dolomite in the SWIR and TIR wavelength regions, which will help in improving carbonate minerals identification and analysis using infrared spectroscopy and hyperspectral imagery approaches.

\subsection{Hyperspectral imagery of carbonate rock chemistry}

After analyzing carbonate absorption feature characteristics, the second research objective was applying of the results to hyperspectral imagery. The application of laboratory-based SisuCHEMA hyperspectral imagery for estimating the relative abundance and chemical composition of carbonate minerals on the rock surfaces using various spectral recognition algorithms were addressed in Chapter 4. These spectral analysis methods consisted of wavelength position analysis (Clark \& Roush, 1984; Kruse, Lefkoff, \& Dietz, 1993; Rodger et al., 2012), spectral angle mapper (SAM) (Kruse, Lefkoff, Boardman, et al., 1993) and linear spectral unmixing (LSU) (Adams et al., 1993; Boardman, 1989). The methods were used to extract compositional information of mineral mixtures from the spectral data of SisuCHEMA images by applying spectral endmembers of the carbonate synthetic samples established in Chapter 3. It was also complemented by geochemical analysis of spot measurements obtained by a portable X-ray fluorescence (PXRF) analyzer for identifying mineral chemistry of the rocks. The accuracy of these classification methods and correlation between geochemical data and spectroscopic parameters in determining mineral components of carbonate rocks were also analyzed.

The SisuCHEMA hyperspectral imager is a complete chemical imaging system and has a high spatial and spectral resolution (Specim, 2007). It allows the system to record distinctive spectral absorption features of mineral assemblages from the visible and near infrared (VNIR) to the SWIR wavelength regions. The SWIR imaging sensor can acquire images with 320 spatial pixels per line at a spatial resolution of $0.21 \mathrm{~mm}$ (Specim, 2007). It configures to record continuous spectral information from $970 \mathrm{~nm}$ to $2500 \mathrm{~nm}$ with 256 spectral bands at a spectral resolution of $10 \mathrm{~nm}$. Therefore, the hyperspectral image data can be used for the characterization of mineralogical and chemical constituents, their quantities and distributions on carbonate rock or geological surfaces (Specim, 2007; Zaini et al., 2014), based on the analysis of spectral reflectance shapes and absorption feature characteristics of SisuCHEMA image pixels. This dataset also offers an opportunity and challenge for quality control and quality assurance of the sustainable exploitation of the quarry raw materials (minerals and rocks), the manufacturing process of the raw materials, and mineral-derived products in many industries, such as the mining industry and cement industry. 
The results of Chapter 4 show that chemical composition (Ca-Mg ratio) of carbonate minerals at a pixel (e.g., sub-grain) level can be extracted from the SWIR image pixel spectra using the spectral recognition approaches (Figures 4.6, 4.7 and 4.8). The results also indicated that differences in calcite-dolomite mixtures identification and proportion estimation of these minerals composing the rock samples depended on the classification approaches, user-selected parameters, and match between reference spectra and image spectra (Figure 4.9). However, the general spatial distribution of carbonate mineral mixtures classified by these spectral methods had nearly the same pattern on the carbonate rock surfaces. The wavelength position analysis approach of the SisuCHEMA image spectra was found to be sensitive to all compositional variations of calcitedolomite mixtures on the rock surfaces. The method was a more stable, standardized and reproducible technique for determining the carbonate mineral chemistry from the image pixel spectra than the SAM and LSU methods (Chapter 4). In comparison to the wavelength position classifier, the SAM and LSU algorithms tended to produce some misclassified and unclassified pixels of carbonate mineral mixtures. The overall classification accuracies of carbonate mineral mixtures using these spectral analysis approaches showed that the classification accuracies of LSU images were slightly higher than SAM images when compared with wavelength position images (Table 4.2).

The geochemical analysis results on the carbonate rock samples (Chapter 4) demonstrate that the rock samples contain mineralogical associations of major elements, such as $\mathrm{Ca}$ and $\mathrm{Mg}$ and trace elements such as $\mathrm{Ba}, \mathrm{Fe}, \mathrm{Al}, \mathrm{Si}, \mathrm{Cl}$, and $\mathrm{S}$ (Table 4.1). These major and trace elements indicated that the rocks were dominated by carbonate minerals with various compositions of mineral mixtures. The relationship between major geochemical elements $(\mathrm{Ca}$ and $\mathrm{Mg}$ ) and spectroscopic parameters (wavelength position, spectral angle of SAM, and fraction value of LSU) also proved the presence of carbonate mixtures with different mineralogical compositions on the rock surfaces (Figure 4.10). As a result, the finding of this study could be implemented to determine naturally mixed minerals and estimate the proportions of minerals on rock surfaces using laboratory-based hyperspectral imagery. In a practical sense, understanding of the carbonate mineral chemistry contributes to the developing a framework for the cement industry in assessing the purity and the chemical composition of carbonate rocks.

\subsection{Shortwave infrared spectroscopy for chemical quality control of Portland cement raw materials}

Carbonate rocks or limestones are the main component of raw materials used for manufacturing Portland cement clinker (Chatterjee, 1983; Ghosh, 1983; Meade, 1926; Taylor, 1997). The mineralogical and chemical compositions of the rocks influence the manufacturing process and quality of cement clinker. Therefore, the accurate and rapid determination and estimation of the abundance and composition of mineral chemistries in carbonate rocks is essential for the cement industry. Conventional analytical methods, such as XRD and XRF are commonly used in the cement industry for characterizing and 
controlling mineralogical and chemical compositions of carbonate rocks or cement raw materials (Anderson et al., 2015).

An alternative approach that is better suited for field application than conventional techniques is infrared spectroscopy. Infrared spectroscopic techniques have been utilized to characterize the chemistry of cement products and the hydration rate (Kocak $\&$ Nas, 2014; Mollah et al., 2000; Perraki et al., 2010; Pipilikaki et al., 2008; Ylmen et al., 2010). However, their applications in determining the compositional characteristics of cement raw materials, such as carbonate rocks or limestones, have not been completely explored.

The last research objective was to investigate the potential of shortwave infrared (SWIR) spectroscopy as an alternative quality control technique for the mineral chemistry analysis of Portland cement-grade limestone. It was discussed at greater length in Chapter 5 of this thesis. Previous studies reported in Chapters 3 and 4 show that the SWIR reflectance spectra of carbonate minerals exhibited distinctive vibrational absorption features of carbonate ions. The carbonate absorption feature characteristics in the wavelength region were influenced by grain size and calcite-dolomite mixtures in the sample (Chapter 3). These spectral shape and absorption feature characteristics were useful in the characterization and estimation of carbonate mineral chemistry from the SWIR image pixel spectra using the spectral recognition approaches (Chapter 4). The spectroscopic method can also be combined with geochemical data to determine the chemical compositions of carbonate rocks (Chapter 4). In Chapter 5, the spectral absorption feature properties of SWIR reflectance spectra, such as wavelength position and depth of absorption feature (Kruse, Lefkoff, \& Dietz, 1993; van der Meer, 2004) and geochemical characteristics of limestone samples were used to identify and estimate the abundance and composition of carbonate and clay minerals on the rock surfaces that are suitable for making Portland cement clinker by following the approaches and results of Chapters 3 and 4.

The results of Chapter 5 demonstrate that the SWIR reflectance spectra of dark gray and light gray limestone samples with prominent carbonate $\left(\mathrm{CO}_{3}\right)$ and weak $\mathrm{Al}-\mathrm{OH}$ absorption features at $\sim 2.34 \mu \mathrm{m}$ and $\sim 2.20 \mu \mathrm{m}$, respectively, indicated the presence of calcium carbonate (calcite) as a dominant mineralogical constituent, which is associated with minor constituents of clays (e.g., montmorillonite and illite) and other phyllosilicate minerals (e.g., muscovite) in the rock samples (Figures 5.3 and 5.4). The SWIR reflectance spectra of dolomitic limestone samples with distinctive carbonate absorption feature at $\sim 2.32 \mu \mathrm{m}$ indicated that the rock samples were dominated by magnesium carbonate (dolomite) (Figure 5.5). These spectroscopic characteristics were confirmed by geochemical analysis results of the rocks samples (Table 5.1). The dark gray and light gray limestone samples contain a major oxide element of $\mathrm{CaO}$ mixed with a significant elemental concentration of $\mathrm{SiO}_{2}$ and $\mathrm{Al}_{2} \mathrm{O}_{3}$. These oxide elements are attributed to the presence of calcite and clays and other phyllosilicate minerals in the rock samples, respectively. Moreover, the dolomitic limestone sample is composed by major elemental concentrations of $\mathrm{CaO}$ and $\mathrm{MgO}$ (Table 5.1), which indicate a 
dominance of dolomite in the rock sample. X-ray diffraction analysis of selected rock samples also proved the presence of minor constituents of Al-containing minerals in the form of montmorillonite, illite, and muscovite in the dark gray and light gray limestone samples (Figure A.1; appendix A).

Table 6.1: Summary of the linear regression results (Figure 5.6) between spectroscopic characteristics (depth of carbonate (CO3) and Al-OH absorption features) and geochemical parameters $(\mathrm{CaO}$ and $\mathrm{Al} 2 \mathrm{O} 3)$ derived from the same spot measurements on both fresh surfaces of the carbonate rock samples.

\begin{tabular}{|c|c|c|c|c|c|}
\hline \multirow{3}{*}{$\begin{array}{c}\text { Rock } \\
\text { Sample }\end{array}$} & \multirow{3}{*}{$\begin{array}{l}\text { Geochemical } \\
\text { Parameter } \\
\text { (y) }\end{array}$} & \multicolumn{4}{|c|}{ Spectroscopic Characteristic (x) } \\
\hline & & \multicolumn{2}{|r|}{ Depth of $\mathrm{CO}_{3}$ Feature } & \multicolumn{2}{|c|}{ Depth of Al-OH Feature } \\
\hline & & $\mathrm{R}^{2}$ & Regression Equation & $\mathrm{R}^{2}$ & Regression Equation \\
\hline \multirow{2}{*}{$\begin{array}{l}\text { Dark gray } \\
\text { limestone }\end{array}$} & $\mathrm{CaO}$ & 0.774 & $y=49.11 x+42.38$ & & \\
\hline & $\mathrm{Al}_{2} \mathrm{O}_{3}$ & & & 0.842 & $y=203 x-1.105$ \\
\hline \multirow{2}{*}{$\begin{array}{l}\text { Light gray } \\
\text { limestone }\end{array}$} & $\mathrm{CaO}$ & 0.787 & $y=20.295 x+43.357$ & & \\
\hline & $\mathrm{Al}_{2} \mathrm{O}_{3}$ & & & 0.723 & $y=79.983 x+0.801$ \\
\hline \multirow{2}{*}{$\begin{array}{l}\text { Dolomitic } \\
\text { limestone }\end{array}$} & $\mathrm{CaO}$ & 0.695 & $y=94.846 x-0.377$ & & \\
\hline & $\mathrm{Al}_{2} \mathrm{O}_{3}$ & & & 0.934 & $y=119.4 x+0.067$ \\
\hline
\end{tabular}

The most interesting outcome of this study (Chapter 5) was that the depth of the carbonate $\left(\mathrm{CO}_{3}\right)$ and $\mathrm{Al}-\mathrm{OH}$ absorption features were linearly correlated with the contents of $\mathrm{CaO}$ and $\mathrm{Al}_{2} \mathrm{O}_{3}$ in the rock samples, respectively (Figure 5.6), as determined by geochemical analysis of X-ray analyzer (PXRF; Table 5.1). Variations in the wavelength position of $\mathrm{CO}_{3}$ and $\mathrm{Al}-\mathrm{OH}$ absorption features were related to changes in the chemical compositions of the samples (Figure 5.7). The results showed that the dark gray and light gray limestone samples were better suited for the manufacturing of Portland cement clinker (Portland cement-grade limestone) than the dolomitic limestone samples. It was indicated by the geochemical characteristics of the $\mathrm{CaO}, \mathrm{MgO}, \mathrm{Al}_{2} \mathrm{O}_{3}$, and $\mathrm{SiO}_{2}$ concentrations and compositions of the rock samples (Table 5.1). These compositional characteristics of the rock samples met the standard quality requirements of cement raw material used for Portland cement manufacturing (Chatterjee, 1983; Meade, 1926; Taylor, 1997).

The practical implications of the study (Chapter 5) with regard to the quality control of cement raw materials or characterization of Portland cement-grade limestones were as follows. A comparison of the spectroscopy and geochemistry parameters illustrated a relatively good correlation between the depths of carbonate and $\mathrm{Al}-\mathrm{OH}$ absorption features and the abundance of carbonate $(\mathrm{CaO})$ and phyllosilicate $\left(\mathrm{Al}_{2} \mathrm{O}_{3}\right)$ mineral chemistries in the carbonate rock samples (Figure 5.6), respectively. Carbonate and clay mineral abundances in carbonate rock samples could be analyzed and estimated by applying these physical models (Table 6.1) based on the spectroscopic characteristic, especially the depth of absorption feature. The results showed that the 
SWIR spectroscopy approach within the selected wavelength range is an applicable technique for the chemical quality control of cement raw materials, particularly for determining the carbonate and clay mineral chemistries in the carbonate rock samples.

\subsection{Future research}

The results of this research show an alternative methodology for the characterization of carbonate rock chemistry using a combination approach of spectroscopy, geochemistry and hyperspectral imagery, particularly for the chemical quality control of carbonate rocks as cement raw materials. A number of future research opportunities could be investigated and implemented:

- Bulk measurements of the rock samples (whole rock analysis). Bulk measurements could potentially enhance the result analysis of rock samples. It may provide a better interpretation of spectroscopic method because bulk measurements can overcome the limitation of spot measurements on the rock surface that always depend on the geological variation within a rock. However, in using the whole rock analysis, the rock samples should be ground into a powder before analyzing spectroscopic and geochemical characteristics from the same area of the powdered sample.

- Including other spectral absorption feature parameters. Wavelength position and absorption feature depth of carbonate and Al-OH absorption features of SWIR reflectance spectra were useful for determining the abundance and composition of carbonate and clay minerals in carbonate rock samples. Other spectroscopic parameters, such as width of absorption feature, should also be analyzed as an alternative spectral feature characteristic for quantitative analysis of mineral chemistry on the rock samples. The width of absorption feature or full width at half maximum (FWHM) of carbonate minerals in the SWIR spectral region were influenced by grain size and mineral contents in the sample (Zaini et al., 2012). This spectral parameter may improve estimation of mineral chemistry in carbonate rocks.

- Application of the quality control method to limestone quarries using hyperspectral imagery. Hyperspectral sensors have been continuously developed with more compact and lightweight technologies, allowing higher spectral and spatial resolution of hyperspectral imagery to be acquired by the imaging sensors mounted on different platforms, such as field-based (Buckley et al., 2013; Kruse et al., 2012; Kurz \& Buckley, 2016; Kurz et al., 2013; Kurz et al., 2012; Murphy \& Monteiro, 2013; Murphy et al., 2012; Murphy et al., 2014) and unmanned aerial vehicles (UAVs) or drone-borne systems (Jakob et al., 2017). These authors have demonstrated the capability and accuracy of the hyperspectral imaging techniques for compositional mapping of surface mineralogy in various mining area or geological site. However, the imaging approaches have not been explored for the 
chemical quality control of cement raw materials on limestone quarries or other calcareous mining area. Further research is advised to extend this study using field- or drone-based hyperspectral imaging as a quality control technique for characterizing the mineral chemistry and chemical compositions of cement raw materials on limestone quarries of outcrop mine faces.

- Implementation to other cement raw materials. The results of this study showed that the SWIR spectroscopy approach within the selected wavelength range is an applicable technique for the chemical quality control of carbonate rocks, as the main component of cement raw materials. The findings should thus be implemented to other cement raw materials, such as argillaceous materials. 


\section{Bibliography}

Adams, J. B., Smith, M. O., \& Gillespie, A. R. (1993). Imaging spectroscopy: Interpretation based on spectral mixture analysis. In C. M. Pieters \& P. A. J. Englert (Eds.), Remote Geochemical Analysis: Elemental and Mineralogical Composition (pp. 145-166). New York, USA: Cambridge University Press.

Agus, A. J. L. (2011). Mapping White Mica in Milled Porphyry Copper Pebbles Using Hyperspectral Imagery: An Exploratory Study. Master's Thesis, University of Twente, Enschede, The Netherlands.

Ahr, W. M. (2008). Geology of Carbonate Reservoirs: The Identification, Description, and Characterization of Hydrocarbon Reservoirs in Carbonate Rocks (p. 296). Hoboken, NJ, USA: John Wiley and Sons.

Anderson, J., Gobbo, L. D., \& van Weeren, H. (2015). X-ray diffraction: New eyes on the process. IEEE Transactions on Industry Applications, 51(1), 20-27.

Andriani, G. F., \& Walsh, N. (2002). Physical properties and textural parameters of calcarenitic rocks: Qualitative and quantitative evaluations. Engineering Geology, 67, 5-15.

Aspinall, R. J., Marcus, W. A., \& Boardman, J. W. (2002). Considerations in collecting, processing, and analysing high spatial resolution hyperspectral data for environmental investigations. Journal of Geographical Systems, 4(1), 15-29.

Baissa, R., Labbassi, K., Launeau, P., Gaudin, A., \& Ouajhain, B. (2011). Using HySpex SWIR-320m hyperspectral data for the identification and mapping of minerals in hand specimens of carbonate rocks from the Ankloute Formation (Agadir Basin, Western Morocco). Journal of African Earth Sciences, 61(1), 1-9.

Baker, A. C., Glynn, P. W., \& Riegl, B. (2008). Climate change and coral reef bleaching: An ecological assessment of long-term impacts, recovery trends and future outlook. Estuarine, Coastal and Shelf Science, 80(4), 435-471.

Bakker, W. (2012). HypPy User Manual: Graphical User-Interface (GUI), Version 2.6. ITC. The Netherlands. URL: https://blog.utwente.nl/bakker/hyppy/

Barber, A. J. (2000). The origin of the Woyla Terranes in Sumatra and the Late Mesozoic evolution of the Sundaland margin. Journal of Asian Earth Sciences, 18(6), 713-738.

Barber, A. J., \& Crow, M. J. (2005). Pre-tertiary stratigraphy. In A. J. Barber, M. J. Crow \& J. S. Milsom (Eds.), Sumatra: Geology, Resources and Tectonic Evolution (pp. 24-53). London, UK: Geological Society.

Barber, C. (1974). Major and trace element associations in limestones and dolomites. Chemical Geology, 14(4), 273-280.

Beccari, M., \& Romano, U. (2005). Encyclopaedia of Hydrocarbons: Exploration, Production and Transport (Vol. 1, p. 910). Rome, Italy: Ente nazionale idrocarburi (ENI), Istituto della Enciclopedia italiana. 
Bedini, E., van der Meer, F., \& van Ruitenbeek, F. (2009). Use of HyMap imaging spectrometer data to map mineralogy in the Rodalquilar caldera, southeast Spain. International Journal of Remote Sensing, 30(2), 327-348.

Bennett, J. D., Bridge, D. M., Cameron, N. R., Djunuddin, A., Ghazali, S. A., Jeffery, D. H., Kartawa, W., Keats, W., Rock, N. M. S., Thomson, S. J., \& Whandoyo, R. (Cartographer). (1981). Geologic Map of the Banda Aceh Quadrangle, Sumatra.

Bertron, A., Escadeillas, G., de Parseval, P., \& Duchesne, J. (2009). Processing of electron microprobe data from the analysis of altered cementitious materials. Cement and Concrete Research, 39(10), 929-935.

Bishop, J. L., Schelble, R. T., McKay, C. P., Brown, A. J., \& Perry, K. A. (2011). Carbonate rocks in the Mojave Desert as an analogue for Martian carbonates. International Journal of Astrobiology, 10(4), 349-358.

Bissell, H. J., \& Chilingar, G. V. (1967). Classification of sedimentary carbonate rocks. In G. V. Chilingar, H. J. Bissell \& R. W. Fairbridge (Eds.), Carbonate Rocks: Developments in Sedimentology (Vol. 9A, pp. 87-168). Amsterdam, The Netherlands: Elsevier.

Blatt, H., Middleton, G., \& Murray, R. (1972). Origin of limestones. In Origin of Sedimentary Rocks (pp. 409-455). Englewood Cliffs, USA: Prentice-Hall.

Boardman, J. W. (1989). Inversion of imaging spectrometry data using singular value decomposition. In proceedings of 12th Canadian Symposium on Remote Sensing IGARSS'89 (10-14 July 1989, pp. 2069-2072). Vancouver, Canada.

Bogdanoff, S., Donnot, M., \& Ellenberger, F. (Cartographer). (1984). Carte Geologique de la France à $1: 50.000$ et Notice Explicative, Feuille Bedarieux.

Boggs, S. (2006). Carbonate sedimentary rocks. In Principles of Sedimentology and Stratigraphy (4th ed., pp. 159-196). Upper Saddler River, NJ, USA: Pearson Prentice Hall.

Brasier, A. T., Martin, A. P., Melezhik, V. A., Prave, A. R., Condon, D. J., \& Fallick, A. E. (2013). Earth's earliest global glaciation? Carbonate geochemistry and geochronology of the Polisarka Sedimentary Formation, Kola Peninsula, Russia. Precambrian Research, 235, 278-294.

Brigatti, M. F., Galan, E., \& Theng, B. K. G. (2006). Structures and mineralogy of clay minerals. In F. Bergaya, B. K. G. Theng \& G. Lagaly (Eds.), Developments in Clay Science (Vol. 1, pp. 19-86). Amsterdam, The Netherlands: Elsevier.

Buckley, S. J., Kurz, T. H., Howell, J. A., \& Schneider, D. (2013). Terrestrial lidar and hyperspectral data fusion products for geological outcrop analysis. Computers and Geosciences, 54, 249-258.

Cameron, N. R., Clarke, M.C.G., Aldiss, D.T., Aspden, J.A., Djunuddin, A. (1980). The geological evolution of northern Sumatra. In proceedings of 9th Annual Convention of Indonesian Petroleum Association (pp. 149-187). Jakarta, Indonesia.

Campbell, J. B. (1996). Hyperspectral remote sensing. In Introduction to Remote Sensing (2nd ed., pp. 399-409). London, UK: Taylor and Francis. 
Chatterjee, A. K. (1983). Chemico-physico-mineralogical characteristics of raw materials of Portland cement. In S. N. Ghosh (Ed.), Advances in Cement Technology (pp. 39-68). Exeter, UK: Pergamon Press Ltd.

Clark, R. N. (1999). Spectroscopy of rocks and minerals, and principles of spectroscopy. In A. N. Rencz (Ed.), Remote Sensing for the Earth Sciences: Manual of Remote Sensing (3rd ed., Vol. 3, pp. 3-58). New York, USA: John Wiley and Sons.

Clark, R. N., King, T. V. V., Klejwa, M., Swayze, G. A., \& Vergo, N. (1990). High spectral resolution reflectance spectroscopy of minerals. Journal of Geophysical Research, 95(B8), 12653-12680.

Clark, R. N., \& Roush, T. L. (1984). Reflectance spectroscopy-quantitative analysis techniques for remote sensing applications. Journal of Geophysical Research, 89(NB7), 6329-6340.

Črne, A. E., Melezhik, V. A., Lepland, A., Fallick, A. E., Prave, A. R., \& Brasier, A. T. (2014). Petrography and geochemistry of carbonate rocks of the Paleoproterozoic Zaonega Formation, Russia: Documentation of 13C-depleted non-primary calcite. Precambrian Research, 240, 79-93.

Crowley, J. K. (1986). Visible and near-infrared spectra of carbonate rocks-reflectance variations related to petrographic texture and impurities. Journal of Geophysical Research-Solid, 91(B5), 5001-5012.

De Weerdt, K., Colombo, A., Coppola, L., Justnes, H., \& Geiker, M. R. (2015). Impact of the associated cation on chloride binding of Portland cement paste. Cement and Concrete Research, 68(0), 196-202.

Deer, W. A., Howie, R. A., \& Zussman, J. (1966). Carbonates. In Introduction to the Rock - Forming Minerals (pp. 473-503). London, UK: Longman.

Dickson, J. A. D. (1965). A modified staining technique for carbonates in thin section. Nature, 205(4971), 587-587.

Fernandez, R., Martirena, F., \& Scrivener, K. L. (2011). The origin of the pozzolanic activity of calcined clay minerals: A comparison between kaolinite, illite and montmorillonite. Cement and Concrete Research, 41(1), 113-122.

Fitton, G. (2014). X-ray fluorescence spectrometry. In R. Gill (Ed.), Modern Analytical Geochemistry: An Introduction to Quantitative Chemical Analysis Techniques for Earth, Environmental and Materials Scientists (pp. 87-115). New York, USA: Routledge.

Forbes, M., Vogwill, R., \& Onton, K. (2010). A characterisation of the coastal tufa deposits of south-west Western Australia. Sedimentary Geology, 232(1-2), 52-65.

Freas, R. C., Hayden, J. S., \& Pryor Jr., C. A. (2006). Limestone and dolomite. In J. E. Kogel, N. C. Trivedi, J. M. Barker \& S. T. Krukowski (Eds.), Industrial Minerals and Rocks: Commodities, markets, and uses (7th ed., pp. 581-597). Colorado, USA: Society for Mining, Metallurgy, and Exploration. 
Frias, M., Derojas, M. I. S., Garcia, N., \& Luxan, M. P. (1994). Contribution of toxic elements-hexavalent chromium in materials used in the manufacture of cement. Cement and Concrete Research, 24(3), 533-541.

Friedman, G. M. (1959). Identification of carbonate minerals by staining methods. Journal of Sedimentary Research, 29(1), 87-97.

Friedman, G. M., \& Sanders, J. E. (1967). Origin and occurrence of dolostones. In G. V. Chilingar, H. J. Bissell \& R. W. Fairbridge (Eds.), Carbonate Rocks: Origin, Occurence and Classification (Vol. 9A, pp. 267-348). Amsterdam, The Netherlands: Elsevier.

Gaffey, S. J. (1985). Reflectance spectroscopy in the visible and near infrared (0.352.55 microns): Applications in carbonate petrology. Geology, 13, 270-273.

Gaffey, S. J. (1986). Spectral reflectance of carbonate minerals in the visible and near infrared (0.35-2.55 microns): Calcite, aragonite, and dolomite. American Mineralogist, 71, 151-162.

Galan, I., Perron, L., \& Glasser, F. P. (2015). Impact of chloride-rich environments on cement paste mineralogy. Cement and Concrete Research, 68(0), 174-183.

Gèze, B. (1979). Guides géologiques régionaux: Languedoc méditerranéen, Montagne Noire. Paris, France: Masson.

Ghosh, S. P. (1983). Raw materials: Geological characteristics, nomenclature, origin, occurrences and exploration. In S. N. Ghosh (Ed.), Advances in Cement Technology (pp. 1-38). Exeter, UK: Pergamon Press Ltd.

Gineys, N., Aouad, G., \& Damidot, D. (2010). Managing trace elements in Portland cement - part I: Interactions between cement paste and heavy metals added during mixing as soluble salts. Cement and Concrete Composites, 32(8), 563-570.

Gineys, N., Aouad, G., Sorrentino, F., \& Damidot, D. (2011). Incorporation of trace elements in Portland cement clinker: Thresholds limits for $\mathrm{Cu}, \mathrm{Ni}$, Sn or $\mathrm{Zn}$. Cement and Concrete Research, 41(11), 1177-1184.

Goldstein, J., Newbury, D. E., Joy, D. C., Lyman, C. E., Echlin, P., Lifshin, E., Sawyer, L., \& Michael, J. R. (2003). Scanning Electron Microscopy and X-Ray Microanalysis (3rd ed., p. 361). New York, USA: Springer.

Green, D., \& Schodlok, M. (2016). Characterisation of carbonate minerals from hyperspectral TIR scanning using features at 14000 and $11300 \mathrm{~nm}$. Australian Journal of Earth Sciences, 63(8), 951-957.

Gupta, R. P. (2003). Remote Sensing Geology (2nd ed., p. 655). Berlin, Germany: Springer.

Haest, M., Cudahy, T., Laukamp, C., \& Gregory, S. (2012a). Quantitative mineralogy from infrared spectroscopic data. I. Validation of mineral abundance and composition scripts at the Rocklea channel iron deposit in Western Australia. Economic Geology, 107(2), 209-228.

Haest, M., Cudahy, T., Laukamp, C., \& Gregory, S. (2012b). Quantitative mineralogy from infrared spectroscopic data. II. Three-dimensional mineralogical 
characterization of the Rocklea channel iron deposit, Western Australia. Economic Geology, 107(2), 229-249.

Hamilton, W. R., Woolley, A. R., \& Bishop, A. C. (1995). Hamlyn Guide: Minerals, Rocks and Fossils (p. 320). Hong Kong: Mandarin Offset.

Harbaugh, J. W. (1976). Carbonate oil reservoir rock. In G. V. Chilingar, H. J. Bissell \& R. W. Fairbridge (Eds.), Carbonate Rocks : Origin, Occurence and Classification (Vol. 9A, pp. 349-398). Amsterdam, The Netherlands: Elsevier.

Hardy, R., \& Tucker, M. (1988). X-ray powder diffraction of sediments. In M. Tucker (Ed.), Techniques in Sedimentology (pp. 191-228). Oxford, UK: Blackwell.

Hatch, F. H., \& Rastall, R. H. (1965). Carbonate rocks: Magnesian limestones and dolomites. In Textbook of Petrology : Vol. 2. Petrology of the Sedimentary Rocks (4th revised ed., pp. 221-234). London, UK: Allen \& Unwin.

Hecker, C., Hook, S. J., van der Meijde, M., Bakker, W., van der Werff, H., Wilbrink, H., van Ruitenbeek, F. J. A., de Smeth, B., \& van der Meer, F. D. (2011). Thermal infrared spectrometer for earth science remote sensing applications - instrument modifications and measurement procedures. Sensors, 11, 10981-10999.

Hecker, C., van der Meijde, M., van der Werff, H., \& van der Meer, F. D. (2008). Assessing the influence of reference spectra on synthetic SAM classification results. IEEE Transactions on Geoscience and Remote Sensing, 46(12), 4162-4172.

Hitzman, M. W. (1999). Routine staining of drill core to determine carbonate mineralogy and distinguish carbonate alteration textures. Mineralium Deposita, 34(8), 794-798.

Hochberg, E. J., \& Atkinson, M. J. (2000). Spectral discrimination of coral reef benthic communities. Coral Reefs, 19(2), 164-171.

Horkoss, S., Lteif, R., \& Rizk, T. (2011). Influence of the clinker SO3 on the cement characteristics. Cement and Concrete Research, 41(8), 913-919.

Huang, C. K., \& Kerr, P. F. (1960). Infrared study of the carbonate minerals. American Mineralogist, 45, 311-324.

Hubbard, B. E., Crowley, J. K., \& Zimbelman, D. R. (2003). Comparative alteration mineral mapping using visible to shortwave infrared (0.4-2.4 $\mu \mathrm{m})$ Hyperion, ALI, and ASTER imagery. IEEE Transactions on Geoscience and Remote Sensing, 41(6), 1401-1410.

Hunt, G. R. (1977). Spectral signatures of particulate minerals in the visible and near infrared. Geophysics, 42(3), 501-513.

Hunt, G. R., \& Salisbury, J. W. (1970). Visible and near-infrared spectra of minerals and rocks: I. Silicate minerals. Modern Geology, 1, 283-300.

Hunt, G. R., \& Salisbury, J. W. (1971). Visible and near infrared spectra of minerals and rocks: II. Carbonates. Modern Geology, 2, 23-30.

Ichikawa, M., \& Kanaya, M. (1997). Effects of minor components and heating rates on the fine textures of alite in Portland cement clinker. Cement and Concrete Research, 27(7), 1123-1129. 
Ifka, T., Palou, M., Baracek, J., Soukal, F., \& Bohac, M. (2014). Evaluation of P2O5 distribution inside the main clinker minerals by the application of EPMA method. Cement and Concrete Research, 59, 147-154.

Irassar, E. F., Bonavetti, V. L., \& González, M. (2003). Microstructural study of sulfate attack on ordinary and limestone Portland cements at ambient temperature. Cement and Concrete Research, 33(1), 31-41.

ITT (2010). Visual Information Solutions, ENVI Version 4.7 SP1. URL: http://www.ittvis.com (accessed on 18 May 2010).

Jakob, S., Zimmermann, R., \& Gloaguen, R. (2017). The need for accurate geometric and radiometric corrections of drone-borne hyperspectral data for mineral exploration: MEPHySTo-a toolbox for pre-processing drone-borne hyperspectral data. Remote Sensing, 9(1), 88.

James, N. P., \& Jones, B. (2015). Analytical methods. In Origin of Carbonate Sedimentary Rocks (pp. 286-296). West Sussex, UK: John Wiley and Sons.

Ji, J. F., Ge, Y., Balsam, W., Damuth, J. E., \& Chen, J. (2009). Rapid identification of dolomite using a Fourier Transform Infrared Spectrophotometer (FTIR): A fast method for identifying Heinrich events in IODP site U1308. Marine Geology, 258(1-4), 60-68.

Johansson, S., Sparrenbom, C., Fiandaca, G., Lindskog, A., Olsson, P.-I., Dahlin, T., \& Rosqvist, H. (2017). Investigations of a Cretaceous limestone with spectral induced polarization and scanning electron microscopy. Geophysical Journal International, 208(2), 954-972.

Kaplan, M. Y., Eren, M., Kadir, S., \& Kapur, S. (2013). Mineralogical, geochemical and isotopic characteristics of quaternary calcretes in the Adana region, Southern Turkey: Implications on their origin. Catena, 101, 164-177.

Kato, K., Wada, H., \& Fujioka, K. (2003). The application of chemical staining to separate calcite and aragonite minerals for micro-scale isotopic analyses. Geochemical Journal, 37(2), 291-297.

Kirkaldy, J. F. (1976). Minerals and Rocks in Colour (3rd ed., p. 184 ). Poole, UK: Blandford Press.

Klug, H. P., \& Alexander, L. E. (1974). X-Ray Diffraction Procedures for Polycrystalline and Amorphous Materials (2nd ed., p. 992). New York, USA: Wiley.

Kocak, Y., \& Nas, S. (2014). The effect of using fly ash on the strength and hydration characteristics of blended cements. Construction and Building Materials, 73, 25-32.

Kokaly, R. F., \& Clark, R. N. (1999). Spectroscopic determination of leaf biochemistry using band-depth analysis of absorption features and stepwise multiple linear regression. Remote Sensing of Environment, 67(3), 267-287.

Kozak, P. K., Duke, E. F., \& Roselle, G. T. (2004). Mineral distribution in contactmetamorphosed siliceous dolomite at Ubehebe Peak, California, based on airborne imaging spectrometer data. American Mineralogist, 89(5-6), 701-713. 
Krukowski, S. T. (2006). Lime. In J. E. Kogel, N. C. Trivedi, J. M. Barker \& S. T. Krukowski (Eds.), Industrial Minerals and Rocks: Commodities, Markets, and Uses (7th ed., pp. 561-580). Colorado, USA: Society for Mining, Metallurgy, and Exploration.

Kruse, F. A., Bedell, R. L., Taranik, J. V., Peppin, W. A., Weatherbee, O., \& Calvin, W. M. (2012). Mapping alteration minerals at prospect, outcrop and drill core scales using imaging spectrometry. International Journal of Remote Sensing, 33(6), 17801798.

Kruse, F. A., Boardman, J. W., \& Huntington, J. F. (2003). Comparison of airborne hyperspectral data and EO-1 Hyperion for mineral mapping. IEEE Transactions on Geoscience and Remote Sensing, 41(6), 1388-1400.

Kruse, F. A., Lefkoff, A. B., Boardman, J. W., Heidebrecht, K. B., Shapiro, A. T., Barloon, P. J., \& Goetz, A. F. H. (1993). The spectral image processing system (SIPS) - Interactive visualization and analysis of imaging spectrometer data. Remote Sensing of Environment, 44(2-3), 145-163.

Kruse, F. A., Lefkoff, A. B., \& Dietz, J. B. (1993). Expert system-based mineral mapping in Northern Death-Valley, California Nevada, using the airborne visible infrared imaging spectrometer (AVIRIS). Remote Sensing of Environment, 44(2-3), 309-336.

Kurokawa, D., Honma, K., Hirao, H., \& Fukuda, K. (2013). Quality design of belitemelilite clinker. Cement and Concrete Research, 54, 126-132.

Kurz, T. H., \& Buckley, S. J. (2016). A review of hyperspectral imaging in close range applications. In proceedings of International Archives of the Photogrammetry, Remote Sensing and Spatial Information Sciences (12-19 July 2016, pp. 865-870). Prague, Czech Republic.

Kurz, T. H., Buckley, S. J., \& Howell, J. A. (2013). Close-range hyperspectral imaging for geological field studies: workflow and methods. International Journal of Remote Sensing, 34(5), 1798-1822.

Kurz, T. H., Dewit, J., Buckley, S. J., Thurmond, J. B., Hunt, D. W., \& Swennen, R. (2012). Hyperspectral image analysis of different carbonate lithologies (limestone, karst and hydrothermal dolomites):The Pozalagua quarry case study (Cantabria, North-west Spain). Sedimentology, 59(2), 623-645.

Lai, P., Moulton, K., \& Krevor, S. (2015). Pore-scale heterogeneity in the mineral distribution and reactive surface area of porous rocks. Chemical Geology, 411, 260273.

Lane, M. D., \& Christensen, P. R. (1997). Thermal infrared emission spectroscopy of anhydrous carbonates. Journal of Geophysical Research-Planets, 102(E11), 2558125592.

Lane, S. J., \& Dalton, J. A. (1994). Electron microprobe analysis of geological carbonates. American Mineralogist, 79, 745-749.

Lein, A. Y. (2004). Authigenic carbonate formation in the ocean. Lithology and Mineral Resources, 39(1), 1-30. 
Li, X. R., Xu, W. L., Wang, S. P., Tang, M. L., \& Shen, X. D. (2014). Effect of $\mathrm{SO}_{3}$ and $\mathrm{MgO}$ on Portland cement clinker: Formation of clinker phases and alite polymorphism. Construction and Building Materials, 58, 182-192.

Liu, Z., \& Zhao, J. (2000). Contribution of carbonate rock weathering to the atmospheric $\mathrm{CO}_{2}$ sink. Environmental Geology, 39(9), 1053-1058.

Longhi, I., Sgavetti, M., Chiari, R., \& Mazzoli, C. (2001). Spectral analysis and classification of metamorphic rocks from laboratory reflectance spectra in the 0.4$2.5 \mathrm{mu} \mathrm{m}$ interval: a tool for hyperspectral data interpretation. International Journal of Remote Sensing, 22(18), 3763-3782.

Luleva, M. I., van der Werff, H., Jetten, V., \& van der Meer, F. (2011). Can infrared spectroscopy be used to measure change in potassium nitrate concentration as a proxy for soil particle movement? Sensors, 11(4), 4188-4206.

Luquot, L., \& Gouze, P. (2009). Experimental determination of porosity and permeability changes induced by injection of $\mathrm{CO}_{2}$ into carbonate rocks. Chemical Geology, 265(1-2), 148-159.

Magendran, T., \& Sanjeevi, S. (2014). Hyperion image analysis and linear spectral unmixing to evaluate the grades of iron ores in parts of Noamundi, Eastern India. International Journal of Applied Earth Observation and Geoinformation, 26, 413426.

Maki, I., Fukuda, K., Yoshida, H., \& Kumaki, J. (1992). Effect of $\mathrm{MgO}$ and $\mathrm{SO}_{3}$ on the impurity concentration in alite in Portland-cement clinker. Journal of the American Ceramic Society, 75(11), 3163-3165.

Marjanovic, L., McCrindle, R. I., Botha, B. M., \& Potgieter, J. H. (2000). Analysis of cement by inductively coupled plasma optical emission spectrometry using slurry nebulization. Journal of Analytical Atomic Spectrometry, 15(8), 983-985.

Mathieu, M., Roy, R., Launeau, P., Cathelineau, M., \& Quirt, D. (2017). Alteration mapping on drill cores using a HySpex SWIR-320m hyperspectral camera: Application to the exploration of an unconformity-related uranium deposit (Saskatchewan, Canada). Journal of Geochemical Exploration, 172(Supplement C), 71-88.

Mazouzi, W., Kacimi, L., Cyr, M., \& Clastres, P. (2014). Properties of low temperature belite cements made from aluminosilicate wastes by hydrothermal method. Cement and Concrete Composites, 53, 170-177.

Meade, R. K. (1926). Raw materials. In Portland Cement: Its Composition, Raw Materials, Manufacture, Testing and Analysis (3rd ed., pp. 51-74). Easton, PA, USA: The Chemical Publishing Company.

Mollah, M. Y. A., Yu, W., Schennach, R., \& Cocke, D. L. (2000). A Fourier transform infrared spectroscopic investigation of the early hydration of Portland cement and the influence of sodium lignosulfonate. Cement and Concrete Research, 30(2), 267273.

Murphy, R. J., \& Monteiro, S. T. (2013). Mapping the distribution of ferric iron minerals on a vertical mine face using derivative analysis of hyperspectral imagery 
(430-970 nm). ISPRS Journal of Photogrammetry and Remote Sensing, 75(0), 2939.

Murphy, R. J., Monteiro, S. T., \& Schneider, S. (2012). Evaluating classification techniques for mapping vertical geology using field-based hyperspectral sensors. IEEE Transactions on Geoscience and Remote Sensing, 50(8), 3066-3080.

Murphy, R. J., Schneider, S., \& Monteiro, S. T. (2014). Consistency of measurements of wavelength position from hyperspectral imagery: Use of the ferric iron crystal field absorption at $900 \mathrm{~nm}$ as an indicator of mineralogy. IEEE Transactions on Geoscience and Remote Sensing 52(5), 2843-2857.

Murphy, R. J., Van Kranendonk, M. J., Kelloway, S. J., \& Wainwright, I. E. (2016). Complex patterns in fossilized stromatolites revealed by hyperspectral imaging (400-2496 nm). Geobiology, 14(5), 419-439.

Mustard, J. F., \& Pieters, C. M. (1987). Quantitative abundance estimates from bidirectional reflectance measurements. Journal of Geophysical Research, 92(B4), E617-E626.

Mutanga, O., Skidmore, A. K., \& Prins, H. H. T. (2004). Predicting in situ pasture quality in the Kruger National Park, South Africa, using continuum-removed absorption features. Remote Sensing of Environment, 89(3), 393-408.

Oh, S., Hyun, C.-U., \& Park, H.-D. (2017). Near-infrared spectroscopy of limestone ore for $\mathrm{CaO}$ estimation under dry and wet conditions. Minerals, 7(10), 193.

Parbhakar-Fox, A., Fox, N., Moltzen, J., \& Lottermoser, B. (2017). Chemical staining techniques for drill core characterization. In B. Lottermoser (Ed.), Environmental Indicators in Metal Mining (pp. 97-114). Switzerland: Springer International Publishing.

Perraki, T., Kontori, E., Tsivilis, S., \& Kakali, G. (2010). The effect of zeolite on the properties and hydration of blended cements. Cement and Concrete Composites, 32(2), 128-133.

Pettijohn, F. J. (1975). Limestones and dolomite. In Sedimentary Rocks (3rd ed., pp. 316-391). New York, USA: Harper \& Row.

Pipilikaki, P., Papageorgiou, D., Teas, C., Chaniotakis, E., \& Katsioti, M. (2008). The effect of temperature on thaumasite formation. Cement and Concrete Composites, 30(10), 964-969.

Pohl, W. L. (2011). Industrial minerals, earths and rocks. In Economic Geology: Principles and Practice: Metals, minerals, coal and hydrocarbons - Introduction to formation and sustainable exploitation of mineral deposits (pp. 285-368). Hoboken, NJ, USA: Wiley-Blackwell.

Post, J. L., \& Noble, P. N. (1993). The near-infrared combination band frequencies of dioctahedral smectites, micas, and illites. Clays and Clay Minerals, 41(6), 639-644.

Potgieter, S. S., \& Maljanovic, L. (2007). A further method for chloride analysis of cement and cementitious materials - ICP-OES. Cement and Concrete Research, $37(8), 1172-1175$. 
Povarennykh, A. S. (1978). Use of infrared-spectra for determination of minerals. American Mineralogist, 63(9-10), 956-959.

Qaid, A. M., Basavarajappa, H. T., \& Rajendran, S. (2009). Integration of VNIR and SWIR Spectral Reflectance for Mapping Mineral Resources; A Case Study, North East of Hajjah, Yemen. Journal of the Indian Society of Remote Sensing, 37(2), 305315.

Reed, S. J. B. (2005). Electron Microprobe Analysis and Scanning Electron Microscopy in Geology (2nd ed., p. 232). Cambridge, UK: Cambridge University Press.

Reig, F. B., Adelantado, J. V. G., \& Moreno, M. C. M. M. (2002). FTIR quantitative analysis of calcium carbonate (calcite) and silica (quartz) mixtures using the constant ratio method. Application to geological samples. Talanta, 58(4), 811-821.

Riaza, A., \& Müller, A. (2010). Hyperspectral remote sensing monitoring of pyrite mine wastes: A record of climate variability (Pyrite Belt, Spain). Environmental Earth Sciences, 61(3), 575-594.

Robinson, P. (1980). Determination of calcium, magnesium, manganese, strontium, sodium, and iron in the carbonate fraction of limestones and dolomites. Chemical Geology, 28(1-2), 135-146.

Rockwell, B. W., \& Hofstra, A. H. (2008). Identification of quartz and carbonate minerals across northern Nevada using ASTER thermal infrared emissivity data Implications for geologic mapping and mineral resource investigations in wellstudied and frontier areas. Geosphere, 4(1), 218-246.

Rodger, A., Laukamp, C., Haest, M., \& Cudahy, T. (2012). A simple quadratic method of absorption feature wavelength estimation in continuum removed spectra. Remote Sensing of Environment, 118, 273-283.

Salisbury, J. W., Hapke, B., \& Eastes, J. W. (1987). Usefulness of weak bands in mid infrared remote sensing of particulate planetary surface. Journal of Geophysical Research, 92(B1), 702-710.

Sanders, J. E., \& Friedman, G. M. (1967). Origin and occurrence of limestones. In G. V. Chilingar, H. J. Bissell \& R. W. Fairbridge (Eds.), Carbonate Rocks: Origin, Occurrence and Classification (Vol. 9A, pp. 169-266). Amsterdam, The Netherlands: Elsevier.

Schodlok, M. C., Whitbourn, L., Huntington, J., Mason, P., Green, A., Berman, M., Coward, D., Connor, P., Wright, W., Jolivet, M., \& Martinez, R. (2016). HyLogger3 , a visible to shortwave and thermal infrared reflectance spectrometer system for drill core logging: functional description. Australian Journal of Earth Sciences, 63(8), 929-940.

Sdiri, A., Higashi, T., Hatta, T., Jamoussi, F., \& Tase, N. (2010). Mineralogical and spectroscopic characterization, and potential environmental use of limestone from the Abiod formation, Tunisia. Environmental Earth Sciences, 61(6), 1275-1287.

Sepulcre, S., Durand, N., \& Bard, E. (2009). Mineralogical determination of reef and periplatform carbonates: Calibration and implications for paleoceanography and radiochronology. Global Planet Change, 66(1-2), 1-9. 
Settle, J. J., \& Drake, N. A. (1993). Linear mixing and the estimation of ground cover proportions. International Journal of Remote Sensing, 14(6), 1159-1177.

Silva, C. S., Blanco, T., \& Nobrega, J. A. (2002). Analysis of cement slurries by inductively coupled plasma optical emission spectrometry with axial viewing. Spectrochimica Acta Part B, 57(1), 29-33.

Sluiter, R. (2005). Mediterranean land cover change: Modelling and monitoring natural vegetation using GIS and remote sensing. Dissertation, Utrecht University, Utrecht, the Netherlands. URL: https://dspace.library.uu.nl/handle/1874/7425

Smith, M. J., Stevens, T., MacArthur, A., Malthus, T. J., \& Lu, H. Y. (2011). Characterising Chinese loess stratigraphy and past monsoon variation using field spectroscopy. Quaternary International, 234, 146-158.

Specim (2007) URL: http://www.specim.fi/index.php/products/geology/sisuchema/ (accessed on 19 October 2010).

Tappert, M., Rivard, B., Giles, D., Tappert, R., \& Mauger, A. (2011). Automated drill core logging using visible and near-infrared reflectance spectroscopy: A case study from the Olympic Dam IOCG deposit, South Australia. Economic Geology, 106(2), 289-296.

Tappert, M. C., Rivard, B., Fulop, A., Rogge, D., Feng, J., Tappert, R., \& Stalder, R. (2015). Characterizing kimberlite gilution by crustal rocks at the Snap Lake Diamond Mine (Northwest Territories, Canada) using SWIR (1.90-2.36 $\mu \mathrm{m})$ and LWIR $(8.1-11.1 \mu \mathrm{m})$ hyperspectral imagery collected from drill core. Economic Geology, 110(6), 1375-1387.

Taylor, H. F. W. (1997). The chemistry of Portland cement manufacture. In Cement Chemistry (2nd ed., pp. 55-88). London, UK: Telford.

Taylor, H. F. W. (1999). Distribution of sulfate between phases in Portland cement clinkers. Cement and Concrete Research, 29(8), 1173-1179.

Taylor, H. F. W., \& Newbury, D. E. (1984). An electron-microprobe study of a mature cement paste. Cement and Concrete Research, 14(4), 565-573.

Thermo Scientific (2010). Thermo Fisher Scientific Niton XL3 Analyzer User's Guide, Version 7.0.1. Munich, Germany: Thermo Fisher Scientific Inc.

Thompson, G., Bankston, D. C., \& Pasley, S. M. (1970). Trace element data for reference carbonate rocks. Chemical Geology, 6(2), 165-170.

Tosun, K., Felekoglu, B., Baradan, B., \& Altun, I. A. (2009). Effects of limestone replacement ratio on the sulfate resistance of Portland limestone cement mortars exposed to extraordinary high sulfate concentrations. Construction and Building Materials, 23(7), 2534-2544.

van der Meer, F. (1996a). Classification of remotely-sensed imagery using an indicator kriging approach: Application to the problem of calcite-dolomite mineral mapping. International Journal of Remote Sensing, 17(6), 1233-1249.

van der Meer, F. (1996b). Spectral mixture modelling and spectral stratigraphy in carbonate lithofacies mapping. ISPRS Journal of Photogrammetry and Remote Sensing, 51(3), 150-162. 
van der Meer, F. (1998). Mapping dolomitization through a co-regionalization of simulated field and image-derived reflectance spectra: a proof-of-concept study. International Journal of Remote Sensing, 19(8), 1615-1620.

van der Meer, F. (2006). The effectiveness of spectral similarity measures for the analysis of hyperspectral imagery. International Journal of Applied Earth Observation and Geoinformation, 8(1), 3-17.

van der Meer, F., \& de Jong, S. M. (2000). Improving the results of spectral unmixing of Landsat Thematic Mapper imagery by enhancing the orthogonality of endmembers. International Journal of Remote Sensing, 21(15), 2781-2797.

van der Meer, F. D. (1995). Spectral reflectance of carbonate mineral mixtures and bidirectional reflectance theory: Quantitative analysis techniques for application in remote sensing. Remote Sensing Reviews, 13, 67-94.

van der Meer, F. D. (2004). Analysis of spectral absorption features in hyperspectral imagery. International Journal of Applied Earth Observation and Geoinformation, 5(1), 55-68.

van der Meer, F. D., \& de Jong, S. M. (2001). Imaging Spectroscopy: Basic Principles and Prospective Applications (p. 403). Dordrecht, The Netherlands: Springer.

van der Meer, F. D., \& Jia, X. P. (2012). Collinearity and orthogonality of endmembers in linear spectral unmixing. International Journal of Applied Earth Observation and Geoinformation, 18, 491-503.

Vincent, B., Fleury, M., Santerre, Y., \& Brigaud, B. (2011). NMR relaxation of neritic carbonates: An integrated petrophysical and petrographical approach. Journal of Applied Geophysics, 74(1), 38-58.

Waltham, A. C. (2009). Sedimentary processes and rocks. In Foundations of Engineering Geology (3rd ed., pp. 8-10). London, UK: Spon Press.

Warner, T. A., Nellis, M. D., \& Foody, G. M. (2009). Electromagnetic radiation and the terrestrial environment. In The SAGE Handbook of Remote Sensing (pp. 33-94). London, UK: SAGE Publications Ltd.

Waseda, Y., Matsubara, E., \& Shinoda, K. (2011). Diffraction from polycrystalline samples and determination of crystal structure. In X-Ray Diffraction Crystallography: Introduction, Examples and Solved Problems (pp. 107-167). Berlin, Germany: Springer.

Windeler, D. S., \& Lyon, R. J. P. (1991). Discriminating dolomitization of marble in the Ludwig Skarn near Yerington, Nevada using high-resolution airborn infrared imagery. Photogrammetric Engineering and Remote Sensing, 57(9), 1171-1177.

Wolf, K. H., Chilingar, G. V., \& Beales, F. W. (1967). Elemental composition of carbonate skeletons, minerals, and sediments. In G. V. Chilingar, H. J. Bissell \& R. W. Fairbridge (Eds.), Carbonate Rocks: Physical and Chemical Aspects (Vol. 9B, pp. 23-150). Amsterdam, The Netherlands: Elsevier.

Wu, K., Shi, H. S., De Schutter, G., Guo, X. L., \& Ye, G. (2012). Preparation of alinite cement from municipal solid waste incineration fly ash. Cement and Concrete Composites, 34(3), 322-327. 
Xie, X., Tian, S., Du, P., Zhan, W., Samat, A., \& Chen, J. (2016). Quantitative estimation of carbonate rock fraction in karst regions using field spectra in 2.0-2.5 $\mu \mathrm{m}$. Remote Sensing, 8(1), 68 .

Yitagesu, F. A., van der Meer, F., van der Werff, H., \& Hecker, C. (2011). Spectral characteristics of clay minerals in the 2.5-14 $\mu \mathrm{m}$ wavelength region. Applied Clay Science, 53(4), 581-591.

Ylmen, R., Wadso, L., \& Panas, I. (2010). Insights into early hydration of Portland limestone cement from infrared spectroscopy and isothermal calorimetry. Cement and Concrete Research, 40(10), 1541-1546.

Youngentob, K. N., Roberts, D. A., Held, A. A., Dennison, P. E., Jia, X. P., \& Lindenmayer, D. B. (2011). Mapping two Eucalyptus subgenera using multiple endmember spectral mixture analysis and continuum-removed imaging spectrometry data. Remote Sensing of Environment, 115(5), 1115-1128.

Younis, M. T., Gilabert, M. A., Melia, J., \& Bastida, J. (1997). Weathering process effects on spectral reflectance of rocks in a semi-arid environment. International Journal of Remote Sensing, 18(16), 3361-3377.

Yue, Y., Zhang, B., Wang, K., Liu, B., Li, R., Jiao, Q., Yang, Q., \& Zhang, M. (2010). Spectral indices for estimating ecological indicators of karst rocky desertification. International Journal of Remote Sensing, 31(8), 2115-2122.

Zaini, N., van der Meer, F., \& van der Werff, H. (2012). Effect of grain size and mineral mixing on carbonate absorption features in the SWIR and TIR wavelength regions. Remote Sensing, 4(4), 987-1003.

Zaini, N., van der Meer, F., \& van der Werff, H. (2014). Determination of carbonate rock chemistry using laboratory-based hyperspectral imagery. Remote Sensing, 6(5), 4149-4172.

Zaini, N., van der Meer, F., van Ruitenbeek, F., de Smeth, B., Amri, F., \& Lievens, C. (2016). An alternative quality control technique for mineral chemistry analysis of Portland cement-grade limestone using shortwave infrared spectroscopy. Remote Sensing, 8(11), 950. 


\section{Biography}

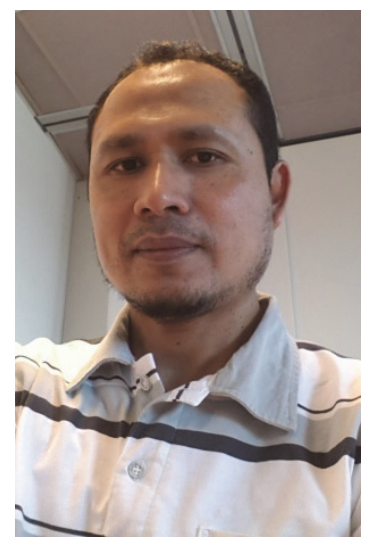

Nasrullah Zaini was born in Sawang II, South Aceh, the Province of Aceh, Indonesia, on January $2^{\text {nd }}, 1975$. He attended the high school at SMAN Sawang, South Aceh, graduating in 1992. He obtained his BSc degree in Physics from Department of Physics, Faculty of Mathematics and Natural Sciences, Syiah Kuala University (Unsyiah), Banda Aceh in 1997. Since March 1999, Nasrullah has been working as a junior lecturer at Department of Physics, Syiah Kuala University. In the period of September 2001 to May 2003, he awarded a scholarship (DUE-Like project) from the Ministry of National Education of Indonesia to continue his master study at Department of Physics, Bandung Institute of Technology (ITB), West Java. He obtained a Master of Science (MSc) degree in Physics with the specialization of Instrumentational Physics. The master thesis research was on the topic of "Design of measurement unit for detecting the purity of nutmeg oil using visible spectroscopy and neural network". From September 2007 to March 2009, he followed an Erasmus Mundus Master Program in Geo-Information Science and Earth Observation for Environmental Modelling and Management (GEM), with the scholarship from the British Universities Scholarship Scheme for Higher Education Institutions in Aceh. He awarded MSc degrees from the University of Southampton (UK), Lund University (Sweden), Warsaw University (Poland), and International Institute for Geo-Information Science and Earth Observation (ITC, The Netherlands). The master thesis was entitled "Calcite-dolomite mapping to assess dolomitization patterns using laboratory spectra and hyperspectral remote sensing: A case study of Bédarieux mining area, SE France". Starting in May 2010, Nasrullah pursued his PhD study at Department of Earth Systems Analysis, Faculty of Geo-Information Science and Earth Observation (ITC), University of Twente, The Netherlands. The PhD studies were funded by the Government of the Province of Aceh, Human Resources Development Commission (HRDC), Indonesia. His $\mathrm{PhD}$ research was focusing on characterization, determination and estimation of mineralogical and chemical compositions of carbonate rocks using a combination approach of infrared spectroscopy, geochemistry and laboratory-based hyperspectral imagery. The research led to an alternative framework for chemical quality control of carbonate rocks that can be used by the cement industries. In April 2015, Nasrullah returned to Indonesia as a lecturer and researcher in the Department of Physics, Syiah Kuala University, Banda Aceh. His research interests are rocks and minerals exploration, infrared spectroscopy, hyperspectral imaging, geochemistry, and the application of remote sensing and geoinformation technologies in geology, earth resources and geo-hazards. 


\section{Author's publication}

1. Zaini, N., van der Meer, F. and van Ruitenbeek, F. (in preparation). Carbonate rock chemistry characterization: A review. Journal of Geochemical Exploration.

2. Zaini, N., van der Meer, F., van Ruitenbeek, F., de Smeth, B., Amri, F. and Lievens, C. (2016). An alternative quality control technique for mineral chemistry analysis of Portland cement-grade limestone using shortwave infrared spectroscopy. Remote Sensing, 8, 950

3. Zaini, N., van der Meer, F. and van der Werff, H. (2014). Determination of carbonate rock chemistry using laboratory-based hyperspectral imagery. Remote Sensing, 6, 4149-4172.

4. Zaini, N., van der Meer, F. and van der Werff, H. (2012). Effect of grain size and mineral mixing on carbonate absorption features in the SWIR and TIR wavelength regions. Remote Sensing, 4, 987-1003.

5. Zaini, N., van der Meer, F. and van der Werff, H. (May 6-8, 2009). Absorption features analysis of carbonate minerals spectra in the shortwave infrared as a proxy for assessing dolomitization patterns and its application in hyperspectral remote sensing, In ICONES 2009: The International Conference on Environmental and Natural Sciences 2009, Banda Aceh, Indonesia. p. 270-275.

6. Zaini, N. (2009). Calcite-dolomite mapping to assess dolomitization patterns using laboratory spectra and hyperspectral remote sensing: A case study of Bédarieux mining area, SE France. MSc Thesis. International Institute for Geo-Information Science and Earth Observation (ITC), Enschede. The Netherlands.

7. Zaini, N. (2003). Design of measurement unit for detecting the purity of nutmeg oil using visible spectroscopy and neural network. MSc Thesis. Bandung Institute of Technology (ITB), West Java. Indonesia. 


\section{Appendix A: XRD analysis of limestone samples}

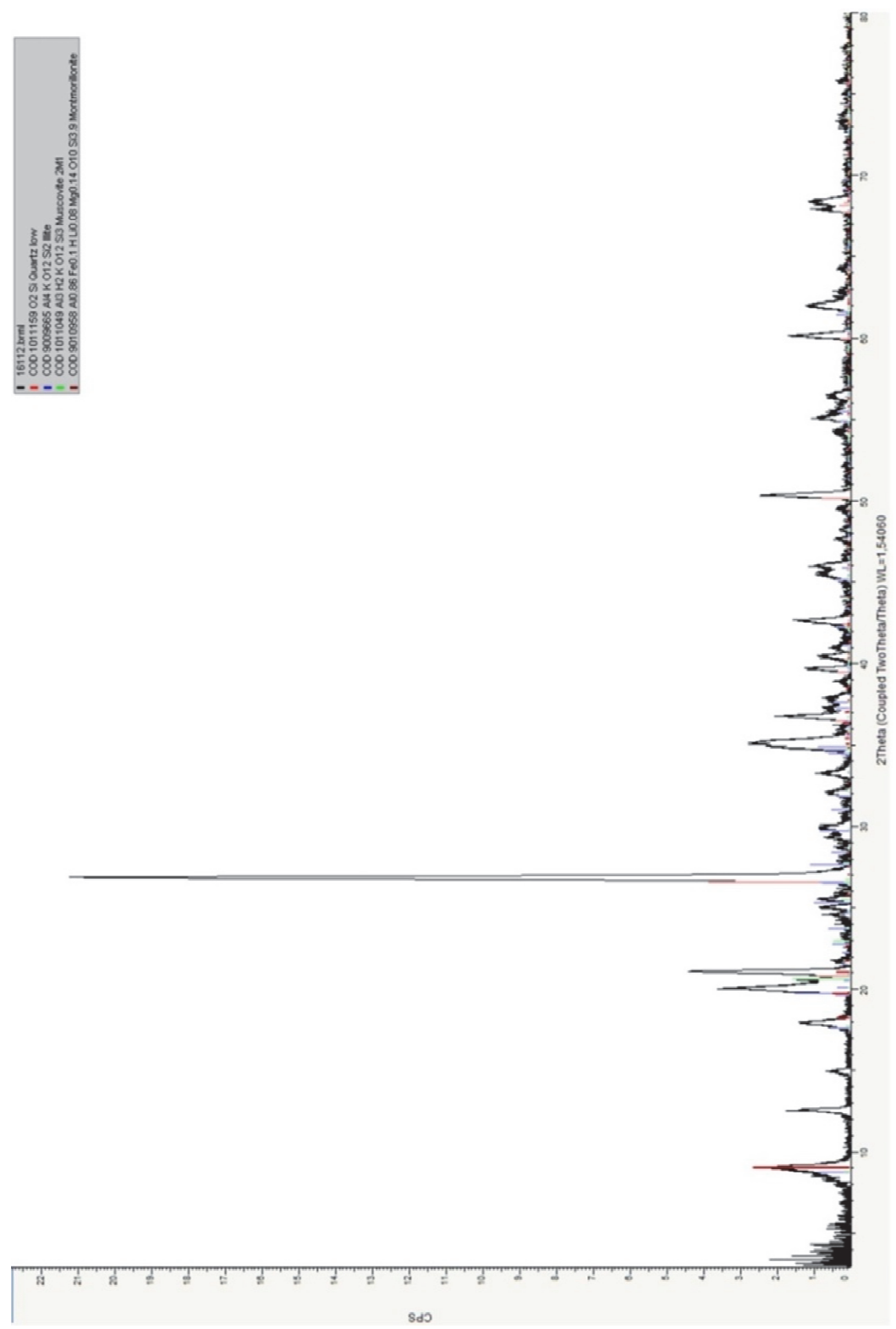

Figure A.1: XRD pattern of clay and other phyllosilicate minerals of selected dark gray and light gray limestone samples, showing the presence of montmorillonite, illite and muscovite in the rock samples. 